\title{
Günter Burkard
}

\section{Bibliotheken im alten Ägypten}

\section{Überlegungen zum Methodik ihres Nachweises und Übersicht zum Stand der Forschung}

Verschiedene und jeweils häufig belegte ägyptische Wörter für „Bibliothek“ lassen keinen Zweifel an der Existenz dieser Institution im alten Ägypten. Einen merkwürdigen Gegensatz dazu bildet die geringe Zahl der bislang bekannten, d.h. der archäologisch und/oder inschriftlich nachweisbaren Bibliotheksgebäude. Die Untersuchung dient zunächst der Verbreiterung der methodischen Basis durch Erarbeitung eines Gerüstes, das bei der Befragung archäologischer und inschriftlicher Befunde Anwendung finden kann. In einem zweiten Teil wird dieses Verfahren praktisch erprobt.

\section{Libraries in ancient Egypt}

There are various Egyptian words for 'library', all occurring frequently in literary citations which leave no doubt as to the existence of such an institution in ancient Egypt. Yet, there is a remarkable contrast to that as far as library buildings hitherto known by archaeologic and/or epigraphic proof are concerned. At the beginning, the paper serves as an enlargement of the methodical basis by working out an outline which may be applied to the treatment of archaeologic or epigraphic findings. The second part offers the practical application of this method.

\section{Inhaltsübersicht}

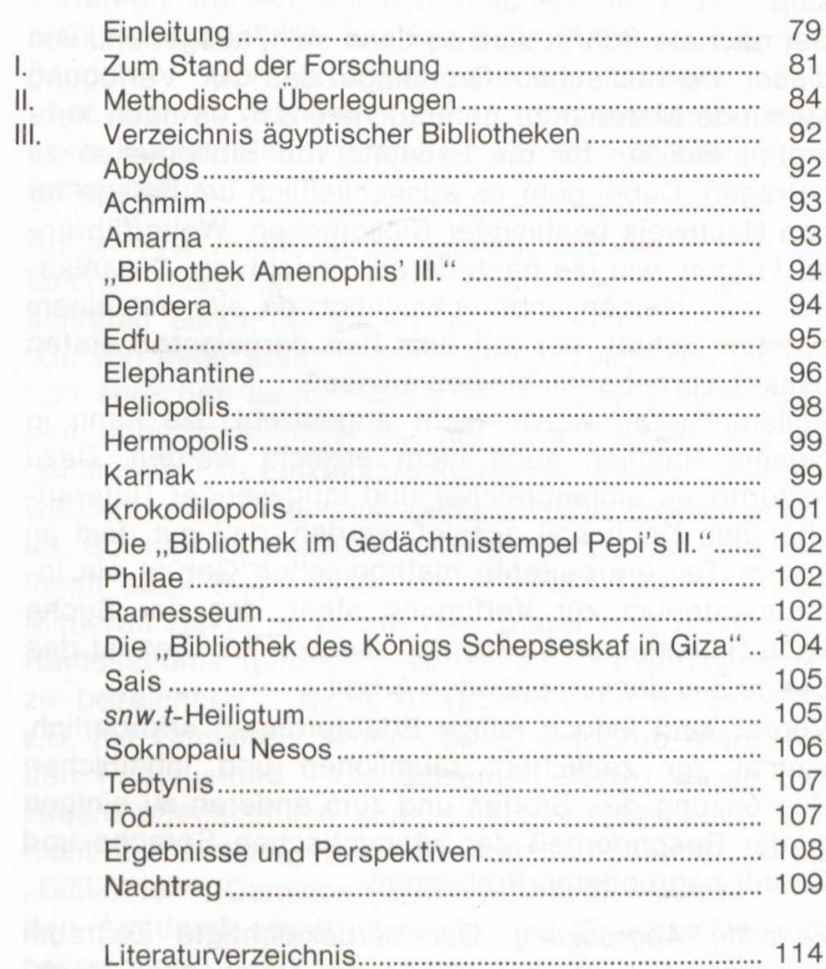

\section{Einleitung*}

Wer sich heute mit dem kulturellen Nachlaß der alten Ägypter befaßt, wird auf Schritt und Tritt mit dem Phänomen konfrontiert, daß die Schrift in dieser Kultur von ganz besonderer Bedeutung gewesen ist. Das zeigt sich am augenfälligsten an den erhaltenen Gebäuden: Die Wände und Mauern der Tempel sind von oben bis unten mit hieroglyphischen Inschriften bedeckt, bisweilen in einem Ausmaße, daß daneben die Reliefs in den Hintergrund zu treten scheinen. Dazu kommen die Inschriften in den Gräbern, auf Grab- und Opferstelen, die zahlreichen Felsinschriften und anderes mehr.
Neben diesen Zeugnissen auf dauerhaftem Material sind es vor allem die vielen Papyrusrollen bzw. deren Reste, die sich trotz der Vergänglichkeit dieses Beschreibstoffes erhalten haben und heute auf die Museen und Sammlungen in aller Welt verteilt sind, die diesen Eindruck bestätigen. Und dabei muß noch in Rechnung gestellt werden, daß diese erhaltenen Papyri nur als ein verschwindend geringer Prozentsatz dessen anzusehen sind, was insgesamt in Ägypten an beschifteten Exemplaren vorhanden war: Schätzungen rechnen mit einem Verhältnis zwischen erhaltenen und ursprünglich vorhandenen Papyri in den einzelnen Epochen der ägyptischen Geschichte von 1:100.000 oder wenig besser ${ }^{1}$.

Dem äußerlichen Reichtum an Papyri entspricht deren vielfältiger Inhalt. Neben den üblichen Verwaltungsund Rechtsurkunden sind zahlreiche literarische, mediznische, astronomische, lehrhafte und vielfältige andere Texte erhalten, die zudem teilweise über Jahrhunderte und sogar Jahrtausende hinweg immer wieder kopiert und so weiterüberliefert worden sind.

Vor diesem Hintergrund wird es verständlich, daß vor allem in den Anfängen der Ägyptologie im letzten Jahrhundert - und etwa zur gleichen Zeit auch auf bibliothekswissenschaftlicher Seite - der Eindruck vom bibliothekenreichen Ägypten vorherrschte: Jedem gröBeren Heiligtum wurde eine Bibliothek an die Seite gestellt, teilweise wurden sogar deren Bestände ,rekonstruiert".

Doch zeigte sich schon bald, daß diesen Ansichten mehr Spekulation und weniger fundierte Fakten zugrundelagen. Fritz Milkau hat dieses Kapitel der Forschungsgeschichte nachgezeichnet und anschließend

* Der vorliegende Aufsatz ist eine überarbeitete Fassung der Hausarbeit zur Prüfung für den höheren Dienst an wissenschaftlichen Bibliotheken beim Bibliothekar-Lehrinstitut des Landes Nordrhein-Westfalen, Köln, 1978. Die Veröffentlichung erfolgt mit Genehmigung des Prüfungsausschusses.

1 Posener, Georges: Histoire et Egypte ancienne. In: Annales 17 (1962), S. 631-646, zitiert bei Hornung, Erik: Einführung in die Ägyptologie. Darmstadt 1967, S. 31. 
dargelegt, wie beim damaligen Stand der Forschung unter Zugrundelegung ausschließlich der bekannten Tatsachen ein völlig anderes Bild entstehen mußte: Bis auf wenige, teilweise zudem unsichere Fälle blieb nichts mehr vom angeblichen Reichtum Ägyptens an Bibliotheken übrig².

Auch in der Ägyptologie ist man längst zu den Fakten zurückgekehrt, die in deutlichem Widerspruch zu den früheren Spekulationen stehen: Noch 1977 mußte der ungarische Ägyptologe Vilmos Wessetzky resignierend feststellen: „Im Vergleich zum Reichtum der ägyptischen Kultur erscheint das $\mathrm{Maß}$ unserer Kenntnisse über die ägyptischen Bibliotheken und Bibliothekare sehr fraglich... Die in Ägypten relativ ärmlichen bibliotheksgeschichtlichen Funde sind nicht ausreichend zur Klärung solcher Probleme wie die Lage und Einrichtungen der Bibliotheken, die Unterbringung der Bücher, der Wirkungskreis der Bibliotheken, die Bestimmung von Privatbibliotheken."3

Dies alles kann nun aber nicht bedeuten, daß Ägypten in Wirklichkeit arm an Bibliotheken gewesen ist. Dagegen spricht einmal ganz sicher der eingangs erwähnte Reichtum an Büchern und deren lange Tradierung, zum anderen und vor allem aber die Tatsache, daß die Ägypter mehrere Wörter für „Bibliothek" kannten (s. dazu unten im 2. Kapitel), und daß wenigstens einige Bibliotheken erhalten bzw. nachgewiesen sind.

Wie ist diese Diskrepanz zwischen dem, was erwartet werden muß, und den tatsächlichen Gegebenheiten zu erklären, d.h. warum fällt es heute so schwer, ägyptische Bibliotheken konkret nachzuweisen?

Es sind wohl vor allem zwei Gesichtspunkte, die ins Gewicht fallen:

1. Man muß davon ausgehen, daß die Bibliotheken im Regelfalle nicht aus Stein, sondern aus den viel vergänglicheren luftgetrockneten (d.h. nicht einmal gebrannten) Nilschlammziegeln erbaut waren: Das dauerhafte Material war den religiösen Bauwerken wie Tempeln und Grabanlagen vorbehalten ${ }^{4}$, reine Nutzbauten - einschließlich z.B. der königlichen Paläste - wurden in Ziegelbauweise errichtet. Bei solchen Gebäuden ist somit ein den ägyptischen Tempeln vergleichbarer Erhaltungszustand a priori nicht zu erwarten. Es kommt hinzu, daß diese aus einem Gemisch von Nilschlamm und Häcksel bestehenden Ziegel besonders im letzten und am Anfang dieses Jahrhunderts als Düngemittel für die Felder sehr begehrt waren: Viele Gebäude und Gebäudereste, die vor 100 Jahren noch gut erhalten waren, sind so unwiederbringlich verloren.

2. Es ist eine allgemein verbreitete Erscheinung, daß Selbstverständliches oder Gewohntes eben aufgrund dieser Eigenschaft nirgends, sei es schriftlich oder gar inschriftlich, fixiert wird: Man hält dies eben nicht für notwendig. So müssen wir uns beispielsweise handwerkliche oder bautechnische Verfahren der Ägypter erst mühsam rekonstruieren, weil Angaben hierüber meist fehlen ${ }^{5}$. Es darf uns daher auch nicht wundern, daß wir über Bau, Funktion, Organisation usw. von Institutionen wie Schreiberschulen, Verwaltungseinrichtungen, oder eben von Bibliotheken, so gut wie keine direkten Informationen besitzen: Wir sind auf mehr oder weniger zufällig erhaltene archäologische oder inschriftliche Indizien angewiesen und erst deren
Sammlung und Systematisierung kann uns helfen, z.B. Spuren bisher nicht bekannter oder nicht erkannter Bibliotheken aufzudecken. Denn solange wir nicht wissen, wo Bibliotheken zu erwarten sind, wie sie ausgesehen haben könnten und auch welche Bestände wir in ihnen erwarten dürfen, wird es uns auch nicht gelingen, Gebäudereste, Papyrusfunde o.ä. zweifelsfrei oder auch nur mit einiger Wahrscheinlichkeit als Reste von Bibliotheken zu bestimmen.

Trotz all dieser Problematik besteht aber heute kein Anlaß mehr, die Situation so pessimistisch zu beurteilen wie Milkau das tat und wie es erst kürzlich noch Wessetzky ausgesprochen hat (s. oben). Neue Ausgrabungen haben uns neue Indizien gebracht und auch ältere Grabungsberichte und Textpublikationen enthalten, teilweise versteckt, Hinweise, die uns auf der Suche nach altägyptischen Bibliotheken einen Schritt weiterbringen können: Es ist die Absicht dieser Arbeit, hier eine neue Standortbestimmung vorzunehmen.

Dieses Vorhaben ist jedoch nur dann sinnvoll, wenn vorher eine solide methodische Basis errichtet wird: Zunächst sind grundsätzliche Erwägungen anzustellen und Kriterien zu erarbeiten, mit deren Hilfe die Suche nach Bibliotheken durchgeführt werden kann. Dies muß daher auch das erste Ziel der vorliegenden Arbeit sein.

Der nächste Schritt wird es dann sein, ausgehend von dieser methodischen Grundlage das zur Verfügung stehende Material zu untersuchen, d.h. es nach konkreten Indizien für die Existenz von Bibliotheken zu befragen. Dabei geht es ausschließlich um Belege für den Nachweis bestimmter Bibliotheken. Weiterführende Fragen, wie die nach deren Einrichtung, Organisation o.ä., bleiben unberücksichtigt, da sie erst einem zweiten Schritt, der auf dem hier dargelegten ersten basiert, vorbehalten bleiben müssen.

Vollständigkeit wurde nicht angestrebt, sie kann in diesem Rahmen auch nicht erreicht werden: Dazu bedürfte es umfangreicher und langwieriger Untersuchungen. Doch soll gezeigt werden, daß mit dem im ersten Teil erarbeiteten methodischen Gerüst ein Instrumentarium zur Verfügung steht, das der Suche nach Bibliotheken in Ägypten dienlich ist: Dies ist das zweite Ziel der vorliegenden Arbeit.

Vorher sind jedoch einige Erläuterungen erforderlich, einmal zur zeitlichen, räumlichen und inhaltlichen Begrenzung des Stoffes und zum anderen zu einigen in der Besonderheit der altägyptischen Sprache und Schrift begründeten Problemen:

Zeitliche Abgrenzung: Der berücksichtigte Zeitraum beginnt mit der ersten Phase der ägyptischen Hochkultur, dem Alten Reich, also etwa um 2600 v. Chr. ${ }^{6}$

2 Milkau, Fritz: Geschichte der Bibliotheken im alten Orient. Aus dem Nachlaß hrsg. von Bruno Meissner. Leipzig 1935, S. 8-22. Diese Darstellung wird im folgenden zitiert nach der letzten Überarbeitung durch Josef Schawe, in: Handbuch der Bibliothekswissenschaft, begründet von Fritz Milkau, 2. vermehrte und verbesserte Auflage hrsg. von Georg Leyh, 3. Band, Geschichte der Bibliotheken, 1. Hälfte, Wiesbaden 1955, S. 4-17.

3 Wessetzky, Vilmos: Gedanken über die Bearbeitung der altägyptischen Bibliothek. In: Göttinger Miszellen 25 (1977), S. 89 und 91

4 vgl. z.B. de Cenival, Jean-Louis: Ägypten, das Zeitalter der Pharaonen. Fribourg 1964, S. 7

5 vgl. Hornung (Anm. 1), S. 119, § 68

6 hier und im folgenden stütze ich mich in den Jahresangaben auf Beckerath, Jürgen von: Abriß der Geschichte des Alten Ägypten. München 1971. 
und reicht bis zum Ende der „heidnischen“ Kultur im 4./5. Jh. n. Chr. Für die Zeit nach dem 4. Jh. v. Chr. gilt dabei die Beschränkung auf die genuin ägyptischen, d.h. in der Tradition auf pharaonische Zeit zurückgehenden Institutionen. Griechische Institutionen wie die Bibliothek von Alexandria bleiben außer Betracht ${ }^{7}$.

Räumliche Abgrenzung: Es ist das eigentlich ägyptische Gebiet vom Nildelta südwärts bis zur Insel Elephantine bzw. (in griechisch-römischer Zeit) bis zur Insel Philae berücksichtigt. Zeitweise dem Staatsgebiet angeschlossene Regionen südlich von Elephantine/Philae und im Osten, d.h. besonders im heutigen Syrien und Palästina, blieben außer Betracht.

Inhaltliche Abgrenzung: Hier ist einmal das Problem der Unterscheidung zwischen Bibliothek und Archiv zu nennen. In Einzelfällen ist diese Trennung zweifellos möglich, z.B. in Amarna, wo Gebäudereste sowohl eines Archivs als auch einer Bibliothek gefunden wurden, s. dazu unter „Amarna" im 3. Kapitel. In der Mehrzahl der Fälle ist beim jetzigen Stand unseres Wissens diese Trennung jedoch nicht gerechtfertigt; sie soll hier daher auch nicht künstlich versucht werden, ein Verfahren, vor dem schon Milkau warnte ${ }^{8}$. Vielmehr soll entsprechend der Definition Wessetzky's verfahren werden, nämlich „daß wir nur dort, wo es sich ausschließlich um spezielle Aktensammlungen handelt,... von Archiven sprechen, demgegenüber aber, wo wir vermuten können, daß planmäßig eben auch Bücherrollen gesammelt wurden, von Bibliotheken sprechen"9.

Als zweiter Punkt ist zu nennen, daß die Suche auf solche Bibliotheken bzw. Büchersammlungen beschränkt bleibt, bei denen man von einer „offiziellen“, d.h. von einer staatlichen und/oder religiösen Institution sprechen kann. Private Büchersammlungen bleiben unberücksichtigt, da ihre Charakterisierung als "Bibliothek" im Einzelfall durchaus in Zweifel gezogen werden kann, insgesamt gesehen also problematisch ist. So mag es vielleicht noch gerechtfertigt sein, den Inhalt einer Bücherkiste, die in einem Grab aus dem Mittleren Reich im Bezirk des später dort errichteten Ramesseums gefunden wurde, als „Privatbibliothek“ zu bezeichnen ${ }^{10}$. Nicht zu rechtfertigen ist es aber, z.B. mit Caminos ${ }^{11}$ einen aus einem Grab stammenden Papyrusfund - die einzelnen Papyri waren hier zudem offensichtlich speziell als Grabbeigaben, d.h. nicht zur Nutzung bei Lebzeiten, vorgesehen - als "Bibliothek" (Caminos verwendet bezeichnenderweise den Ausdruck „tomb-library“!) des Grabbesitzers zu bezeichnen.

Schließlich sei noch darauf hingewiesen, daß es in Einzelfällen erforderlich sein wird, ägyptische Hieroglyphen zu verwenden. Dabei ist zu beachten, daß die Hieroglyphen von rechts nach links zu lesen sind. In diesen Fällen wird jeweils auch die in der Ägyptologie übliche phonetische Transkription beigefügt sowie die deutsche Übersetzung.

\section{Zum Stand der Forschung}

Wie in der Einleitung bereits bemerkt wurde, haben sich sowohl Bibliothekare als auch Ägyptologen mit der Frage der altägyptischen Bibliotheken befaßt.
Einiges zu der dabei aufgetretenen Problematik wurde schon erwähnt und manche Ergebnisse dieser Bemühungen wurden gestreift. Vor weitergehenden Schritten ist es nun zunächst erforderlich, den allgemeinen Stand der Forschung auf diesem Gebiet zusammenzufassen und kritisch zu würdigen.

\section{la. Allgemeine Überblicke und zusammenfas- sende Darstellungen ${ }^{12}$}

\section{Auf bibliothekswissenschaftlicher Seite}

Obwohl einige Jahrzehnte inzwischen vergangen sind, besitzen die bereits erwähnten Untersuchungen Milkaus $^{13}$ nach wie vor zentrale Bedeutung. Mit innen soll dieser Überblick daher auch begonnen werden.

Milkaus dankenswerte „Abrechnung" mit-Teilen der vorausgehenden Forschungsgeschichte und seine Beschränkung auf die Fakten wurden bereits genannt. Ebenso positiv ist zu vermerken, daß er sich um den konkreten Nachweis bestimmter Bibliotheken bemüht hat: Er führt einzelne Bibliotheken auf, die in früheren Untersuchungen als solche bezeichnet oder identifiziert worden waren, und prüft kritisch die Belege für ihre Existenz. Diese Zusammenstellung bildet das bisher einzige „Verzeichnis“ ägyptischer Bibliotheken, das gegenüber früherer Euphorie tatsächlich allein durch seinen Umfang recht ernüchternd wirkt: Es enthält ganze fünf Bibliotheken, deren Zahl sich durch Milkaus Untersuchungen noch weiter verringert:

1. die Bibliothek des Künigs Schepseskaf in Giza

2. die Bibliothek König Amenophis' III.

3. die Bibliothek König Ramses' II.

4. die Bibliothek des Horustempels in Edfu

5. die Bibliothek des Isistempels auf der Insel Philae Die Detailergebnisse seiner Untersuchungen zu diesen Bibliotheken sind, soweit erforderlich, im 3. Kapitel unter den entsprechenden Orten und Namen berücksichtigt. Hier genügt die zusammenfassende Feststellung, daß er letztlich nur die Bibliothek in Edfu als sicher nachgewiesen und die auf Philae als wahrscheinlich akzeptieren kann, während er die Belege für die übrigen Bibliotheken als ungenügend oder zumindest noch nicht ausreichend beurteilt.

Mit dieser kritischen Zusammenstellung steht Milkau ohne Zweifel auf der Höhe der Forschung seiner Zeit, manches des von ihm Gesagten besitzt noch heute Gültigkeit, zumindest solange eine vergleichbare, die

7 natürlich ist in griechisch-römischer Zeit mit intensiven kulturellen Einflüssen auf beiden Seiten zu rechnen. Doch ist beim hier behandelten Gegenstand, wie sich zeigen wird, die Unterscheidung zwischen ägyptischen und griechisch-römischen Elementen in der Regel durchaus möglich, ihre Trennung daher auch gerechtfertigt.

8 (Anm. 2), S. 4, 2. Absatz.

9 (Anm. 3), S. 90

10 so Hermann Kees in: Orientalistische Literaturzeitung 54 (1959), Sp. 23-25 (Besprechung von Gardiner, Alan H.: The Ramesseum papyri, plates. Oxford 1955).

11 Caminos, Ricardo A.: Another hieratic manuscript from the library of Pwerem son of Kiki (P.B.M. 10288). In Journal of Egyptian Archaeology 58 (1972), S. 205-224.

12 Es sind hier im allgemeinen nur die wichtigsten bzw. umfangreicheren Darstellungen der letzten Jahre und Jahrzehnte berücksichtigt. Kleinere, oft nur halbseitige Beiträge in neueren Handbüchern oder Lexika wurden ebenso übergangen wie alte, inzwischen überholte Darstellungen: Erstere sind in das Literaturverzeichnis aufgenommen - wobei Vollständigkeit nicht angestrebt wurde -, letztere sind in den späteren Untersuchungen in der Regel berücksichtigt und dort auch nachgewiesen.

13 (Anm. 2), S. 4-17. 
jüngsten Forschungsergebnisse mit einbeziehende Untersuchung noch ein Desiderat bleibt ${ }^{14}$.

Eine von Milkau noch nicht berücksichtigte Frage ist die nach möglichen verschiedenen Bibliothekstypen. Zu diesem Problem sei auf bibliothekarischer Seite vor allem auf die Darstellung Carl Wendels verwiesen ${ }^{15}$, der, basierend auf den Untersuchungen vor allem Gardiners ${ }^{16}$, neben der Handbibliothek des Tempels, wie sie z.B. die Bibliothek von Edfu darstellte, und die nur den Handapparat für den Kult enthalten habe, auf die große Bedeutung der „Häuser des Lebens" verweist. Diese seien in Verbindung mit den Tempeln gestanden und in ihnen sei die Masse der Literatur aufbewahrt worden.

Hierzu muß kritisch angemerkt werden, daß Wendel mit keinem Wort auf den zumindest damals noch längst nicht entschiedenen Streit, ob in den „Lebenshäusern“ eine Bibliothek vorhanden war oder nicht, eingeht. Gerade Gardiner, auf den er sich beruht, zieht in seiner genannten Untersuchung diese Möglichkeit durchaus in Zweifel $^{17}$.

Damit ist aber bereits die Summe dessen, was auf bibliothekarischer Seite als "Stand der Forschung" bezeichnet werden kann, erreicht. Später erschienene Überblicke und Zusammenfassungen bieten nichts Neues oder müssen sogar, wie dies vor allem für einige Abhändlungen aus dem angelsächsischen Sprachbereich anzumerken ist, eher als Rückschritt bezeichnet werden.

Dies gilt beispielsweise für die Darstellung John A. Sperry's, die sich ausschließlich auf veraltete, z.T. schon von Milkau widerlegte Literatur stützt und wichtige neuere Untersuchungen wie die schon erwähnte von Gardiner außer acht läßt ${ }^{18}$. Die Notwendigkeit der Existenz von Bibliotheken versucht er u.a. mit allgemeinen Feststellungen zu belegen wie der, daß die ägyptische Literatur über sehr lange Zeiträume tradiert wurde. An konkreten Beispielen nennt er wenig und nichts Neues. Die ganze Unbefangenheit seiner Argumentation ergibt sich z.B. aus seiner Folgerung, daß die Bibliothek des Tempels von Edfu wohl auch ein Skriptorium gewesen sei, da über der Tür mehrmals Schreiberpaletten abgebildet seien: Abgesehen davon, daß die Abbildung von Schreiberpaletten einen solchen Schluß durchaus nicht nahelegt, hat Sperry es versäumt, die örtlichen Gegebenheiten in Rechnung zu stellen; sowohl die geringe Größe wie auch die ungenügenden Lichtverhältnisse machen den Raum für ein Skriptorium mit Sicherheit ungeeignet.

Ähnlich negativ muß auch die Bewertung der Darstellung ausfallen, die Johnson und Harris vom ägyptischen Bibliothekswesen geben ${ }^{19}$. Besonders kritisch anzumerken ist hier, daß die vermutlich zugrundegelegte Forschungsliteratur - Quellenangaben fehlen in der Regel - offenbar teilweise mißverstanden wurde. Nur so ist es beispielsweise zu erklären, daß das "Lebenshaus", also eine religiös-wissenschaftliche Einrichtung ${ }^{20}$, hier selbst als Tempel auftritt, noch dazu als eine nur einmal vorhandene, individuelle Institution. Unerklärlich ist auch, aufgrund welcher Quellen die Verfasser die Existenz von „Schulbibliotheken" nicht nur als Faktum vermerken, sondern auch deren Bestände rekonstruieren. ${ }^{21}$.

Soviel zum Stand der Forschung auf bibliothekarischer Seite. Zusammenfassend läßt sich sagen, daß nach wie vor Milkaus Darstellung - mit einigen Ergänzungen wie z.B. denen Wendels - als grundlegend anzusehen ist, entscheidende neue Gesichtspunkte sind seither nicht hinzugekommen. Dies ist u.a. sicher darauf zurückzuführen, daß neuere Untersuchungen auf ägyptologischer Seite nicht genügend berücksichtigt wurden. Doch fällt dieser Vorwurf teilweise wieder auf die Ägyptologie zurück: Die dort vorliegenden zusammenfassenden Darstellungen bauen zu oft auf bereits Bekanntem auf und unterlassen das - wegen der Streuung über die gesamte Forschungsliteratur zugegeben mühsame und zeitraubende, aber auch weiterführende - Sammeln von Einzelindizien. Der Bibliothekswissenschaftler muß sich aber in erster Linie auf solche Darstellungen stützen; das Zusammentragen der einzelnen Fakten ist Aufgabe des Ägyptologen.

\section{Auf ägyptologischer Seite}

Hier ist zunächst auf die zusammenfassende Darstellung Eberhard Ottos im Handbuch der Orientalistik zu verweisen ${ }^{22}$. Wie das Wort „Bibliothekswesen“ im Titel erkennen läßt, ist nicht der Nachweis einzelner Bibliotheken das Ziel Ottos, sondern eine Übersicht über das, was sich unter diesem Stichwort zusammenfassen läßt, wie ägyptische Bezeichnungen für Bücher, für Bibliothekare, Inhalt der Bücher u.a.m. Für die hier gestellte Frage ist vor allem wichtig, daß die verschiedenen Bezeichnungen für „Bibliothek" genannt und deren unterschiedliche Funktion erörtert werden. Dabei sind einmal das „Bücherhaus" und zum anderen das "Lebenshaus" zu nennen. Unter „Bücherhaus" sieht Otto eine Institution mehr allgemeiner Natur, die unsere Ausdrücke „Bibliothek" und „Archiv" zugleich umfassen. Erst in der Ptolemäerzeit, also seit dem 3. Jh. v. Chr., sei die Bedeutung „Bibliothek“, die das Wort natürlich von vornherein haben konnte, die ausschließliche geworden, während es in der Zeit davor mehr allgemein die Bezeichnung für ein Verwaltungsressort gewesen sei. Seinen Namen habe dieses daher erhalten, weil dort die einschlägigen Akten geführt und registriert worden seien. Danach wäre

14 ausschließlich auf der Darstellung Milkaus basiert Kampman, A.A.: Archieven en bibliotheken in het oude nabije Oosten. In: Handelingen van het zesde wetenschappelijk Vlaamsch Congress voor Boek- en Bibliothekswesen. Gent 1941, S. 214-220. Kampmans Darlegung entspricht in der Anlage genau der Milkaus, auf den er sich auch ausdrücklich beruft und enthält keine neuen Gesichtspunkte.

15 z.B. sein Artikel "Bibliothek" in: Reallexikon für Antike und Christentum, Bd. 2. Stuttgart 1954, Sp. 231-274; diese und andere Abhandlungen erschienen auch in: Wendel, Carl: Kleine Schriften zum antiken Buch- und Bibliothekswesen, hrsg. von Werner Krieg. Köln 1974 (Veröffentlichung des BibliothekarLehrinstituts des Landes Nordrhein-Westfalen).

16 Gardiner, Alan H.: The house of life. In: Journal of Egyptian Archaeology 24 (1938), S. $157-179$, s. dazu auch unten im 2. Kapitel.

17 zu dieser Problematik s. im einzelnen unten im 2. Kapitel unter "Lebenshaus".

18 Egyptian libraries: a survey of the evidence. In: Libri 7 (1957), S. 145-155. Dieser Aufsatz stellt offensichtlich die Zusammenfassung der Ergebnisse einer Magisterarbeit dar (Ancient Egyptian libraries, Kent State University 1953; typewritten).

19 Johnson, Elmer D. and Harris, Michael H.: History of libraries in the Western world, 3. ed., completely revised. Metuchen, N.J., 1976 , S. $28-39$

20 s. dazu im 2. Kapitel unter "Lebenshaus".

21 s. zu diesem Problem unter "Ramesseum" im 3. Kapitel.

22 Otto, Eberhard: ägyptisches Buch- und Bibliothekswesen, in: Handbuch der Orientalistik, hrsg. von Bertold Spuler, 1. Band: Ägyptologie, 2. Abschnitt: Literatur. 2. Aufl. Leiden 1970, S. $251 \mathrm{ff}$. 
also, so ist im Anschluß an diese Argumentation zu folgern, in vorptolemäischer Zeit der Nachweis eines „Bücherhauses" noch nicht gleichbedeutend mit dem Nachweis einer Bibliothek, es bedürfte zusätzlicher Kriterien.

Die Funktion des „Bücherhauses" in ptolemäischer Zeit untersucht Otto am Beispiel des Tempels von Edfu, wo ein solches „Bücherhaus“ erhalten ist. Verschiedene Indizien wie die Kleinheit des Raumes und das inhaltliche Spektrum der in ihm aufbewahrten Bücher (die Liste ist in die Wände eingemeißelt) führen inn zu dem Schluß, daß es sich dabei mehr um ein Magazin als um eine Bibliothek handle.

Als eigentliche Stelle, an der Bücher aufbewahrt wurden, sieht Otto das „Lebenshaus“ an, das ,zugleich etwa als Bibliothek und geistliche Universität bezeichnet werden kann"23. Das „Lebenshaus" sei eine Stätte, an der Bücher sowohl aufbewahrt wie auch verfaßt und tradiert worden seien. Er stützt sich dabei auf die schon erwähnten Untersuchungen Gardiners und auf die Voltens ${ }^{24}$. Hier muß jedoch der gleiche kritische Einwand erhoben werden wie gegen die Darstellung Wendels ${ }^{25}$. Otto verschweigt die erheblichen Unterschiede, die zwischen den Auffassungen Gardiners und Voltens bestehen, und vermeidet so die Notwendigkeit, seine Auffassung näher zu begründen ${ }^{26}$.

Die Ausführungen Ottos lassen sich somit wie folgt zusammenfassen: Es existierten zwei Arten von Bibliotheken, das „Bücherhaus" und die Bibliothek im ,Lebenshaus". Ersteres ist mehr als Magazin anzusehen und kann in vorptolemäischer Zeit ein breiteres Bedeutungsspektrum besitzen. Das "Lebenshaus" ist demgegenüber die eigentlich wichtige Stelle, an der Bücher aufbewahrt wurden.

Eine Reihe wichtiger Abhandlungen zum ägyptischen Bibliothekswesen verdanken wir dem ungarischen Ägyptologen Wessetzky, der sich unter verschiedenen Gesichtspunkten mit dieser Thematik auseinandergesetzt hat. Neben Untersuchungen zu konkreten Bibliotheken wie der des Ramesseums ${ }^{27}$ befaßte er sich auch mit der Problematik des Nachweises von Bibliotheken in Ägypten allgemein und mit Fragen der dabei anzuwendenden Methodik. Seine Auffassung zur Frage der Unterscheidung zwischen Bibliothek und Archiv wurde bereits genannt ${ }^{28}$.

In der Frage des konkreten Nachweises bestimmter Bibliotheken sieht Wessetzky zu Recht eine besondere Schwierigkeit, aber auch die Voraussetzung erfolgreichen Suchens in dem Problem, die archäologischen Gegebenheiten und die schriftlichen Quellen miteinander in Einklang zu bringen ${ }^{29}$. Er bezieht sich dabei vor allem auf Hinweise auf die Existenz von „Bücherhäusern" in Tempeln vor der ptolemäischen Zeit, die sich nicht so leicht verifizieren lassen wie in den ptolemäischen Tempeln; denn nur in letzteren ist das „Bücherhaus" auch direkt als solches inschriftlich gekennzeichnet. In den älteren Tempeln findet sich diese Kennzeichnung noch nicht.

Als ein zweites wichtiges Problem ist mit Wessetzky die Frage nach dem Verhältnis des "Bücherhauses“ zur Bibliothek des „Lebenshauses“ anzusehen. Wessetzky schließt „aus der Natur beider Institutionen“, daß das „Bücherhaus" heilige Schriften, theologische und magische Trakate enthalten habe und außerdem „Sammelstelle der Tempeladministration und der die Tempelinschriften bildenden historischen Texte und
Darstellungen bzw. der Vorlagen derselben" gewesen $\mathrm{sei}^{30}$. Dies folgert er zum Teil aus der Bücherliste der Bibliothek des Tempels von Edfu, steht damit also auf recht sicherem Boden. Seine weitergehenden Vermutungen verlassen dann allerdings diese sichere Basis, da er keine Belege anführen kann, und bieten damit Anlaß zur Kritik: Beide Bibliotheken hätten auch wissenschaftliche Werke enthalten und die „Bücherhäuser" hätten nur einen Teil der Bestände aufgenommen, der Rest sei aus Platzgründen in außerhalb des Tempels liegenden Magazinen aufbewahrt worden. Zu den beiden Institutionen „Bücherhaus“ und "Lebenshaus" wird unten im 2. Kapitel ausführlich Stellung genommen; hier sei nur darauf verwiesen, daß sich weder ein Hinweis finden läßt, daß die Bestände der „Bücherhäuser“ mehr umfaßten, als z.B. in der Bücherliste von Edfu für diese Bibliothek aufgeführt ist, noch daß ein Indiz für die Existenz von zum „Bücherhaus“ gehörenden, außerhalb des Tempels liegenden Magazinen bekannt ist.

Von Wessetzky stammt im übrigen auch die jüngste Zusammenfassung zum Thema „Bibliothek" im Lexikon der Ägyptologie ${ }^{31}$, wo er in knappster Form die genannten Fakten und Probleme umreißt.

Schließlich muß hier noch der Name Siegfried Schotts genannt werden, der ebenfalls in einer Reihe von Artikeln immer wieder zu Fragen des ägyptischen Bibliothekswesens Stellung genommen hat. Gegenstand seiner Untersuchungen waren bestimmte Bibliothekstypen (s. dazu unten im 2. Kapitel), aber auch Bücherverzeichnisse, Buchtitel u.a.m. Das von ihm geplante Hauptwerk mit dem Titel „Bücher und Bibliotheken im alten Ägypten" konnte er leider nicht mehr vollenden. Die Herausgabe aus dem Nachlaß ist geplant $^{32}$, wird aber, besonders was die Frage der Bibliotheken betrifft, wohl noch einige Zeit auf sich warten lassen ${ }^{33}$

Faßt man den Stand der Forschung, wie er sich auf ägyptologischer Seite aus den erwähnten Übersichten darstellt, zusammen, so ist festzustellen; Das Interesse galt vor allem grundlegenden Fragen wie den verschiedenen Bibliothekstypen, den Beständen dieser Bibliotheken und ihrer Lokalisation im allgemeinen. Eine listenartige Zusammenstellung konkreter Bibliotheken, wie sie Milkau erarbeitet hatte, und die einen wichtigen Beitrag zur Beantwortung der Frage nach dem „Bibliothekenreichtum" Ägyptens bilden könnte, wurde seither nicht wieder vorgenommen. Gemeinsam ist diesen Übersichten weiterhin, daß sie zu wenig ausführlich sind und daß Einzeluntersuchun-

23 (Anm. 22), S. 255.

24 Aksel Volten, demotische Traumdeutung (Pap. Carlsberg XIII und XIV Verso). Kopenhagen 1942, S. $17 \mathrm{ff}$.

25 s. oben S. 82.

26 s. dazu unten im 2. Kapitel unter "Lebenshaus".

27 s. dazu im 3. Kapitel unter „Ramesseum “.

28 s. oben S. 81.

29 vgl. Wessetzky, Vilmos: Zur Problematik des altägyptischen Buch- und Bibliothekswesens. In: Akten des vierundzwanzigsten Internationalen Orientalistenkongresses, hrsg. von Herbert Franke. Wiesbaden 1959, S. 89-91; ders.: die ägyptische Tempelbibliothek, in: Zeitschrift für ägyptische Sprache und Altertumskunde 100 (1973), S. 54; ders.: (Anm. 3), S. 90-91.

30 (1973, Anm. 29), S. 55

31 Artikel „Bibliothek" in: Lexikon der Ägyptologie, Bd. 1. Wiesbaden 1975, Sp. 783-785.

32 vgl. Erika Schott, Bücher und Bibliotheken im alten Ägypten. In: Göttinger Miszellen 1 (1972), S. $24 \mathrm{ff}$.

33 vgl. Erika Schott, Bücher und Bibliotheken im alten Ägypten. In: Göttinger Miszellen 25 (1977), S. $73 f f$. 
gen und versteckte Hinweise der im folgenden $A b$ schnitt behandelten Art zu wenig berücksichtigt wurden.

\section{lb. Einzelhinweise}

Neben den bisher besprochenen Übersichten ist nun noch eine Reihe von Einzeluntersuchungen bzw. hinweisen zu nennen, die sehr verschiedenartig und über einen großen Teil der Forschungsliteratur verstreut sind. Als wichtigste Typen lassen sich die folgenden nennen:

1. Spezielle Abhandlungen zu Einzelproblemen. Derartige Untersuchungen, meist in Form von Zeitschriftenaufsätzen, sind relativ leicht zu finden, da in der Regel der Titel die Thematik bereits benennt. Als Beispiel für diesen Typus sei die schon erwähnte Untersuchung Gardiners zum „Lebenshaus" genannt ${ }^{34}$.

2. Die Behandlung von Einzelfragen innerhalb von Aufsätzen oder auch Monographien, wo diese Fragen als Teil- oder Randgebiete auftauchen und untersucht werden. Ihre Auffindung ist schon erheblich schwieriger, weil der Titel meist keinen Hinweis gibt, so daß erst die Auswertung des Inhalts zum Ziel führt. Hier ist als Beispiel die Publikation eines Papyrus mit magischem Inhalt durch Derchain zu nennen, innerhalb der sich ein wichtiger Beitrag ebenfalls zum „Lebenshaus" findet ${ }^{35}$.

3. "Versteckte" Einzelhinweise. Hier sind in erster Linie Grabungsberichte bzw. -publikationen zu nennen. Beschreibungen von Gebäuderesten oder Fundberichte von Papyri u.ä. können manchmal wertvolle Indizien enthalten. Dies gilt beispielsweise für Pendlebury's Publikation der Ausgrabungen in Amarna, wo vermerkt ist, daß ein Gebäudekomplex aufgrund der entsprechenden Kennzeichnung der dort verwendeten Lehmziegel eindeutig als "Lebenshaus" zu identifizieren ist $^{36}$.

Während derartige Belege noch recht eindeutig sind, müssen bei anderen oft zunächst noch methodische Fragen geklärt werden, bevor sie als tatsächlich ernstzunehmende Indizien eingestuft werden können. Dies gilt z.B. für einige Publikationen von aus dem Faijum stammenden Papyri, wo vermerkt ist, daß die Bestände „aus der Tempelbibliothek" stammen, eine nähere Begründung dieser Vermutung aber teilweise unterbleibt $^{37}$

Als letzte sei eine Gruppe von Indizien genannt, die wohl am schwierigsten aufzuspüren ist, aber zu überraschenden Einsichten verhelfen kann: Sie finden sich - in der Tat oft sehr versteckt - in Textpublikationen verschiedenster Art und besitzen als Primärquellen natürlich besonderen Wert. Ein schönes Beispiel für diesen Typ von Hinweisen bietet die Publikation der Texte des Tempels von Edfu, die mit dem Kult des dortigen Hauptgottes Horus in Zusammenhang stehen $^{38}$. Dort ist u.a. der Verlauf einer der Kultprozessionen beschrieben, und darin findet sich auch die Anweisung, daß die Prozession zum "Lebenshaus" hinüberziehen soll, um dort bestimmte Riten zu vollziehen $^{39}$. Das ist ein klarer Beleg für die Existenz eines "Lebenshauses" in Edfu, von dem sich ansonsten offenbar keine Spur erhalten hat ${ }^{40}$.

Bereits aus diesen wenigen Beispielen wird ersichtlich, wie bedeutsam derartige Einzelhinweise oft sind. Ge- rade in der Frage des Nachweises bestimmter Bibliotheken kann ihre Sammlung eine wichtige Hilfe sein, entweder weil auf diese Weise direkte Belege für Bibliotheken gefunden werden können - wie der erwähnte für das "Lebenshaus“ in Edfu -, oder weil so mehrere, einzeln zu schwache Indizien zusammengeführt werden können, die gemeinsam dann einen eindeutigen Beleg darstellen ${ }^{41}$.

\section{Methodische Überlegungen}

\section{Ila. Grundsätzliches}

Im Verlauf des Überblicks über den Stand der Forschung wurde verschiedentlich auf Unsicherheiten oder Fragwürdigkeiten in der Argumentation bzw. auf ungenügende Berücksichtigung unterschiedlicher Meinungen hingewiesen und die Notwendigkeit einer tragfähigen methodischen Basis betont. Um eine solche Basis zu erreichen, wird es zunächst erforderlich sein, die Quellen teilweise erneut zu befragen, zu welchen der Interpretationen sie uns greifbare Hinweise geben können. Da die unterschiedlichen Meinungen teils so grundsätzliche Fragen betreffen wie die, ob im „Lebenshaus" überhaupt eine Bibliothek vorauszusetzen ist ${ }^{42}$, muß die Erörterung dieser Fragen am Anfang stehen. In einem zweiten Schritt sind dann Kriterien zu erarbeiten, anhand derer das zur Verfügung stehende ärchäologische und inschriftliche Material nach Indizien für die Existenz bestimmter Bibliotheken befragt werden kann.

Diese Zweiteilung des Vorgehens wird im übrigen auch durch die zwei verschiedenen Arten von Indizien nahegelegt, die man a priori von den Quellen erwarten darf: Einmal Hinweise, die Bibliotheken im allgemeinen betreffen, also insbesondere ägyptische Bezeichnungen für diese Institution und möglicherweise Nachrichten über ihre Zweckbestimmung, ihre Bestände o.ä.; zum anderen spezielle Hinweise für die Existenz einzelner Bibliotheken.

\section{Ilb. Allgemeine Indizien}

Der Begriff „allgemeines Indiz" ließe sich sehr weit fassen: Eine Notiz wie z.B. die auf der sog. „Satrapenstele", wo sich Ptolemaios Lagi unter anderm rühmt, alle von den Persern geraubten heiligen Bücher der Tempel von Ober- und Unterägypten zurückgeführt zu haben ${ }^{43}$, kann durchaus als Hinweis auf die Existenz von Bibliotheken gewertet werden. Man könnte auch, wie dies z.B. Richardson allerdings ohne Erfolg ver-

34 (Anm. 16) S. 157-179.

35 Derchain, Philippe: le papyrus Salt 825 (B.M. 10051), rituel pour la conservation de la vie en Egypte, vol. I und II. Bruxelles 1965.

36 Pendlebury J.D.S. The city of Akhenaten, part III. London 1951 S. 115 , Taf. XX

37 so z.B. Tait, W.J.: Papyri from Tebtunis in Egyptian and in Greek (P. Tebt. Tait). London 1977, S. VII.

38 Alliot, Maurice: Le culte d'Horus à Edfou au temps des Ptolémées. Le Caire 1949 (= Bibliothéque d' Etude 20)

39 Alliot (Anm. 38), S. 531; s. auch Gardiner (Anm. 16), S. 174 Nr. 50.

40 im einzelnen s, unten im 3. Kapitel zu Edfu“"

41 s. z.B. im 3. Kapitel unter "Sais" oder auch unter „Elephantine“, das allerdings insofern ein Sonderfall ist, als dort zusätzlich noch unveröffentlichtes Material zur Verfügung stand.

42 s. oben S. 83.

43 Urkunden des ägyptischen Altertums, Abt. II: Hieroglyphische Urkunden der griechisch-römischen Zeit, bearb. von Kurt Sethe, Leipzig 1904, S. 14, Z. 9-11 
sucht hat ${ }^{44}$, auf die Suche nach altägyptischen Bibliothekaren gehen. Doch solange derartige Hinweise keine Nachricht über eine bestimmte Bibliothek enthalten, erübrigt sich ihre Erörterung durch die einfache Tatsache, daß uns ägyptische Bezeichnungen für „,Bibliothek" bekannt sind, an der Existenz dieser Institution also kein Zweifel besteht.

Anders ist der Sachverhalt jedoch, wenn versucht wird, diese Bezeichnungen inhaltlich näher zu bestimmen, wenn also nach Funktion, Beständen u.ä. gefragt wird. Und ebenso problematisch ist, wie schon mehrmals erwähnt, die Frage nach der Existenz von Bibliotheken im ,Lebenshaus“.

Die gesuchten allgemeinen Indizien sollen also einmal die Frage beantworten, wie sich die ägyptischen Wörter für „Bibliothek" inhaltlich näher bestimmen lassen, und zum anderen, ob man im „Lebenshaus" tatsächlich in der Regel eine Bibliothek erwarten darf, ob somit der Nachweis eines "Lebenshauses" mit dem Nachweis einer Bibliothek gleichgesetzt werden kann.

\section{1. „Bücherhaus“ und ,Gottesbücherhaus“}

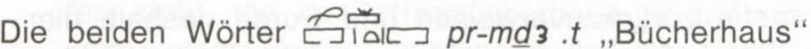
(wörtlich: "Haus der Buchrollen") und P prmd 3 .t-ntr "Gottesbücherhaus" (wörtlich: „Haus der Buchrollen des Gottes") sind in Ägypten seit dem Alten Reich bekannt. Der wohl wichtigste Beleg findet sich im Tempel von Edfu, wo ein „Bücherhaus“, d.h. ein inschriftlich so gekennzeichneter Raum erhalten ist, an dessen Wänden sich außerdem Listen mit den Titeln der dort aufbewahrten Bestände befinden.

Doch so klar wie im Tempel von Edfu ist der Sachverhalt leider nicht immer. Otto weist auf eine mögliche Verlagerung der Bedeutung in Richtung auf "Archiv" hin - so war z.B. das einmal belegte „Bücherhaus des (königlichen) Speisemeisters" sicher ein Archiv und keine Bibliothek - und begrenzt die zweifelsfreie Bedeutung „Bibliothek" auf die Ptolemäerzeit. Für die Zeit davor sieht er einen erheblich weiteren Bedeutungsumfang: Seiner Ansicht nach wird dort sowohl das Archiv miterfaßt, als auch die zugehörige Dienststelle selbst, so daß er im „Bücherhaus“ die Bezeichnung für ein Verwaltungsressort sieht ${ }^{45}$.

Die letztere Vermutung geht jedoch, wie im folgenden dargelegt werden soll, sicher zu weit.

Als Ausgangspunkt soll die Ptolemäerzeit dienen, da dort, so Otto, die Bedeutung „Bibliothek" gesichert ist ${ }^{46}$.

Wichtigster Beleg ist hier das schon mehrfach genannte „Bücherhaus“ in Edfu und seine Bücherlisten. Die dort aufgeführten Titel sind mit Alliot ${ }^{47}$ in vier Sachgruppen zu gliedern:

1. Handbücher für den täglichen Kult

2. Ritualbücher für besondere Feste

3. Beschwörungen und Schutzbücher, also Texte magischen Inhalts

4. Inventarien der heiligen Orte, ein Handbuch für die Tempeldekoration u.ä., also Archivalien

Ähnlich ist der Sachverhalt offenbar im "Bücherhaus" des Tempels von Philae. Dort ist der Text am Türpfosten rechts des Eingangs zu übersetzen ${ }^{48}$ : „Das ist das Bücherhaus... Alle Bücher sind darin an [...] des ganzen Lebenshauses. Und auch der Plan dieses Gaues auf einer Urkunde aus reinem Leder und alle königlichen Befehle...": Es wurden dort also sowohl Bücher wie auch Archivalien aufbewahrt.

Die Reste einer Bücherliste, die offenbar dem Verzeichnis von Edfu entspricht, wurde im Tempel von Tôd gefunden. Sie ist leider noch nicht veröffentlicht, doch sind wenigstens einige Titel bekannt ${ }^{49}$, die alle auf Bücher religiösen Inhalts verweisen.

Abgesehen von diesen auf konkrete „Bücherhäuser" in Tempeln bezogenen Belegen seien noch drei weitere von allgemeinerer Natur genannt, die auch alle aus ptolemäischer Zeit stammen:

Im Ritual, das im Verlauf der Einbalsamierung des Toten rezitiert wurde ${ }^{50}$, findet sich die Stelle: (angesprochen ist der wiederbelebte Tote) „Du hörst die Bücher im Bücherhaus." Vorher hatte es im gleichen Text geheißen: „(der Gott Thot) macht, daß du aus dem 'Buche vom Atmen' hörst, die Sprüche der Bücherhäuser, die im Westen (= dem Totenreich) sind." Hier kann natürlich nur von religiösen Büchern die Rede sein und nicht von Archivalien; dabei ist es unerheblich, daß das „Bücherhaus" in diesem Fall ein jenseitiges, also nicht real existierendes ist, da das Jenseits als Abbild des diesseitigen Lebens gedacht wurde.

Der zweite Beleg stammt von einer Stele ${ }^{51}$, wo vom Besitzer, einem Priester, gesagt ist: „der alles berechnet für das Bücherhaus, der ausfüllt, was er zerstört gefunden hat in den heiligen Schriften." Auch mit den „,heiligen Schriften" können nur religiöse Bücher bezeichnet sein: Das ägyptische Wort $b_{3} w-R^{c}$ ist wörtlich mit Gardiner ${ }^{52}$ als „Emanationen des Re" wiederzugeben, diese Bücher gehen also auf unmittelbare Inspirationen durch den Sonnengott zurück ${ }^{53}$.

Auf einer weiteren, heute im Louvre aufbewahrten Stele ${ }^{54}$ steht u.a.: ,(Ihr Priester,) die ihr eingetreten seid in die Archive (o.ä.) des Bücherhauses und die Geheimnisse der heiligen Schriften erklären könnt." Auch hier ist ganz sicher nicht von Archivalien die Rede.

Für die Ptolemäerzeit kann somit zusammenfassend gesagt werden: Die Bedeutung „Bibliothek" läßt sich aus allen genannten Belegen eindeutig erschließen und darf, da gegenteilige Belege nicht bekannt sind, in dieser Zeit dem ägyptischen Wort pr-md 3 .t zugrundegelegt werden. Dabei ist es durchaus möglich, daß auch Archivalien in den „Bücherhäusern“ aufbewahrt

44 Richardson, Ernest Cushing: Some old Egyptian librarians. New York 1911; widerlegt von Friedrich Vogelsang: Altägyptische Bibliothekare? In: Zentralblatt für Bibliothekswesen 30 (1913), S. 17-22.

45 (Anm. 22), S. 254f.

46 die im folgenden aufgeführten Belege für "Bücherhaus" stammen, soweit sie nicht veröffentlicht sind (die Publikation ist dann angegeben), von den Zetteln des „Wörterbuchs der ägyptischen Sprache" die in der Akademie der Wissenschaften in Ostberlin aufbewahrt werden. Herr Dr. Weber vom Seminar für Ägyptologie der Universität Köln stellte mir seine Abschriften zur Verfügung, wofür ich ihm an dieser Stelle herzlich danken möchte.

47 (Anm. 38), S. 147

48 Junker, Hermann: und Schäfer, Heinrich: Berliner Photos der Preussischen Expedition 1908-1911 nach Nubien. Wiesbaden 1975 (Ägyptologisches Microfiche-Archiv 3), Photo 856.

49 aufgezählt von Sauneron, Serge: Les prêtres de l'ancienne Egypte. Paris 1962, S. 136-137.

50 P. Boulaq 3, col. 8, Z. 6-7, s. Sauneron, Serge: Rituel de l'embaumement, Pap. Boulaq III, Pap. Louvre 5.185. Le Caire 1952, S. 28.

51 Wien, Kunsthistorisches Museum, Stele Nr. 154.

52 (Anm. 16), S. 168.

53 vgl. auch Otto (Anm.22), S. 253

54 Stele Louvre C 232, vgl. auch Gardiner (Anm. 16), S. 172-173, Nr. 43. 
wurden, wie die Beispiele aus Edfu und Philae zeigen, doch spricht das nicht gegen die Interpretation als Bibliothek ${ }^{55}$.

In allen Belegen läßt sich auch ein eindeutiger Zusammenhang mit den Tempeln erkennen. Da auch hierzu keine Gegenbeispiele bekannt sind, darf man davon ausgehen, daß das „Bücherhaus" in der Ptolemäerzeit in der Regel eine zum Tempel gehörende Institution ist. Eine wichtige Einschränkung muß freilich berücksichtigt werden: Geht man von den am besten erhaltenen Bücherlisten in Edfu aus - und gegenteilige Belege stehen auch in diesem Punkt nicht zur Verfügung - und berücksichtigt außerdem die geringe Größe des Raumes ${ }^{56}$, dann zeigt sich deutlich, daß das "Bücherhaus “ nicht eine Sammlung im Sinne einer „Universalbibliothek" gewesen sein kann. Aus diesem Grund hat z.B. Otto im "Bücherhaus" eher ein Magazin als eine Bibliothek gesehen ${ }^{57}$, doch ist diese Bezeichnung irreführend: Die Bestände des „Bücherhauses“ in Edfu sind ganz offenkundig für Zwecke des täglichen Kultes $^{58}$ und evtl. der Archivierung wichtiger Urkunden bestimmt. Daher ist eine Bezeichnung wie etwa „Handbibliothek" sicher zutreffender; vielleicht ist es sogar erlaubt, von einer ,Spezialbibliothek" zu sprechen ${ }^{59}$.

Inwieweit kann nun diese Deutung auf frühere Epochen übertragen werden? Zur Beantwortung dieser Frage ist es notwendig, die greifbaren Belege, die hierzu verwertbare Indizien enthalten, einzeln zu prüfen. Dies soll im folgenden geschehen, wobei die Quellen, soweit dies möglich ist, chronologisch geordnet $\operatorname{sind}^{60}$.

1. In einem Grab in Giza (4. Dynastie, um 2570-2450 v.Chr.) hat der Grabbesitzer u.a. die Titel ,Vorlesepriester, Vorsteher der Geheimnisse der geheimen Schrift des Hauses der Gottesworte"61. Der Begriff „Haus der Gottesworte" ist sonst nicht belegt und mit Junker (a.a.O.) zweifellos in Beziehung zu „Bücherhaus" zu setzen. Daß mit ,geheimen Schriften", mit denen ein Vorlesepriester befaßt ist, sicherlich religiöse Bücher und nicht Archivalien gemeint sind, leuchtet ohne weiteres ein.

2. In einem zweiten Grab in Giza aus der gleichen Zeit trägt der Besitzer u.a. die Titel „Prophet, Vorsteher der Geheimnisse und Aufseher der Archivare des Gottesbücherhauses des Großen Hauses (= des Königs) "62. Hier ist die Funktion als Archiv offensichtlich stärker betont, doch ist beim „Vorsteher der Geheimnisse (sc. des „Gottesbücherhauses")" wie im ersten Beispiel ganz sicher auch mit Bücherbeständen zu rechnen.

3. In einer Inschrift aus dem ersten Regierungsjahr des Königs Neferirkare (5. Dynastie, um 2430 v.Chr.) wird u.a. berichtet, daß das „,Gottesbücherhaus" des snw.t-Heiligtums ${ }^{63}$ mit Ländereien beschenkt wird ${ }^{64}$. Dieser Beleg ist nicht ganz eindeutig für eine der beiden Interpretationen zu werten, doch läßt sich zumindest sagen, daß die Bezeichnung "Gottesbücherhaus" und die Angliederung an einen Tempel durchaus eher für als gegen die Annahme spricht, daß dort auch Bücher aufbewahrt wurden.

4. Aus der gleichen Zeit wie der vorige stammt der bereits genannte Beleg für ein „Bücherhaus des Speisemeisters". Aus dem Kontext dieser Inschrift, die aus einem Grab stammt, lassen sich keine weiteren Indizien entnehmen, doch ist bei dieser Bezeichnung gewiß eher an ein Archiv als an eine Bibliothek zu denken: Der Grabherr nennt sich u.a. „Aufseher der Schreiber des Bücherhauses des Speisemeisters" 65 .

5. Auf der Stele eines Königs Neferhotep aus der 13. Dynastie (1785 - ca. 1650 v.Chr.) wird berichtet, daß der König die „,uralten Bücher des (Gottes) Atum" sehen möchte. Die Hofleute raten dem König, ins „Haus der Schriften“ zu gehen und die „Gottesworte“ dort einzusehen. Der Text fährt fort: „Da ging seine Majestät zum Bücherhaus und breitete die Buchrollen aus."66 Dieses Bücherhaus ist ganz eindeutig als Bibliothek zu interpretieren.

6. Auf einer Stele aus der 18. Dynastie (1554-1305 v.Chr.) ${ }^{67}$ findet sich der Titel ,Vorsteher der Geheimnisse des Bücherhauses"; vgl. den Beleg Nr. 2: Diese „Geheimnisse" betrafen sicher nicht nur Archivalien, sondern auch Bücher.

7. Auf einem Papyrus aus ptolemäischer Zeit, der religiöse Texte enthält ${ }^{68}$, findet sich der Vermerk: „,Gefunden auf einer Papyrusrolle aus der Zeit des Königs Thutmosis und der Zeit des Königs Amenophis im Bücherhaus des Osiristempels in Abydos." Dieser Beleg scheint auf die 18. Dynastie zurückzuverweisen und wurde deshalb hier plaziert, doch ist nicht auszuschließen, daß hier, wie das öfter geschah, ein hohes Alter nur fingiert worden ist. Unbestritten bleibt freilich, daß eindeutig eine Bibliothek gemeint ist: Bei Echtheit der Angabe kann dies ein Beleg dafür sein, daß in Abydos schon sehr lange, möglicherweise eben seit der 18. Dynastie, ein „Bücherhaus“ existierte (denn wo sonst wäre die Papyrusrolle so viele Jahrhunderte aufbewahrt worden); im Falle einer Fiktion würde der Hinweis nur für die Ptolemäerzeit gelten.

8. In einem in der 18. und 19. Dynastie (1554-1196 v.Chr.) mehrfach belegten Opferritual ${ }^{69}$ lautet eine Passage: „Jene Schrift, welche (der Gott) Thot für Osiris im Bücherhaus (Variante: Gottesbücher-

55 vgl. die Definition Wessetzky's oben S. 81

56 Wessetzky's Vermutung, die Bestände seien in Magazinen auBerhalb des Tempels gelagert worden, muß wie erwähnt (s. oben S. 83) mangels eines Belegs unberücksichtigt bleiben.

57 s. oben S. 83.

58 so z.B. auch Alliot (Anm. 38), S. 135.

59 die speziellen für den Kult bestimmten Bücherbestände würden diese Bezeichnung ohne weiteres erlauben; auch die Tatsache da $B$ auch Archivalien dort aufbewahrt wurden, spricht nicht unbedingt dagegen: in Edfu scheinen dies Urkunden für spezielle Bedürfnisse des Tempels gewesen zu sein, in Philae ist ein Zusammenhang mit den Erfordernissen der dortigen Gauverwaltung erkennbar.

60 die unpublizierten Belege stammen von der Berliner Zettelsammlung des „Wörterbuchs", s. oben Anm. 46.

61 Junker, Hermann: Bericht über die von der Akademie der Wissenschaften in Wien ... unternommenen Grabungen ... bei den Pyramiden von Giza, Bd. VII. Leipzig 1944, S. 236.

62 Junker (Anm. 61), Bd. VIII. Leipzig 1947, S. 163-164.

63 zu diesem Heiligtum s. unten im 3. Kapitel zur „Bibliothek des snw.t-Heiligtums“.

64 Urkunden des ägyptischen Altertums, Abt. I: Urkunden des alten Reiches, bearb. von Kurt Sethe, Leipzig 1903, S. 246, 14.

65 (Anm. 64), S. 47, 13

66 Pieper, Max: die große Inschrift des Königs Neferhotep in Abydos. Leipzig 1929, S. 13-14.

67 Stele Louvre C 65.

68 P. Berlin 3057 („P. Schmitt"), vgl. Möller, Georg: Über die in einem späthieratischen Papyrus des Berliner Museums erhaltenen Pyramidentexte. Berlin 1900, S. 2f.

69 zusammengestellt von Schott, Siegfried: Die Opferliste als Schrift des Thot. In: Zeitschrift für ägyptische Sprache und Altertumskunde 90, (1963), bes. S. $109 \mathrm{f}$. 
haus) gemacht hat." Auch hier ist eindeutig eine Bibliothek gemeint, wenn auch eine im mythologischen Bereich und nicht eine real existierende, s. aber oben S. 85 zur Passage aus dem Balsamierungsritual: Man kann durchaus davon ausgehen, daß hier reale Verhältnisse ins Mythologische transponiert wurden.

9. Im Tempel Sethos' I. (1303-1290 v.Chr.) in Abydos findet sich bei der Darstellung eines Opfers der Satz: „(die Götterneunheit,) die auf ihren Sitzen ruht in ihrer ursprünglichen Gestalt, in ihrer Bildung, die Ptah geschaffen hat gemäß dem, was Thot geschrieben hat für sie in dem großen Inventar, das sich im Bücherhaus befindet. "70 Das Wort „Inventar" (so die gebräuchliche Übersetzung, vgl. Wb IV,36,11) scheint auf ein Archiv hinzuweisen, doch ist auch zu berücksichtigen, daß dieses Inventar als von einem Gott verfaßt ganz sicher auch als geheiligte Schrift angesehen wurde: Diese Passage ist somit für beide Interpretationen offen.

10. Im kleinen Tempel Ramses' II. (1290-1224 v.Chr.) in Abydos lautet eine Inschrift: „Der Weihrauch, der reine, angenehme, der Duft, der in den Schriften steht, die im Gottesbücherhaus sind."71 Es kann keinem Zweifel unterliegen, daß diese göttliche Emanationen verströmenden Schriften - die wörtliche Übersetzung von Weihrauch lautet ,Gottesduft" - keine Archivalien, sondern (wohl religiöse) Bücher waren.

11. Im Papyrus Anastasi I aus der 19. Dynastie steht der Satz: „Das Bücherhaus ist geheim, nicht wird es gesehen."72 $\mathrm{Vgl}$. den oben schon mehrmals genannten Titel „Vorsteher des Geheimnisses des Bücherhauses": Der Gedanke, daß ein geheimes „Bücherhaus" nicht nur Archivalien enthielt, liegt nahe.

12. In einem thebanischen Grab aus der Zeit Psammetichs I. (26. Dynastie, 664-610 v.Chr.) findet sich die Passage: „... Schreiber, die die Palette empfangen haben und eingeweiht sind in [die Gottesworte], die geschickt sind in der Schrift und die - ? - des Bücherhauses aufrollen."73 Die kaum bezweifelbare Ergänzung „Gottesworte“ als gesichert vorausgesetzt, spricht mehr für die Bedeutung „Bibliothek“, zumindest im Sinne der Definition Wessetzky's ${ }^{74}$.

Die Summe dieser insgesamt 12 Belege spricht, dies läßt sich mit einiger Sicherheit sagen, entgegen der oben zitierten Meinung Ottos recht klar für eine Tendenz zur Bedeutung „Bibliothek“, doch kann diese nicht a priori angenommen werden: In jedem Einzelfall ist der Kontext sorgfältig nach weiteren Indizien zu befragen. Etwas eindeutiger scheint die Lage dort zu sein, wo das "Bücherhaus" im Zusammenhang mit einem Tempel belegt ist: In keinem der entsprechenden Belege findet sich ein Indiz, das gegen eine den „Bücherhäusern“ der ptolemäischen Tempel vergleichbare Funktion spricht.

Es muß nun noch nach dem Verhältnis zwischen der Bezeichnung „Bücherhaus" und dem besonders im Alten Reich, aber auch noch bis ins Neue Reich belegten „,Gottesbücherhaus“ gefragt werden. Die Belege rufen den Eindruck hervor, daß es sich dabei nicht um zwei verschiedene Institutionen handelt, vgl. besonders oben Beleg Nr. 8, wo die Parallelen zu ein und demselben Text zwischen diesen beiden Bezeichnungen variieren. Auch eine Beschränkung etwa der Art, daß das "Gottesbücherhaus" nur im Zusammenhang mit einem Tempel begegnet, also die Tempelbibliothek bezeichnet, ist anscheinend nicht zu rechtfertigen, vgl. bes. den Beleg Nr. 2, wo ein solcher Zusammenhang offenbar nicht besteht. Man muß also wohl davon ausgehen, daß beide Bezeichnungen Synonyma sind, wobei allenfalls ein chronologischer Unterschied denkbar ist: "Gottesbücherhaus" ist vor allem im Alten Reich belegt und offenbar nach dem Neuen Reich nicht mehr gebräuchlich, während sich „Bücherhaus“ zu allen Zeiten findet.

Zusammenfassend ergibt die Auswertung der Belege somit folgendes Bild:

In ptolemäischer Zeit bezeichnet das „Bücherhaus“ zweifelsfrei eine Bibliothek im Zusammenhang mit einem Tempel, wobei - da teilweise auch Archivalien dort aufbewahrt wurden - die Definition dieser Bibliothek im Sinne Wessetzky's zu verstehen ist ${ }^{75}$. Die Besonderheit der Bestände, wie sie z.B. in Edfu durch Listen nachgewiesen sind, und äußere Faktoren wie die Raum- und Lichtverhältnisse erlauben eine nähere Spezifizierung als „Handbibliothek" oder - mit Abstrichen - als "Spezialbibliothek".

In pharaonischer Zeit ist offenbar eine Verlagerung der Bedeutung in Richtung „Archiv" möglich, doch zeigt die Mehrzahl der Belege die Tendenz zu einer der späteren Zeit entsprechenden Interpretation; wenn ein „Bücherhaus " im Zusammenhang mit einem Tempel belegt ist, scheint diese Deutung grundsätzlich möglich zu sein: In diesem Fall kann also ein Beleg für ein "Bücherhaus" in der Regel auch als Beleg für die Existenz einer Bibliothek gelten, alle anderen Fälle sind sorgfältig auf zusätzliche Indizien zu überprüfen. Entsprechendes gilt für das „,Gottesbücherhaus“, dessen Unterschied zum „Bücherhaus“ allenfalls chronologischer Natur ist.

\section{$2 . \quad$ "Lebenshaus"}

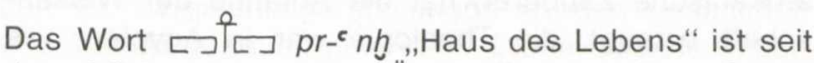
dem Mittleren Reich in Ägypten gut belegt. Schon mehrmals wurde oben auf die unterschiedlichen Auffassungen über diese Institution verwiesen. Im hier interessierenden Rahmen ist dabei vor allem die Frage von Bedeutung, ob das "Lebenshaus" auch eine Bibliothek besaß oder nicht. Gardiner ${ }^{76}$ hat das bestritten, Volten ${ }^{77}$ als selbstverständlich angesehen, Spätere haben jeweils eine dieser beiden Ansichten übernommen, ohne sich selbst noch mit diesem Problem zu befassen.

Im folgenden soll die Grundproblematik vor allem anhand der Untersuchungen Gardiners und Voltens kurz umrissen werden, und anschließend ist es auch hier erforderlich, erneut die Quellen zu befragen, ob sie

70 Mariette-Bey, Auguste: Abydos, description des fouilles, vol. II. Paris 1880, pl. 9.

71 Mariette (Anm. 70), vol. I. Paris 1869, pl. 44.

72 P. Anastasi I, 11, 5-6, s. Gardiner, Alan H.: Egyptian hieratic texts. Leipzig 1911, S. 40

73 Grab Theben Nr. 36.

74 s. oben S. 81.

75 s. oben S. 81

76 (Anm. 16), S. 157-179.

77 (Anm. 24), bes. S. 17-44. 
Aussagen über die Existenz von Büchern im „Lebenshaus" enthalten. Denn nur in diesem Fall wird es möglich sein, durch den Nachweis eines ,Lebenshauses" auch die Bibliothek als einen notwendigen Bestandteil dieser Institution eindeutig zu belegen.

In seiner schon mehrfach zitierten Untersuchung hat Gardiner fast 60 Belege für ,Lebenshäuser" zusammengetragen und nach der Funktion dieser Institution befragt. Er gelangte zu dem Ergebnis, daß das „Lebenshaus" vor allem die Stätte war, an der Bücher kopiert und auch verfaßt wurden, und zwar besonders solche religiösen, magischen und medizinischen Inhalts; außerdem sei es wohl auch eine Stätte der gelehrten Diskussion gewesen, in der z.B. Entscheidungen über königliche und göttliche Titulaturen, über die Feier religiöser Feste und anderes mehr getroffen wurden. Die Hauptbedeutung sah er aber offensichtlich in der Tradierung und Zusammenstellung von Büchern: „... that the was neither a school nor a university, but rather a scriptorium where books connected with religion and cognate matters were compiled. "78 Die Frage nach der Existenz einer Bibliothek verneint er ausdrücklich: ,... . they do not seem to have contained libraries of their own. The temples, or at all events some temples, possessed libraries, and these had their special name pr-mds.t."

Dieser Auffassung, der sich später beispielsweise Hellmut Brunner anschlo ${ }^{80}$, steht Voltens im großen und ganzen auf den gleichen Belegen fußende Interpretation gegenüber, die dem „Lebenshaus" erheblich umfassendere Funktionen zuweist. Er sieht in inm ein Kollegium, das das Leben des Königs und der Götter zu schützen hat und sich zu diesem Zwecke der „Wissenschaften“ bedient, zunächst der Magie und der Medizin, zu denen später z.B. die Balsamierung, das Verfassen theologischer und theologisch-magischer Werke, Astronomie und Astrologie und anderes mehr kommen. Sein Urteil faßt Volten wie folgt zusammen: „Das pr-'nh war also wirklich - mutatis mutandis - eine Art Universität. Der primitive Theologe, der afrikanische Zauberer, hat die Anfänge der Wissenschaft erzeugt, die Theologie war in Ägypten, wie später in Europa, die Mutter aller anderen Wissenschaften... Und Bibliotheken waren an die Lebenshäuser geknüpft wie an die jetzigen Universitäten."81

Dieser Auffassung schlossen sich - um nur einige wichtige Stellungnahmen zu vermerken - z.B. Jean Capart ${ }^{82}$, Baudouin van de Walle ${ }^{83}$ und Eberhard Otto ${ }^{84}$ an.

Die unterschiedliche Auffassung als "Skriptorium“ oder „Universität" ist in diesem Zusammenhang nur am Rande von Interesse, da keine der beiden Möglichkeiten eo ipso die Existenz oder Nichtexistenz einer Bibliothek beinhaltet: So wenig Voltens Verweis auf die jetzigen Universitäten für sich allein stichhaltig ist, kann auf der anderen Seite Gardiners Argumentation überzeugen. Selbst wenn im „Lebenshaus“ nur die von ihm beschriebenen Funktionen ausgeübt wurden, ist durchaus damit zu rechnen, daß dazu eine Büchersammlung benötigt wurde. Gardiners Verweis auf die „Bücherhäuser" ist nicht überzeugend und wird von ihm selbst unfreiwillig abgeschwächt, da er belegt, daß das „Lebenshaus" eine eigene Institution und teilweise auch in einer gewissen räumlichen Entfernung zum Tempel gewesen ist (s. dazu weiter unten in diesem Abschnitt).
Doch sind derartige Vermutungen - um solche handelt es sich letztlich - natürlich nicht ausreichend für die hier allein interessierende Frage nach der Existenz von Bibliotheken im „Lebenshaus“. Die Hoffnung, der Lösung dieses Problems näher zu kommen, ruht allein auf der Aussage der Quellen: Sie müssen nach Indizien befragt werden, die eindeutig auf das Vorhandensein von Büchern in den „Lebenshäusern“ schließen lassen.

Hierfür fanden sich folgende Anhaltspunkte (soweit möglich in chronologischer Reihenfolge):

1. In einem Grab in El Bersheh aus dem Mittleren Reich (ca. 2000-1600 v.Chr.) ${ }^{85}$ trägt der Grabherr u.a. den Titel: „Verwalter (o.ä.) des Geschriebenen im Lebenshaus, dem alle Herrlichkeit (o.ä.) enthüllt wird." Das Wort _fo sś, das allgemein mit "Geschriebenes" wiedergegeben wurde, kann außer der Bedeutung "Schrift", die hier sicher nicht in Frage kommt, „Schriftstück, Buch“ o.ä. bedeuten ${ }^{86}$. Der Beleg läßt sich dahingehend interpretieren, daß Geschriebenes ohne nähere Qualifikation - im „Lebenshaus" vorhanden war, und zwar immerhin in einem solchen Umfang, daß ein Verwalter benötigt wurde. Da diese Schriften nicht eindeutig bestimmt sind, kann auch der Beleg nicht als eindeutig gewertet werden; dennoch ist seine Berücksichtigung hier gerechtfertigt: Der zweite Teil des Titels: „dem alle Herrlichkeit (o.ä.) ${ }^{87}$ enthüllt wird“ ist, wie die syntaktische Stellung nahelegt, inhaltlich in enger Verbindung zu dem „Geschriebenen“ zu sehen. Damit können aber auch Passagen wie z.B. oben Beleg Nr. 2, 6 oder 11 für „Bücherhaus“ herangezogen werden, wo ein Zusammenhang zwischen geheimen Dingen (die den dazu Berufenen „enthüllt" werden) und Bibliothek festzustellen ist.

So ist dieser Titel zwar kein eindeutiger Beleg, aber immerhin ein mögliches Indiz für die Existenz von Büchern im „Lebenshaus“.

2. Im sog. Papyrus Salt (P.B.M. 10051) aus der 30. Dynastie oder 1.Perserherrschaft (4. Jh. v. Chr. $)^{88}$ wird die ideale Struktur des "Lebenshauses" in Abydos beschrieben ${ }^{89}$. Dort heißt es: „Die Bücher, die in ihm sind, sind die Emanationen des Re, damit dieser Gott lebt und damit seine Feinde gefällt werden." Als Wort für „Bücher" ist $m \underline{d} \mathbf{3}$.t verwendet, das auch in pr-md 3 .t „Bücherhaus" enthalten ist. $\mathrm{Zu}$ den "Emanationen des Re" als Bezeichnung für heilige Schriften s. oben S. 85. Ungeachtet der hier ohne Einfluß bleibenden Frage, ob das beschriebene „Lebenshaus" eine konkrete oder ideale Institution sein soll, ist klar und deutlich gesagt, daß im „Lebenshaus" Bücher existieren, in diesem Fall offenbar vor allem solche magischen Inhalts bzw. Ritualbücher.

78 (Anm. 16), S. 175

79 (Anm. 16), S. 177

80 Altägyptische Erziehung. Wiesbaden 1957, S. 28ff.

81 Volten (Anm. 24), S. 38-39.

82 in der Rezension von Voltens Untersuchung in: CdE 18, 1943 , S. 259-263.

83 la transmission des textes littéraires égyptiennes. Bruxelles 1948, S. 13.

84 (Anm. 22), S. 255.

85 Gardiners Beleg Nr. 5, (Anm. 16), S. 160.

86 Wb III, S. 476-477.

87 das Wort $\underline{d} s r w$ kann „Pracht, Herrlichkeit, Reinheit" o.ä. bedeu ten, vgl. Wörterbuch der ägyptischen Sprache hrsg. von Adolf Ermann und Hermann Grapow, Berlin 1926-1963, Band V, 615; Gardiners freie Wiedergabe ,private matters" muß somit im Sinne von "Geheimnisse, heilige Dinge" o.ä. verstanden werden.

88 Gardiners Beleg Nr. 33, (Anm. 16), S. 167.

89 s. Gardiner (Anm. 16), S. 167. 
3. Im etwa aus der gleichen Zeit stammenden sog. Papyrus Bremner-Rhind ${ }^{90}$ lautet der Abschnitt 29,16: „Es ist ein geheimes Buch im Lebenshaus, das kein Auge sehen soll, (nämlich) das Buch vom Niederwerfen des (Götterfeindes) Apophis." Auch dies ist eine eindeutige Aussage, die sich dadurch und durch den Titel des aufgeführten Buches mit dem obigen Beleg Nr. 2 vergleichen läßt.

4. Auf der sog. „Hungersnotstele“ auf der Insel Sehel im 1. Nilkatarakt ${ }^{91}$ - einer in der Ptolemäerzeit entstandenen bewußten Fälschung, die vorgibt, aus der Zeit des Erbauers der Stufenpyramide, des Königs Djoser (um 2620-2600 v.Chr.), zu stammen - fragt Djoser seinen Wesir Imhotep nach den Quellen des Nils und dem für diese „zuständigen“ Gott. Imhotep muß hierzu Recherchen anstellen und sagt: „Ich will eintreten in das Lebenshaus ${ }^{92}$ und die heiligen Schriften ausbreiten und von ihnen Weisung erhalten." Damit liegt eine weitere eindeutige Aussage vor, die von Imhotep gesuchten Bücher sind offenbar allgemein theologischen bzw. mythologischen Inhalts.

5. Auf der sog. „Mendesstele"93 aus ptolemäischer Zeit wird u.a. von der Auffindung eines neuen heiligen Widders berichtet: Eine Petition wurde an den Pharao gesandt, damit dieser die Schreiber des „Lebenshauses" sende, die den Widder als göttlich anerkennen sollten. Und so geschah es auch: Die Schreiber vollzogen die Anerkennung ,gemäß dem Ritualbuch“.

Dieser Beleg scheint nicht so klar wie die vorigen zu sein, ist aber dennoch deutlich genug: Wo anders als im „Lebenshaus", dessen Angehörige eigens herbeigeholt wurden, ist auch das genannte Ritualbuch zu denken? Im übrigen läßt sich aus dieser Passage eine weitere bedeutsame Folgerung ziehen: Nicht bei jedem Tempel, nicht einmal bei jedem größeren (und der Tempel des heiligen Widders von Mendes war ein größerer) bestand auch ein „Lebenshaus“, diese Institution existierte also offenbar nur an einigen bestimmten Orten.

6. Im sog. „Kanopusdekret“94, das aus ptolemäischer Zeit (238 v.Chr.) stammt, werden u.a. besondere Ehrungen für die tote Prinzessin Berenike beschlossen, wie z.B. das Absingen von Hymnen. Die hier interessierende Passage lautet in der Übersetzung Gardiners a.a.O.: „(es sollen gesungen werden) the hymns of worship written by the staff of the House of Life and given to the head-teacher of the singers, and the like shall be written in the books of the House of Life." Zum letzten Teil dieser Aussage bemerkt Gardiner: „The expression 'books of the House of Life' does not necessarily mean 'kept in the House of Life'; the place of production may be intended."

Doch sind Gardiners Zweifel nicht berechtigt. Einer Deutung der Stelle als Beleg für die Existenz von Büchern im ,Lebenshaus" steht kein ernsthaftes Argument entgegen; gerade die eindeutige genitivische Verbindung „Bücher des Lebenshauses" spricht für diese Interpretation ${ }^{95}$.

7. Auf einer Stele aus Achmim ${ }^{96}$, die ebenfalls aus ptolemäischer Zeit stammt, wird vom Besitzer gesagt, er sei ,ausgebildet (o.ä.) an jeder Bücherkiste des Lebenshauses des Min-Tempels". Auch dieser Beleg ist eindeutig; Gardiners Bemühen, auch hierin kein Indiz für die Existenz einer Bibliothek erkennen zu wollen, widerspricht sich selbst: „This probably serves only to indicate that the boxes in question contained papyri written in hieroglyphic." Genau das aber spricht für eine Büchersammlung.

Die Summe der Aussage dieser insgesamt sieben Belege spricht also ganz eindeutig für die Folgerung, daß der Nachweis eines "Lebenshauses" mit dem Beleg für die Existenz einer Bibliothek gleichzustellen ist. In dieselbe Richtung - wenn auch als ,,argumentum e silentio" methodisch fraglich und deshalb hier nur als Zusatzindiz zu werten - weist auch die Beobachtung, daß von den immerhin 60 Belegen, die Gardiner gesammelt hat, kein einziger Angaben enthält, die gegen diese Folgerung sprechen.

Eine Einschränkung darf aber nicht verschwiegen werden: Mit Ausnahme des - isoliert gesehen zudem sicher nicht tragfähigen - Beleges Nr. 1 stammen alle diese Hinweise aus der Spätzeit oder der Ptolemäerzeit. Nur für diese beiden Epochen können wir uns somit auf eindeutige Belege stützen. Immerhin ist durch die spätzeitlichen Belege gesichert, daß das "Lebenshaus" mit Bibliothek eine genuin ägyptische und nicht eine griechisch beeinflußte Institution gewesen ist; außerdem ist der Zufall der Überlieferung in Rechnung zu stellen bzw. die Tatsache, daß aus den jüngsten Epochen der ägyptischen Geschichte naturgemäß mehr Material erhalten ist als aus früherer Zeit: Diese beiden Fakten in Verbindung mit dem Beleg Nr. 1 erlauben also durchaus Rückschlüsse auf die klassischen ägyptischen Epochen, doch muß dabei immer bedacht werden, daß gesicherte Aussagen eben erst aus späterer Zeit stammen.

Über die Bestände der Bibliothek eines „Lebenshauses" läßt sich abgesehen von den bei den obigen Einzelbelegen erhaltenen Hinweisen auf Rituale, Hymnen und allgemein theologische Werke keine weitere konkrete Aussage anführen. Doch ist es gerechtfertigt, Bücherbestände in einer der Funktion des ,Lebenshauses" entsprechenden Bandbreite vorauszusetzen. Letztere faßt Otto folgendermaßen zusammen: ,,Magie und Medizin, Astronomie und Theologie wurden gepflegt und gelehrt. Religiöse Texte und ebenso Vorlagen für Zeremonialdarstellungen wurden gesammelt und ihre Anwendung gelehrt." 97 Diese Gebiete haben wohl auch die Bestände der Bibliothek umfaßt. Ob darüber hinaus Bücher vorhanden waren, ist nicht bekannt, insbesondere fehlt jede Angabe über die Pflege literarischer Werke, wie auch Gardiner anmerkt ${ }^{98}$ : Die wichtige Frage, ob literarische Werke in der Bibliothek des ,Lebenshauses" aufbewahrt wurden, kann somit derzeit nicht sicher beantwortet werden ${ }^{99}$.

90 Gardiners Beleg Nr. 36, (Anm. 16), S. 169

91 Gardiners Beleg Nr. 31, (Anm. 16), S. 166.

92 das hier verwendete synonyme hw.t- ${ }^{c} n h$ "Lebenshaus" statt pr-c $n b$ ist ein im Zusammenhang mit der Fälschung entstandener - falscher - sprachlicher Archaismus, vgl. dazu Gardiner a.a.Q.

93 Gardiners Beleg Nr. 37, (Anm. 16), S. 169

94 Gardiners Beleg Nr. 39, (Anm. 16), S. 172

95 einer Interpretation im Sinne Gardiners würde eher eine Formulierung entsprechen wie „ähnliches soll im Lebenshaus in den Büchern geschrieben werden", d.h. im Ägyptischen statt des

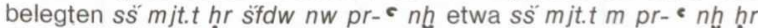
śfdw.

96 Gardiners Beleg Nr. 46, (Anm. 16), S. 173

97 (Anm. 22), S. 257

98 (Anm. 16), S. 176, 2. Absatz

99 In ptolemäischer Zeit sind unter Papyrusfunden des oben genannten für das "Lebenshaus" typischen Inhalts auch z.B. Weisheitslehren erhalten, s. besonders im 3. Kapitel unter "Tebtynis", doch besteht dort wieder die Schwierigkeit, die Bibliothek eindeutig als einem „Lebenshaus" zugehörig zu identifizieren. 
Die Frage nach dem Aussehen und der Größe der Bibliothek des "Lebenshauses" läßt sich ebenfalls nicht beantworten, da wir für das Aussehen des gesamten Komplexes dieser Institution nur zwei zudem widersprüchliche Aussagen besitzen:

1. Im schon mehrfach zitierten Papyrus Salt findet sich col. 6 , Z. $5 \mathrm{ff}$. die spielerische Schreibung für $p r^{-c} n h$ "Lebenshaus":

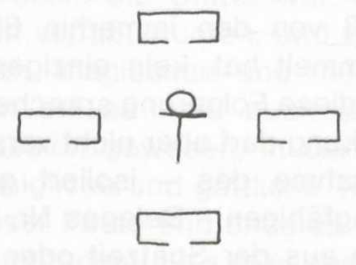

und dazu folgender Text ${ }^{100}$ :

„Das Lebenshaus ist in Abydos. Es ist erbaut aus vier Körpern ... Die vier äußeren Körper sind aus Stein und umgeben es vollständig .... An den vier Außenseiten befinden sich vier Eingänge, einer nach Süden, einer nach Norden, einer nach Westen, einer nach Osten ..." Im Innern des von den vier „Körpern" umfaßten Bereichs befand sich, wie aus dem Text weiter hervorgeht, eine dem Osiris heilige Stätte.

Derchain erörtert a.a.O. diese Beschreibung ausführlich, insbesondere auch im Hinblick auf die Frage, wo in einem solchen Komplex die aus anderen Quellen bekannten Teile eines "Lebenshauses" wie Verwaltungsbereich, Wohnungen, Magazine, Bibliothek, Skriptorien etc. Platz haben könnten. Dabei gelangt er über die Beobachtungen Gardiners hinaus, der das Ganze als einen von einer hohen Steinmauer umgebenen Komplex interpretiert hatte ${ }^{101}$ : Derchain verweist darauf, daß das oben mit "Körper" wiedergegebene Wort h.t in architektonischem Kontext auch "Gebäude" heißen kann. Damit werden aus den „Mauern" Gardiners Gebäude, und in diesen Gebäuden haben alle erforderlichen Einrichtungen, auch die Bibliothek, Platz. Folgt man der überzeugenden Darstellung Derchains, dann kann man die Beschreibung des "Lebenshauses" in Abydos etwa folgendermaßen zeichnerisch wiedergeben:

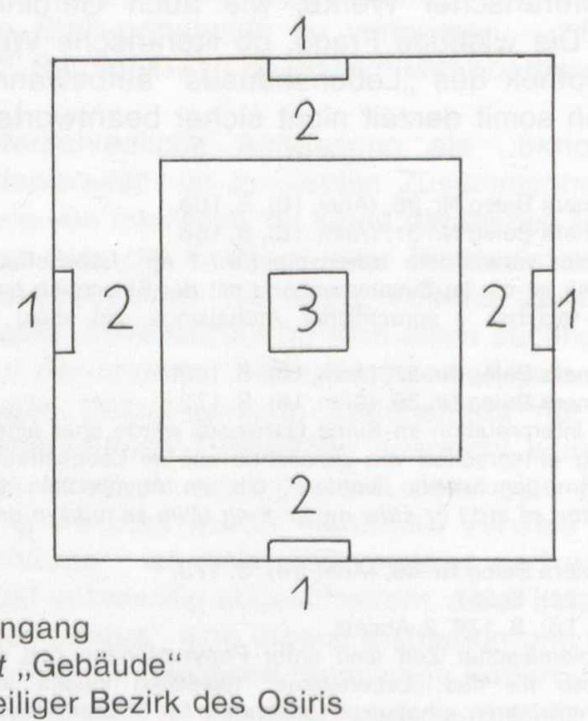

2 = h.t "Gebäude "

$3=$ heiliger Bezirk des Osiris

Abb. 1
2. In Amarna, der Hauptstadt Echnatons, wurden bei Ausgrabungen die Überreste eines "Lebenshauses" gefunden. Ihre eindeutige Identifikation wurde dadurch ermöglicht, daß die Lehmziegel mit $\square$ 의 gestempelt sind. Das „Lebenshaus" besteht demnach aus sechs Gebäuden, die ihrerseits in einzelne Räume aufgeteilt sind. Vier dieser Gebäude liegen in einem Komplex, die zwei restlichen jenseits einer Straße und in einiger Entfernung; s. den Plan in Abb. $2^{102}$.

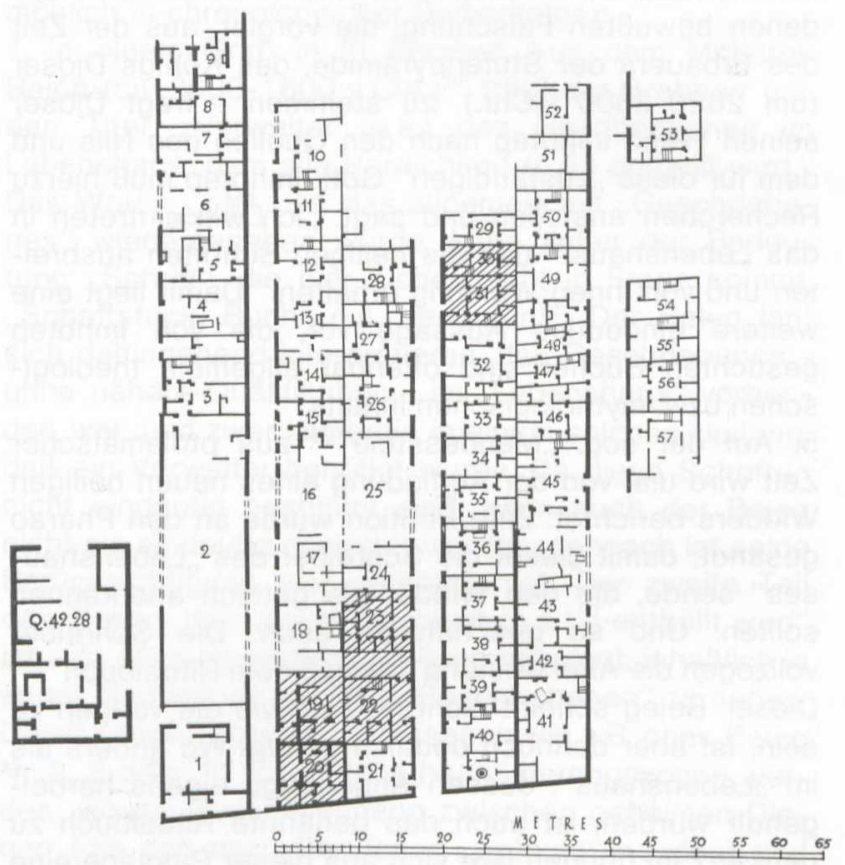

Abb. 2: Records Office and its Surroundings: Plan of the Clerks' Houses

Da jeweils nur die Grundmauern erhalten sind, ist die Funktion der Räumlichkeiten im einzelnen nicht mehr zu bestimmen; zu weiteren hier nicht interessierenden Details s. im 3. Kapitel unter „Amarna“.

$\mathrm{Ob}$ und wie dieser Widerspruch zwischen Abydos und Amarna zu klären ist, hat für die hier gestellten Fragen keinen Belang und soll daher auch nicht weiter erörtert werden. Vielleicht - um nur dies anzudeuten - liegt hier der Gegensatz zwischen Ideal und Wirklichkeit vor, schon Gardiner nennt die Beschreibung des „Lebenshauses" in Abydos ,, an ideal structure ${ }^{103 " . ~}$

Die letzte im Zusammenhang mit dem "Lebenshaus" zu erörternde Frage gilt der Lokalisation dieser Institution, d.h. vor allem, ob wir sie grundsätzlich innerhalb oder möglicherweise auch außerhalb des Tempelbezirkes zu suchen haben. Für die Lokalisation im Tempelbezirk scheint z.B. der oben S. 35 genannte Beleg Nr. 7 zu sprechen, wo vom „,Lebenshaus des MinTempels" die Rede ist. Doch lassen sich auch zwei einander ergänzende Quellen anführen, die für die andere Möglichkeit sprechen:

100 meine Übersetzung basiert auf der französischen von Derchain, Philippe: Le papyrus Salt 825. Bruxelles 1965, S. $139 \mathrm{f}$

101 (Anm. 100), S. 169, fig. 2.

102 der Plan ist entnommen aus Pendlebury, J.D.S.: The city of Akhenaten, part III. London 1951, pl. XX. Die zum „Lebenshaus“ gehörenden Gebäude (Pendlebury's Nummern 19, 20, 22, 23, 30, 31) wurden von mir schraffiert.

103 (Anm. 16), S. 167; für diese "ideal structure" spricht auch die Angabe, daß die vier "Körper" aus Stein gebaut sein sollen, während sich in Amarna die bei einem nichtreligiösen Gebäude zu erwartende Lehmziegelbauweise findet. 
1. Das „Lebenshaus" in Amarna liegt in einiger Entfernung zu den dortigen Tempeln - genauer gesagt $400 \mathrm{~m}$ südlich des großen und $100 \mathrm{~m}$ östlich des kleinen Tempels - und damit auch außerhalb der jeweiligen Tempelbezirke.

2. Die bereits erwähnte ${ }^{104}$ Kultprozession von Edfu zieht u.a. zum „Lebenshaus" hinüber, vollzieht dort bestimmte Riten und verbringt dort auch die Nacht: Auch hier besteht der deutliche Eindruck, daß das "Lebenshaus" in einiger Entfernung zum Tempel gelegen haben muß, wie auch Gardiner hervorhebt $^{105}$

Daraus ist zu schließen, daß das „Lebenshaus" nicht so unmittelbar dem Tempel zuzuordnen ist wie das „Bücherhaus", sondern möglicherweise (zumindest fallweise) eine eigene, vom Tempel durchaus unabhängige und auch räumlich von inm getrennte Institution gewesen ist.

Zusammenfassend kann somit festgestellt werden: Aus der Spätzeit und der Ptolemäerzeit besitzen wir eindeutige Belege, daß im ,Lebenshaus“ Bücher nicht nur verfaßt bzw. kopiert, sondern auch aufbewahrt wurden. Der Nachweis eines „Lebenshauses" ist also dem Nachweis der Existenz einer Bibliothek gleichbedeutend. Rückschlüsse auf vergleichbare Verhältnisse in früherer Zeit sind aufgrund einiger Zusatzindizien erlaubt. Die Zusammensetzung der Bestände ist nur teilweise aus Belegen bekannt, kann aber entsprechend der durch die Quellen erschlossenen Funktion des "Lebenshauses" mit ausreichender Wahrscheinlichkeit rekonstruiert werden; dabei ergibt sich eine erheblich umfassendere Bandbreite als dies bei den Beständen des „Bücherhauses“ der Fall ist. Zur architektonischen Gestaltung sind keine allgemeingültigen Angaben möglich. Die mittels zweier Quellen erschließbare Lokalisation außerhalb des Tempelbezirks ist ein Indiz dafür, daß das „Lebenshaus" möglicherweise nicht so eng mit dem Tempel in Verbindung stand wie das bei den „Bücherhäusern“ der Tempel der Fall war.

\section{Ilc. Spezielle Indizien für einzelne Bibliotheken}

Im Anschluß an die Erörterung der allgemeinen Fragen ist es, wie oben bereits bemerkt ${ }^{106}$, nun noch erforderlich, die Kriterien zusammenzustellen, die bei der Suche nach einzelnen Bibliotheken zu berücksichtigen sind.

Dabei können aufgrund rein formaler Gesichtspunkte drei Gruppen unterschieden werden, die je nach ihrer Tragfähigkeit als gesicherte oder wahrscheinliche Belege gelten können,oder doch wenigstens als so deutliche Indizien zu werten sind, daß ihre Berücksichtigung zu rechtfertigen bzw. zu fordern ist:

1. Gesicherter archäologischer und inschriftlicher Nachweis. Dieser Idealfall liegt dann vor, wenn ein erhaltenes Gebäude oder ein Gebäuderest durch zugehörige oder eindeutig zuzuordnende Inschriften zweifelsfrei als Bibliothek indentifiziert werden kann.

Als Beispiel seien das schon mehrfach erwähnte „Bücherhaus" in Edfu und das „Lebenshaus" in Amarna genannt: In Edfu ist der Raum komplett erhalten und durch die in inm angebrachten Inschriften eindeutig als Bibliothek bestimmbar; in Amarna ist ein in den Grundmauern erhaltener Lehmziegelkomplex durch die Stempel auf diesen Ziegeln als „Lebenshaus" ebenso sicher zu identifizieren ${ }^{107}$.
2. Eindeutiger inschriftlicher Beleg ohne archäologische Unterstützung. Ein solcher Fall liegt dann vor, wenn sich zwar eindeutige inschriftliche Hinweise finden, die besagen, daß an einem bestimmten Ort eine Bibliothek - „Bücherhaus “ oder „Lebenshaus“ - existiert haben muß, der archäologische Nachweis aber nicht geführt werden kann: Entweder sind keine Gebäudereste mehr erhalten bzw. können erhaltene Gebäudereste nicht mehr eindeutig bestimmt werden, oder, auch das ist möglich, es sind an den entsprechenden Stätten noch keine Ausgrabungen durchgeführt worden.

$\mathrm{Zu}$ diesem Belegtypus sei ebenfalls auf zwei Beispiele verwiesen: das „Bücherhaus" im Osiristempel von Abydos $^{108}$ und das "Lebenshaus" in Achmim" ${ }^{109}$. Im ersten Fall ist der Hinweis auf einer Papyrusrolle: „,Gefunden ... im Bücherhaus des Osiristempels in Abydos" ebenso eindeutig wie im zweiten Fall die Inschrift auf einer Stele: ,,ausgebildet an jeder Bücherkiste des Lebenshauses des Min-Tempels".

In beiden Fällen sind von den jeweiligen Gebäuden keine oder nur sehr geringe Spuren erhalten, dennoch läßt sich sagen, $d a ß$ an diesen beiden Orten die Existenz einer Bibliothek gesichert ist.

3. Archäologische Indizien ohne inschriftliche Unterstützung. $\mathrm{Zu}$ dieser Gruppe sind zwei Arten von Belegen zu rechnen:

a) Gebäude bzw. Gebäudereste, die aufgrund von gesicherten Parallelen, wie sie oben in Gruppe 1 genannt sind, mit einem gewissen Grad von Sicherheit als Bibliotheken bestimmt werden können;

b) Papyrusfunde, die aufgrund der Fundumstände und weiterer noch zu benennender Kriterien mit großer Wahrscheinlichkeit aus Bibliotheksbeständen stammen.

Bei diesem Typus von Belegen ist naturgemäß mit mehr oder weniger großen Unsicherheitsfaktoren zu rechnen, das Für und Wider ist also in jedem Einzelfall besonders sorgfältig abzuwägen. Eine große Hilfe kann hierbei das Zusammenwirken mehrerer solcher Indizien sein, die in ihrer Gesamtheit dann durchaus das Gewicht der in den ersten beiden Gruppen genannten Belege erreichen können.

Auch hierzu seien zur Verdeutlichung zwei Beispiele genannt:

Im Tempel von Karnak sind in einem von Thutmosis I. erbauten hypostylen Saal rechts und links des Eingangs zwei kleine Räume in die Wand eingelassen ${ }^{110}$. An genau gleicher Stelle: im hypostylen Saal, in der Wand rechts und links des Eingangs, befinden sich im Tempel von Edfu die „Sakristei“ und das „Bücherhaus". Unglücklicherweise sind in Karnak nur die Grundmauern erhalten, Inschriften fehlen; eine eindeutige Identifikation ist daher nicht mehr möglich. Aber die architektonische Parallele ist immerhin so deutlich, daß die Möglichkeit, hier mit den Resten eines „Bücherhauses " zu rechnen, in jedem Fall in Betracht zu ziehen ist ${ }^{111}$. Dieses Beispiel zeigt aber auch sehr klar,

104 s. oben S. 84

105 (Anm. 16), S. 174, Nr. 50

106 s. oben S. 84

107 s. oben S. 90

108 s. oben S. $86, \mathrm{Nr} .7$.

109 s. oben S. 89

110 s. Barguet, Paul: Le temple d'Amon-Rê à Karnak, essai d'exégèse. Le Caire 1962, S. 97, n. 1

111 zu Einzelheiten s. unten im 3. Kapitel zu „Karnak“. 
wie schwierig es ist, mit Hilfe solcher Belege zu gesicherten Indizien zu gelangen: Solange sich kein zusätzlicher Hinweis findet - und bislang ist keiner bekannt - muß die Existenz eines „Bücherhauses“ in Karnak mit vielen Fragezeichen versehen bleiben.

Im Falle der Papyrusfunde müssen, wie oben gesagt, zunächst die Fundumstände geklärt werden: Stammen die Papyri aus Gäbern - und das ist bei der Mehrzahl der Fall -, dann sind sie natürlich nicht als Belege für eine Bibliothek zu nutzen, ungeachtet ihres Inhalts oder ihrer Zahl ${ }^{112}$. Stammen sie dagegen aus Siedlungsgebiet, vor allem aus der Nähe eines Tempels - in dessen Umgebung ja auch weitere offizielle Gebäude standen -, dann ist weiterzufragen nach ihrer Zahl, ihrem Inhalt, ihrer Qualität (hastig beschriftete Stücke oder Palimpseste sind sicher keine Bibliotheks-, sondern Privatexemplare gewesen) und gegebenenfalls nach Zusatzindizien z.B. archäologischer Art. Mit anderen Worten: Werden in altem Siedlungsgebiet in der Nähe der oben genannten Gebäudereste Papyri gefunden, die sehr verschiedenartige Texte von großer inhaltlicher Bandbreite enthalten und von guter Qualität sind, dann ist mit der Möglichkeit zu rechnen, daß man auf Überreste einer Bibliothek gestoßen ist. Für sich allein ist ein solches Indiz natürlich ähnlich unsicher wie das oben genannte Beispiel aus Karnak. Kommen aber weitere Hinweise dazu, wie Paralleltexte (,Mehrfachexemplare“, s.z.B. im 3. Kapitel unter „Tebtynis") und anderes, dann sind auch mit diesem Hilfsmittel durchaus gesicherte Ergebnisse möglich.

Ein sehr glückliches Zusammentreffen solcher Indizien - und das ist das zweite der oben angekündigten Beispiele - ist auf der Insel Elephantine zu beobachten: Dort sind neben den entsprechenden Papyrusfunden Hinweise historischer Art auf aramäischen Papyri und schließlich eine einzigartige literarische Quelle zu verzeichnen, die insgesamt die Existenz einer Bibliothek an diesem Ort sehr klar belegen, s. dazu im einzelnen im 3. Kapitel unter „Elephantine“.

Bei einer solchen, hauptsächlich auf Papyrusfunden basierenden Beleglage ist es natürlich sehr schwer, wenn nicht unmöglich, zu erkennen, ob die Reste eines „Bücherhauses" oder eines „Lebenshauses" vorliegen. Bestandsreste von sehr großer inhaltlicher Bandbreite lassen nach dem in Ilb Dargelegten eher an ein „Lebenshaus" denken, Texte der z.B. in der Edfu-Liste belegten Art $^{113}$ eher an ein „Bücherhaus“, doch kann hierüber keine Sicherheit erreicht werden; die von Wessetzky angedeutete Möglichkeit eines „Magazins“ zum „Bücherhaus" beispielsweise ist, wie gesagt ${ }^{114}$ zwar nicht zu beweisen, aber auch nicht a priori abzulehnen. Aus diesem Grund wird in entsprechenden Fällen im 3. Kapitel auf eine eindeutige Zuordnung verzichtet und lediglich die „vermutliche" Zugehörigkeit benannt.

Die Beurteilung der Tragfähigkeit der verschiedenen Indizien ist nach dem oben Gesagten wie folgt zusammenzufassen:

Belege entsprechend Punkt 1, dem Idealfall, sind sowohl in der Frage der Existenz einer Bibliothek an sich wie auch in der ihrer exakten Lokalisation absolut gesicherte Quellen.

Belege entsprechend Punkt 2 können bei entsprechender Eindeutigkeit ihrer Aussage die Frage nach der Existenz einer Bibliothek mit der gleichen Sicherheit wie Belege nach Punkt 1 beantworten, sie erlau- ben aber nicht die genaue Lokalisation des Gebäudes. Belege entsprechend Punkt 3 können keine der beiden Fragen sicher beantworten; sie sind als Einzelindizien von teilweise nur sehr geringer Beweiskraft, doch kann das Zusammenwirken mehrerer Hinweise auch hier zu tragfähigen Ergebnissen führen.

\section{Verzeichnis ägyptischer Bibliotheken}

Auf den in Kapitel Ilc erläuterten Indiziengruppen basieren im wesentlichen die nun dargelegten Ergebnisse der Einzeluntersuchungen: Anhand der erarbeiteten Kriterien wurde die in Kapitel lb näher qualifizierte Forschungsliteratur ausgewertet, in einem Fall (Elephantine) konnte auch bisher unveröffentlichtes Material zu Rate gezogen werden. Dabei ist, wie bereits in der Einleitung erwähnt, keine Vollständigkeit beabsichtigt, wohl aber soll die Anwendbarkeit der erarbeiteten Methodik belegt werden.

Das so entstandene und hier folgende Verzeichnis der Bibliotheken ist alphabetisch geordnet, wobei die Einordnung in der Regel unter dem Namen des betreffenden Ortes erfolgte. Wenn dies nicht möglich war oder eine andere Bezeichnung geläufiger ist (z.B. „Bibliothek Amenophis' III."), dann erfolgte die Einordnung unter dem entsprechenden Begriff (im genannten Beispiel unter „Amenophis III.“). Zur geographischen Orientierung sei auf die Übersichtskarten im Anhang verwiesen (die im folgenden Verzeichnis besprochenen Orte sind dort unterstrichen, vgl. S. 112 u. 113).

Die innere Gliederung des Stoffes ist bei den einzelnen Orten in der Regel dreigeteilt: Unter dem Begriff "Quellenlage" sind die verschiedenen Indizien (wenn möglich in chronologischer Folge) und ggf. die dazu schon vorhandene Forschungsliteratur zusammengefaßt. Unter „Bemerkungen“ werden dann die einzelnen Gesichtspunkte erörtert und schließlich in einem dritten Abschnitt das Fazit gezogen.

\section{Abydos}

\section{Quellenlage}

1. Im Tempel Sethos' I. (1303-1290 v. Chr.) findet sich innerhalb einer Szene, die Sethos I. und seinen Sohn Ramses II. beim Opfer darstellt, u. a. die Beischrift: „Der Weihrauch, der reine, angenehme, der Duft, der in den Schriften ist, die sich im Gottesbücherhaus befinden." 115

2. Ein „Chefarzt" des Pharao Apries (589-568 v.Chr.) berichtet auf seiner Statue von den Arbeiten, die er im Bereich des Osiristempels in Abydos durchführen ließ. Dabei heißt es u. a. : „Ich erneuerte das Lebenshaus, nachdem es zerfallen war."116

3. Im Papyrus Salt 825 aus der 30. Dynastie oder der ersten Perserherrschaft (4. Jh. v. Chr.) findet sich

112 dies betrifft die Gültigkeit als "primärer" Beleg; möglich sind natürlich "sekundäre" Belege, wie dies beim oben genannten Hinweis auf das "Bücherhaus" in Abydos der Fall ist: der betreffende Papyrus, der nach eigener Aussage von einem Bibliotheksexemplar kopiert wurde, stammt selbst aus einem Grab.

113 s. oben S. 85.

114 s. oben S. 83

115 Mariette-Bey, Auguste (Anm. 70), vol. I, Paris 1869, pl. 44

116 s. Gardiner, (Anm. 16), S. 165, Nr. 27. 
col. 6, Z. $5 \mathrm{ff}$. die bereits genannte Beschreibung des "Lebenshauses" von Abydos, die mit den Worten beginnt: ,Das Lebenshaus ist in Abydos."117

4. Im aus ptolemäischer Zeit stammenden Papyrus Berlin 3057 (,Papyrus Schmitt") findet sich der Vermerk: „Gefunden auf einer Papyrusrolle aus der Zeit des Königs Thutmosis und der Zeit des Königs Amenophis im Bücherhaus des Osiristempels in Abydos." 118

\section{Bemerkungen}

Der Beleg aus der Zeit Sethos' I. ist nicht eindeutig, da nicht expressis verbis gesagt wird, daß das erwähnte "Gottesbücherhaus" konkret in diesem Tempel lokalisiert ist. Doch läßt der bildliche und inschriftliche Kontext diese Möglichkeit immerhin zu: Der Titel zu der genannten Opferszene lautet: „Ein Königsopfer geben dem (Gott) Ptah-Sokar-Osiris, dem Ersten der Westlichen (Bez. für den Totengott) in 'Es dauert die Maat des Re'"; letzteres ist der Name des Tempels, das Opfer ist also, wie nicht anders zu erwarten, konkret in diesem Tempel gedacht, und das gleiche gilt daher möglicherweise auch für das wenig später im gleichen Kontext genannte "Gottesbücherhaus“.

Eine Unterstützung dieser Annahme von archäologischer Seite fehlt bislang, obgleich der Tempel Sethos'I. teilweise sehr gut erhalten ist. Doch muß berücksichtigt werden, daß in dieser Zeit die eindeutige Kennzeichnung eines bestimmten Raumes als „Bücherhaus“, wie sie später in den ptolemäischen Tempeln zu finden ist, offenbar noch nicht üblich war. Aus diesem Grund ist auch z. B. die Bibliothek des Ramesseums trotz aller Bemühungen der Forschung noch immer nicht eindeutig identifiziert ${ }^{119}$.

Auf festem Boden steht man dagegen mit Beleg Nr. 2. Dort ist gesagt, daß in der Zeit des Apries, also im 6. Jh. v. Chr. ein "Lebenshaus" erneuert wurde: Das bedeutet, daß in einem nicht näher zu bestimmenden Zeitraum sowohl vor wie nach dieser Epoche ein „Lebenshaus" und damit auch dessen Bibliothek in Abydos existierten. Archäologische Reste davon sind bisher nicht bekannt.

Ebenso klar scheint die Aussage des P. Salt 825, doch ist hier zu berücksichtigen, daß die Beschreibung des „Lebenshauses" möglicherweise nicht einem konkreten irdischen Gebäude, sondern einer idealen Konzeption gilt ${ }^{120}$.

Die Existenz eines „Bücherhauses“ in ptolemäischer Zeit ist durch den Vermerk auf dem Papyrus Berlin 3057 gesichert. Da sich vom Komplex des Osiristempels in Abydos aber nur wenige Reste erhalten haben, ist dieses „Bücherhaus" - wenigstens bislang archäologisch nicht faßbar.

\section{Fazit}

Für die Existenz von Bibliotheken in Abydos besitzen wir ausschließlich inschriftliche Belege unterschiedlicher Tragfähigkeit. Als gesichert darf nach Aussage dieser Quellen die Existenz eines „Lebenshauses" in der Spätzeit gelten, d. h. in der Zeit vor und nach Apries, unter dessen Regierung es wieder aufgebaut wurde. Ein „Bücherhaus" hat mit Sicherheit in ptolemäischer Zeit im Osiristempel bestanden. Ob dagegen auch noch im 4. Jh. v. Chr. ein "Lebenshaus" und im 14. Jh. v. Chr. ein "Gottesbücherhaus" existierten, ist zwar möglich, aber nicht eindeutig zu belegen.
Eine genaue Lokalisation ist in keinem dieser Fälle möglich, da archäologische Indizien in Form von Gebäuderesten oder Papyrusfunden bislang nicht bekannt sind.

\section{Achmim \\ Quellenlage}

Auf einer Stele aus Achmim sagt der Eigentümer u.a. von sich, er sei ,,ausgebildet (o.ä.) an jeder Bücherkiste des Lebenshauses des Min-Tempels". Die Stele stammt aus ptolemäischer Zeit ${ }^{121}$.

\section{Bemerkungen und Fazit}

Achmim, das Panopolis der Griechen, war die Heimat des von den Griechen mit Pan gleichgesetzten Fruchtbarkeitsgottes $\mathrm{Min}^{122}$. Es kann somit als gesichert gelten, daß der Fundort der Stele ihrem früheren Aufstellungsort entspricht. Damit besitzen wir einen eindeutigen inschriftlichen Beleg für die Existenz eines "Lebenshauses" - mit zugehöriger Büchersammlung, wie der gleiche Beleg aussagt - in Achmim in ptolemäischer Zeit.

Eine Lokalisation des Gebäudes ist vorläufig nicht möglich und vermutlich auch nicht mehr zu erwarten: Die Tempelbauten, von denen im vergangenen Jahrhundert noch Überreste zu erkennen waren, sind heute so gut wie vollständig zerstört ${ }^{123}$, auch Papyri sind bislang nicht gefunden worden.

\section{Amarna \\ Quellenlage}

Im Verlaufe von Grabungen im Gebiet von Amarna zu Beginn der 20er-Jahre dieses Jahrhunderts wurden von den britischen Ausgräbern auch die Überreste eines „Lebenshauses" gefunden. Die Identifikation ist gesichert, da die für diesen Komplex verwendeten Lehmziegel mit der hieroglyphischen Schreibung für

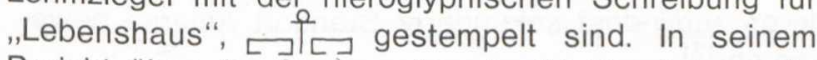
Bericht über die Grabung beschreibt Pendlebury die Überreste dieses „Lebenshauses"124. Alle Gebäude waren aus Lehmziegeln gemauert, was zu erwarten war, vgl. oben S. 80; wegen der Zerstörungen ist es nicht mehr möglich, ihre Funktion im einzelnen zu bestimmen, also kann auch die Bibliothek innerhalb dieses Komplexes nicht mehr identifiziert werden.

Ein zusätzliches Indiz für die Identifikation als „Lebenshaus" bildet der Fund einer Reihe von Ostraka in diesen Gebäuden, die Listen mit Namen von königlichen Schreibern enthalten. Pendlebury erwähnt diesen Fund in einem Vorbericht zur Grabung ${ }^{125}$ und nimmt wohl zu Recht an, daß es sich bei diesen Schreibern

117 s. oben S. 88, Beleg Nr. 2.

118 s. Möller, Georg (Anm. 68), S. 2f.; s. auch oben S. 86.

119 s. unter „Ramesseum “.

120 s. oben S. 90.

121 s. Gardiner (Anm. 16), S. 173, Nr. 46: s. auch oben S. 89, Nr. 7.

122 vgl. Bonnet, Hans: Panopolis, in: Reallexikon der ägyptischen Religionsgeschichte. 2. Aufl. Berlin 1971, S. 580-581.

123 vgl. Bonnet (Anm. 122), S. 581 und J. Karig in: Lexikon der Agyptologie, Band I. Wiesbaden 1975, Sp. 54 s.v. Achmim.

124 Pendlebury (Anm. 102), S. 115 und pl. XX; zum Plan s. oben S. 90 .

125 Journal of Egyptian Archaeology 20, (1934), S. 134 
um die „lecturers", also um das „wissenschaftliche Personal" des ,Lebenshauses" handelt.

Erwähnenswert ist im übrigen noch, daß neben dem „Lebenshaus", und ebenso eindeutig wie diese durch entsprechende Ziegelstempel zu identifizieren, die Reste des königlichen Archivs ausgegraben wurden ${ }^{126}$, aus dem die bekannten „Amarna-Tafeln“ stammen. Die ägyptische Benennung „Platz der Korrespondenz Pharaos" zeigt deutlich, daß es sich um ein reines Archiv handelte, das von der Institution „Bibliothek" getrennt zu sehen ist ${ }^{127}$.

\section{Bemerkungen und Fazit}

Das „Lebenshaus" in Amarna ist das einzige zweifelsfrei identifizierte Gebäude dieser Art, das in Ägypten bisher bekannt ist. Trotz dieser Singularität hat es uns zu wichtigen Erkenntnissen verholfen: Es zeigte sich, daß das "Lebenshaus" zumindestens auch eine vom Tempel getrennte Institution gewesen sein kann ${ }^{128}$ und daß es als profane Einrichtung aus Lehmziegeln erbaut war $^{129}$. Die chronologische Einordnung ist sehr leicht, aber auch sehr punktuell: Da Amarna um 1360 v. Chr. von Echnaton gegründet und um 1330 von Tut-anchAmun bereits wieder aufgegeben wurde, kann dieses "Lebenshaus" im Höchstfall etwa 30 Jahre, wahrscheinlich aber für einen kürzeren Zeitraum, in Funktion gewesen sein.

\section{,,Bibliothek Amenophis' III.“}

\section{Quellenlage}

Unter den aus Amarna stammdenden Funden befindet sich auch ein kleines Fayencetäfelchen mit dem Namen Amenophis'lll. und seiner Gemahlin Teje, das außerdem die Inschrift trägt: „Buch von der Sykomore und der Dattelpalme". Schon in der ersten Erwähnung dieses Täfelchens durch Borchardt ${ }^{130}$ wird es als Etikett für einen Bücherkasten gedeutet. Milkau schloß sich dieser Deutung an und wertete das Ganze als Beleg für eine Bibliothek Amenophis'll.., deren zumindest sekundärer Standort Amarna gewesen sei $^{131}$.

Mit einem weiteren Fayencetäfelchen gleicher Provenienz machte Jean Capart bekannt ${ }^{132}$; dieses nicht vollständig erhaltene Exemplar trägt ebenfalls einen mit einer Baumart zusammenhängenden Buchtitel. Capart schloß daraus, daß die Palastbibliothek neben literarischen auch wissenschaftliche Texte enthielt. Er nahm an, daß die genannten Titel von Werken stammten, die sich mit bestimmten Bäumen und Pflanzen auseinandersetzten, wie später die Schriften von Theophrast, Dioskurides und Plinius.

\section{Bemerkungen}

Der einzige Hinweis auf die „Bibliothek Amenophis' III.“ sind diese Fayencetäfelchen. Leider ist ihr genauer Fundort nicht mehr zu ermitteln, da sie vermutlich bei Raubgrabungen Einheimischer gefunden wurden. Die erwähnte Notiz Borchardts nennt das erste Täfelchen in Zusammenhang mit den Amarna-Tafeln. Daraus ist vielleicht zu schließen, daß es zusammen mit diesen Tafeln oder wenigstens in ihrer unmittelbaren Nähe gefunden wurde. Da nun letztere aus dem königlichen Archiv stammen, liegt die Vermutung nahe, daß die Fayencetäfelchen im selben Gebiet, möglicherweise im benachbarten „Lebenshaus" gefunden wurden. Doch ist dies nicht sicher und auch höchstens von untergeordneter Bedeutung, denn Amarna ist ganz gewiß nicht der primäre Standort dieser „Bibliothek" gewesen: Als Eigentümer ist Amenophis III. ausgewiesen, der nie in Amarna residiert haben kann, da diese Stadt erst nach seinem Tod gegründet wurde. Seine Hauptstadt lag vielmehr in der Nähe von Memphis und dort ist vielleicht auch seine „Bibliothek" zu lokalisieren: Eines der Täfelchen enthält das Epitheton für den König: ,geliebt von Ptah", und der Schöpfergott Ptah hat seinen Sitz eben in Memphis. Jedoch kann dies nur Vermutung bleiben, eine gesicherte Grundlage fehlt.

Abgesehen von der Frage der Lokalisation ist auch noch ein anderer Gesichtspunkt zu berücksichtigen: Die genannten „Ex-Libris“ stellen einen persönlichen Besitzvermerk für Amenophis III. und Teje dar, und das bedeutet zunächst nur, daß diese Bücher Eigentum des Königs und seiner Gemahlin waren, daß also die Büchersammlung, zu der sie gehörten und zu deren Umfang keine Angaben gemacht werden können, wohl königlicher Privatbesitz gewesen ist: Für die Zugehörigkeit zu einer offiziellen Institution findet sich kein Anhaltspunkt.

Diese Büchersammlung ist offensichtlich sekundär nach Amarna verlagert worden; dort wurde sie vielleicht Bestandteil der Sammlung des „Lebenshauses", vielleicht ging sie aber auch - weder das eine noch das andere läßt sich belegen - in den Privatbesitz Amenophis' IV.-Echnatons über.

\section{Fazit}

Es existiert kein eindeutiges Indiz dafür, daß die Büchersammlung Amenophis' III., die durch die beiden Fayencetäfelchen bezeugt ist, eine offizielle Institution gewesen ist; vielmehr scheint es sich lediglich um eine private Sammlung gehandelt zu haben. Eine solche Privatsammlung als „Bibliothek" zu bezeichnen ist aber nach dem derzeitigen Stand der Fakten und aus den oben S. 81 dargelegten Gründen m. E. nicht gerechtfertigt. Man muß sich also damit bescheiden, daß wir zwar wissen, daß Amenophis III. Bücher besessen hat, daß die Indizien für die Existenz einer regelrechten Bibliothek in seinem Besitz bzw. unter seiner Herrschaft aber nicht ausreichen.

\section{Dendera}

\section{Quellenlage}

In unmittelbarer Nähe des Tempels von Dendera, noch innerhalb des von einer großen Umfassungsmauer umgebenen Tempelbezirks, wurden unter anderem

126 Pendlebury (Anm. 102), S. 113f. und (Anm. 125), S. 134

127 damit muß Milkaus Annahme, daß in Amarna Bibliothek und Archiv eine Einheit bildeten (Anm. 2, S. 9) als widerlegt gelten.

128 s. oben S. 91.

129 dies unterstützt im übrigen die Vermutung, daß die Beschreibung des "Lebenshauses" von Abydos im Papyrus Salt 825 einem idealen und nicht einem realen Zustand gilt, s. oben S. 90 mit Anm. 103.

130 Borchardt, Ludwig: Ein Ex-libris Amenophis'lll. In: Zeitschrift für ägyptische Sprache und Altertumskunde 33 (1895), S. 72-73.

131 (Anm. 2), S. 8-10; s. auch oben Anm. 127: Die von Milkau angenommene Einheit von "Lebenshaus" und Archiv ist inzwischen widerlegt.

132 les exlibris d'Aménophis III. In: Chronique d'Egypte 10 (1935), S. 23-25. 
auch die Überreste eines Lehmziegelgebäudes freigelegt; dieses Gebäude hat Daumas als ein „Sanatorium" identifizieren können ${ }^{133}$ : Kranke suchten dort durch medizinisch-magische Praktiken Heilung von ihren Leiden. Aus erhaltenen Architekturteilen und Inschriftenresten sind uns diese Praktiken teilweise bekannt: Die medizinische Therapie sollte z. B. durch Inkubationsschlaf in diesem Gebäude unterstützt werden, besonders aber vertraute man auf Waschungen und Bäder in Wasser, das vorher über eine mit Zaubersprüchen beschriftete Statuette geflossen war und dabei heilende Kräfte erlangt haben sollte. Da sowohl die Magie wie auch die Medizin wichtige Disziplinen im „Lebenshaus" waren, spricht einiges für die Vermutung Daumas', daß er mit diesem Gebäude einen Teil des "Lebenshauses" von Dendera wiedergefunden habe: „Pour la première fois, il nous parait fournir, dans un grand temple qui a conservé tous ses éléments, un des bâtiments essentiels que la Maison de Vie devait entretenir dans I' enceinte sacrée: le sanatorium." 134

\section{Bemerkungen}

So eindeutig das "Sanatorium" von Dendera als solches indentifiziert ist und so sehr auch die Wahrscheinlichkeit für dessen Zugehörigkeit zur Institution des "Lebenshauses" spricht, so klar muß auf der anderen Seite auch hervorgehoben werden, daß zusätzliche Indizien vorläufig fehlen: Weder ist bislang ein eindeutiger inschriftlicher Beleg für ein „Lebenshaus" in Dendera bekannt, noch fanden sich weitere Hinweise, wie etwa Papyrusreste, die die Existenz eines „Lebenshauses" und der dazu gehörenden Bibliothek greifbarer machen könnten.

Während sich somit aber für ein ,Lebenshaus“ immerhin ein Indiz fassen ließ, verlief die Suche nach einem „Bücherhaus“ in Dendera bislang völlig negativ. Das scheint deswegen überraschend, weil sich das aus griechisch-römischer Zeit stammende Hauptgebäude des Tempels in einem exzellenten Erhaltungszustand befindet und man nach dem Beispiel von anderen Tempeln dieser Epoche wie Edfu, Philae und Tôd (s. jeweils unter diesen Orten) auch hier ein „Bücherhaus" erwartet. Doch ist zu berücksichtigen, daß auch in dieser späten Zeit die Einrichtung des „Bücherhauses" nicht architektionisch kanonisiert war: in Edfu und Philae liegen die „Bücherhäuser" in verschiedenen Teilen des Tempels (in Tôd ist die genaue Lage nicht mehr feststellbar); außerdem sind uns weitere gut erhaltene Tempel bekannt, wie die von Kom Ombo oder von Esna, wo sich ebenfalls keine Spur eines „Bücherhauses“ erhalten hat: Entweder ist in diesen Fällen der Bibliotheksraum wie in pharaonischer Zeit nicht eigens gekennzeichnet, oder er war nicht innerhalb des Hauptgebäudes untergebracht. Eine dieser beiden Möglichkeiten ist wohl auch für Dendera in Betracht zu ziehen, wo eine Reihe der zahlreichen im Innern des Tempels liegenden Nebenräume zwar schon (als Magazine, ,Laboratorien" für die Zubereitung wohlriechender Essenzen u. a.) identifiziert wurde, in keinem Fall aber der Hinweis auf ein „Bücherhaus" gefunden werden konnte.

\section{Fazit}

Aus griechisch-römischer Zeit haben sich in Dendera die Reste eines "Sanatoriums" gefunden, die zwar nicht als Beleg, aber doch als Indiz für die Existenz eines „Lebenshauses“ gewertet wurden dürfen. Weitere Hinweise sind bislang nicht bekannt, ein „Bücherhaus" ist nicht nachzuweisen.

\section{Edfu}

\section{Quellenlage}

1. Das komplett erhaltene „Bücherhaus" im Tempel von Edfu soll hier nicht nochmals behandelt werden, es ist der Forschung längst bekannt und eingehend untersucht worden. Die Inschriften dieses Bibliotheksraumes wurden von Chassinat komplett veröffentlicht ${ }^{135}$, aus der Reiche der Untersuchungen, die nach der Darstellung Milkaus ${ }^{136}$ veröffentlicht wurden, seien die von Alliot ${ }^{137}$, Schott ${ }^{138}$ und Wessetzky ${ }^{139}$ genannt, die sich besonders auch mit der Frage der Funktion dieses „Bücherhauses" befaßten und deren Summe zur Deutung als „Handbibliothek" oder „Spezialbibliothek" führte ${ }^{140}$.

2. Unter den an den Wänden des Tempels angebrachten Texten finden sich auch solche, die den Weg und die zu vollziehenden Zeremonien bei Kultprozessionen an bestimmten Feiertagen im Tempel genau beschreiben. In einem dieser Rituale - die ganz zweifelsfrei speziell auf Edfu bezogen sind, also konkret von Gegebenheiten und Räumlichkeiten dieses Tempels sprechen - findet sich die folgende, oben S. 84 bereits erwähnte Passage 141: „Dann geht man zur Halle des Lebenshauses. Man führt alle Zeremonien des Lebenshauses aus. Wenn es Abend wird, verbringt man die Nacht an diesem Platz."

\section{Bemerkungen}

Der Beleg für das „Bücherhaus“ in Edfu enspricht dem oben im 2. Kapitel so genannten ,Idealfall": Der Gebäudeteil ist komplett erhalten und durch seine Inschriften eindeutig zu bestimmen.

Der zitierte inschriftliche Beleg für das „Lebenshaus“ ist ebenfalls eindeutig: An der Existenz dieser Institution in Edfu in griechischer Zeit kann kein Zweifel bestehen, auch wenn archäologische Reste bislang nicht bekannt sind. Immerhin wissen wir durch diesen Beleg, daß das "Lebenshaus" in Edfu in einiger Entfernung zum Tempel zu lokalisieren ist, s. dazu oben S.91. Da das antike Stadtgebiet von Edfu bislang nur zum Teil ausgegraben wurde, besteht durchaus die Möglichkeit, daß sich in dem noch unerforschten Gebiet Reste dieses Gebäudes erhalten haben (abgesehen von der anderen Möglichkeit,

133 Daumas, François: Le sanatorium de Dendara. In: Bulletin de I'Institut Français d' Archéologie Orientale 56 (1957), S. 35-57.

134 (Anm. 133), S. 56.

135 Chassinat, Emile: Le temple d'Edfou, tome 3. Cairo 1928, S. 339-351.

136 (Anm. 2), S. 12-13

137 (Anm. 38), S. 133-135, 147.

138 Schott, Siegfried: Thot als Verfasser heiliger Schriften. In: Zeitschrift für ägyptische Sprache und Altertumskunde 99 (1972), S. 21 .

139 (1973, Anm. 29) S. 55.

140 s. dazu auch oben S. $85 \mathrm{ff}$

141 vgl. Alliot (Anm. 38), S. 531, dessen französische Übersetzung des ägyptischen Textes hier deutsch wiedergegeben ist. 
daß die Uberreste zwar schon ausgegraben, aber nicht erkannt sind). Doch muß es fraglich bleiben, ob diese Reste jemals ans Tageslicht gelangen können: das moderne Edfu ist über der alten Stadt errichtet, die Möglichkeiten, dort noch zu graben, sind somit sehr gering.

\section{Fazit}

Neben dem längst bekannten „Bücherhaus“ existierte, wie inschriftlich zweifelsfrei belegt ist, auch ein ,Lebenshaus " in Edfu, das archäologisch (noch) nicht zu identifizieren ist und vermutlich in einiger Entfernung zum Tempel lag.

Beide Belege, der für das „Bücherhaus“ wie der für das "Lebenshaus", betreffen ausschließlich die griechische Zeit, also die drei letzten vorchristlichen Jahrhunderte. Indizien für die Existenz einer dieser Institutionen bereits in führerer Zeit sind bislang nicht bekannnt.

\section{Elephantine}

\section{Quellenlage und Bemerkungen}

Die antiken Baureste auf der Insel Elephantine bieten sich dem heutigen Betrachter nur noch als ein riesiger Schutthügel dar, der meist aus Resten von Lehmziegelhäusern besteht; nur vereinzelt sind noch Teile der steinernen Tempelgebäude erhalten, meist Reste der Grundmauern, einzelne Säulentrommeln und ähnliches. Das Gelände wurde zudem immer wieder von Einheimischen durchwühlt, da die Reste der Lehmziegel mit ihrer Beimischung von Häcksel ein begehrtes Düngemittel sind. Die Suche nach Resten von bestimmten Gebäuden, also auch von „Bücherhäusern“ oder „Lebenshäusern", ist daher vielleicht für immer zum Scheitern verurteilt.

Dennoch existiert eine Reihe sehr deutlicher Indizien dafür, daß sich auf Elephantine eine Bibliothek befunden haben muß:

1. Um die Jahrhundertwende erregte ein großer Fund aramäischer Papyri in der Wissenschaft Aufsehen; diese Papyri unterrichteten sehr detailliert über Leben und Schicksal einer jüdischen Militärkolonie auf Elephantine im 5. bis 4. Jh.v.Chr. Diese von Einheimischen gemachten Funde regten u.a. eine Ausgrabung der Berliner Museen in den Jahren 1906-1908 an, die aber insofern eine Enttäuschung war, als kaum weitere aramäische Papyri gefunden wurden. Doch tauchte eine sehr große Zahl - insgesamt wenigstens einige Zehntausend - meist sehr kleiner ägyptischer Papyri auf, die allerdings wegen inres fragmentarischen $\mathrm{Zu}$ standes größtenteils noch heute in Berlin in den Kisten lagern, in die sie nach ihrer Auffindung verpackt wurden. Lediglich einige größere Texte wurden bisher veröffentlicht ${ }^{142}$. Die Mehrzahl dieser Papyri stammt, wie aus paläographischen Gründen feststeht, etwa aus dem 9.-6. Jh. v.Chr.

2. In den aramäischen Papyri findet sich die Nachricht, daß Kambyses 525 v.Chr. im Verlauf seines Zugies gegen Ägypten die Tempel des Landes habe zerstören lassen, wobei er in Elephantine nur den Jahwe-Tempel geschont habe ${ }^{143}$. Wenn diese Nachricht richtig ist, dann müßte auch eine Bibliothek, falls eine solche vorhanden war, dieser Zerstörung zum Opfer gefallen sein.
Doch ist inzwischen durch die Forschung klargestellt, daß das negative Bild des Kambyses erst im Laufe der folgenden Jahrzehnte und unter griechischem Einfluß entstand: Kambyses hat zwar Sanktionen gegen einige Tempel erlassen, ganz sicher aber nicht alle zerstört ${ }^{144}$.

Auch auf Elephantine ist zumindest ein kleiner Tempel aus der 18. Dynastie der Zerstörung entgangen, da er im 19. Jh. noch fast komplett erhalten war. Bei den beiden Haupttempeln, dem des Gottes Chnum und dem der Göttin Satet, ist der archäologische Befund aber ein anderer: In der 30. Dynastie hat Nektanebos I. (380-362 v.Chr.) mit der Neuerrichtung dieser Tempel begonnen und konnte dabei offenbar in keinem Fall auf älteren Gebäudekernen aufbauen: Die von ihm errichteten Tempel sind komplette Neubauten, lediglich in den Fundamenten sind Blöcke älterer Tempel wiederverwendet worden ${ }^{145}$. Es hat also den Anschein, daß die älteren Gebäude vollständig zerfallen oder abgetragen worden waren, und das mag durchaus mit einer Aktion des Kambyses in Zusammenhang stehen.

Ein weiteres Indiz kommt hinzu: Die erwähnten ägyptischen Papyri wurden nicht an einer Stelle, sondern über das ganze Stadtgebiet verteilt gefunden - sie schienen buchstäblich in alle Winde zerstreut zu sein und sie stammen in der Mehrzahl aus der der vermuteten Zerstörung vorausgehenden Zeit $^{146}$. Die Vermutung scheint daher erlaubt, in innen die Reste der Bestände einer Bibliothek zu sehen.

Doch könnten diese äußerlichen Indizien auch nur zufällig zusammengetroffen sein, sie allein rechtfertigen noch nicht die genannte Folgerung. Betrachtet man jedoch den Inhalt der Papyri, ergibt sich ein wesentlich anderes Bild: Zwar sind, wie erwähnt, nur wenige Texte bereits publiziert; eine weitere Gruppe von größeren Fragmenten wurden jedoch von mir im Verlaufe meiner Arbeiten für die „Katalogisierung der orientalischen Handschriften in Deutschland " inventarisiert und u.a. inhaltlich bestimmt ${ }^{147}$. Dabei hat sich deutlich gezeigt, daß das inhaltliche Spektrum dieser Texte sehr breit ist: Es fanden sich religiöse Hymnen, Rituale für Chnum, den Hauptgott von Elephantine, medizinische, literarische, mythologische Texte, Archivalien sowie ein Fragment der aus dem Mittleren Reich stammenden ,Lehre Amenemhets I. für seinen Sohn Sesostris"; das letztgenannte Fragment bildet im übrigen den mit Abstand jüngsten Beleg für diese Weisheitslehre und zeigt, daß sie fast anderthalb Jahrtausende nach ihrer Entstehung noch tradiert wurde ${ }^{148}$

142 Zusammenstellungen der publizierten Berliner Papyri finden sich bei: Jankuhn, Dieter: Bibliographie der hieratischen und hieroglyphischen Papyri. Wiesbaden 1974, S. 14-27 und Zauzich, K.-Th.: Textveröffentlichungen der Museen: Berlin. In: Textes et langages de l'Egypte pharaonique (hommage à J.-F. Champollion). Le Caire 1974, S. 131-139.

143 vgl. z.B. Meyer, Eduard: Der Papyrusfund von Elephantine. Leipzig 1912 , S. 36.

144 vgl. z.B. Posener, Georges: La première domination Perse en Egypte. Le Caire 1936, S. 168ff.

145 vgl. Stadt und Tempel von Elephantine, erster Grabungsbericht, von Werner Kaiser u.a. In: Mitteilung des Deutschen Archäologischen Instituts Abteilung Kairo 26, (1970), S. 109.

146 zu einem weiteren Indiz s. unten Quelle Nr. 3.

147 die genaue Beschreibung dieser und anderer Papyri wird in absehbarer Zeit in einem weiteren Band der Reihe „Verzeichnis der orientalischen Handschriften in Deutschland " vorliegen.

148 dieser Text ist inzwischen publiziert, vgl. Burkard, Günter: Textkritische Untersuchungen zu ägyptischen Weisheitslehren des Alten und Mittleren Reiches. Wiesbaden 1977, S. 7-8 und Tafel im Anhang. 
dies mag ein Indiz für die kontinuierliche Tätigkeit der „Lebenshäuser" sein, s. auch im folgenden Abschnitt. Ein weiteres gemeinsames Kennzeichen dieser Texte ist neben ihrer Datierung ihre durchwegs sorgfältige Ausführung: Die Schrift ist sorgfältig, es finden sich so gut wie keine sinnentstellenden Fehler (vgl. dazu das unter "Ramesseum" über die Schulhandschriften Gesagte); beachtenswert ist außerdem an den medizinischen Texten, daß sie in keinem Fall Kopien der bekannten medizinischen Papyri des Mittleren und Neuen Reiches, sondern selbständige Texte sind: Das spricht für die ungebrochene Tradition der, wenn man so will, „medizinischen Forschung" in der Spätzeit; auch das weist auf die Tätigkeit der "Lebenshäuser" hin, s. oben S.63. Umgekehrt weist kein einziger dieser Texte Indizien auf, durch die er als private Kopie bestimmt werden könnte (Indizien wie flüchtige Schrift oder Palimpseste, s. oben S. 92), man gewinnt vielmehr deutlich den Eindruck, daß es sich um „Originaltexte“ handelt, oder, wie Dino Bidoli bei der Beschreibung eines dieser Texte, einer religiösen Hymne, ohne diesen Gedanken weiter zu verfolgen, feststellte: „Der Wert des ... Textes liegt darin, daß er nicht aus einer Totenbuchrolle stammt, sondern Teil eines originalen Buches von einer Tempelbibliothek ist ${ }^{149}$.

Faßt man alle aufgeführten Indizien: Fundumstände, historischer und archäologischer Kontext, äußere Form und inhaltliche Bandbreite der Texte zusammen, so erreicht man eine genügend tragfähige Basis für die Annahme, daß im 9.-6. Jh. v.Chr. auf Elephantine eine Bibliothek existierte. Die genannte Verschiedenartigkeit der Texte scheint darüber hinaus - dies unter allem Vorbehalt, s. oben S. 92 - eher auf ein „Lebenshaus" als auf ein „Bücherhaus" hinzuweisen.

3. Ein drittes, bei aller Schwierigkeit, das es dem Verständnis entgegensetzt, doch entscheidendes Indiz verdanken wir einem einzigartigen Text, der auf einem ebenfalls auf Elephantine gefundenen Papyrus fragmentarisch erhalten ist:

Der Papyrus Berlin 23040 a-c, der noch unveröffentlicht ist ${ }^{150}$, enthält im ersten Teil eine hymnische Klage an den Gott Chnum über den Zerfall der Tempel und der zugehörigen Gebäude auf Elephantine und im zweiten Teil in Form einer Litanei die Aufforderung an den Gott, die Feinde, die dies getan haben, einer Reihe von Bestrafungen zu unterwerfen. Damit besitzen wir nun auch eine eindeutige ägyptische Quelle, die uns von der Zerstörung der Tempel berichtet. Das Verständnis des Textes ist durch zwei Umstände sehr erschwert: Einmal durch den sehr fragmentarischen Zustand, der es nur ausnahmesweise erlaubt, einen längeren Kontext zu restituieren, zum anderen durch innere Schwierigkeiten: Der Text ist recht flüchtig geschrieben, offenbar ein Palimpsest und enthält eine Reihe unverständlicher Wörter bzw. ganzer Passagen. Es hat den Anschein, daß es sich um eine private Kopie handelt, deren Schreiber aus Nachlässigkeit oder Unverständnis viele sinnentstellende Fehler beging. Der paläographische Befund ergibt, daß der Text gegen Ende der Spätzeit oder in der frühen Ptolemäerzeit, also etwa im 4. Jh. v.Chr. niedergeschrieben wurde.

Die in diesem Zusammenhang interessierende Passage P. 23040 b, Kolumne 2, Z. 19-20 steht im ersten Teil des Textes innerhalb der Klage über den Zerfall des Tempels und der zugehörigen Gebäude. Da der Papyrus noch unpubliziert ist und die genannten äußeren und inneren Besonderheiten das Verständnis erschweren, muß vor der Interpretation der Stelle die philologische und textkritische Erörterung der einzelnen Probleme erfolgen.

Die hieroglyphische Transkription der zwei Zeilen lautet:

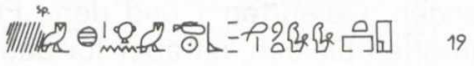

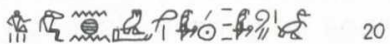

Zunächst zu Z. 19: Die Zeichenfolge - pola dieser Zusammensetzung bisher zwär nicht belegt, doch erscheint ihr Verständnis möglich, wobei freilich offenbleiben muß, ob es sich dabei um eine fehlerhafte oder um eine seltene Schreibung handelt:

Im Wb III,418,10 findet sich der Titel $s 3$ w.tj sšw „Archivar" (wörtlich „Hüter der Schriften") in der Schreibung til "A

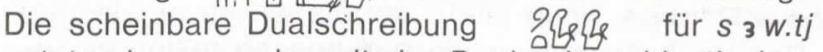
entstand wegen der mit der Dualendung identischen Endung tij in $s 3 w \cdot t j^{151}$. Die Schreibung $\uparrow_{\text {für } s s^{\prime}}$ „Schrift" ist m.W. bisher nicht belegt, erscheint aber in sich plausibel, da $\uparrow$ als Determinativ für sš sehr häufig ist, vgl. Wb III,476-477: in diesem Falle läge eine abgekürzte Schreibung von sš vor. Diese Annahme wird durch den Determinativstrich I unter \& unterstützt, der nahelegt, $\uparrow$ als selbständiges Wort und nicht etwa als Determinativ zum Vorangehenden zu lesen.

Demnach ist die erste Hälfte dieser Zeile zu lesen: hw.t s 3 w.tj ssiw „das Haus des Hüters der Schriften“: Das ist eine zwar sonst nicht belegte, aber dem Verständnis keine Schwierigkeit bietende Bezeichnung für eine mit „Schriften“ in Zusammenhang stehende Insitution, deren nähere Qualifikation sich aus der folgenden Zeile ergeben wird, s. unten.

Das dann folgende Verbum $\odot$ bd hat die Bedeutung "leuchten, erleuchten"152, und dies scheint nur auf den ersten Blick in diesem Kontext befremdlich zu sein: Was vermutlich gemeint ist, wird aus der schon zitierten Stelle im P. Anastasil aus der 19. Dynastie deutlich ${ }^{153}$ : „Das Bücherhaus ist geheim, nicht wird es gesehen." Hier ist vom genauen Gegenteil die Rede: nach seiner Zerstörung sind das Haus des Hüters der Schriften und damit auch die Schrift selbst eben nicht mehr „geheim", sondern „(hell) erleuchtet“, d.h. sie liegen offen zutage.

In diesen Kontext fügt sich auch der Rest der Zeile, wenn auch wegen der Zerstörung am Ende letzte Sicherheit nicht zu gewinnen ist: $m$ br $n b m[\ldots]$,in Gegenwart von ...". Der Zusammenhang erfordert hier die Nennung von Personen ( $m$ hr $n$ heißt wörtlich „im Angesicht von"); diese Vermutung wird im übrigen auch durch den parallel konstruierten zweiten Teil der folgenden Zeile unterstützt, s. unten. Unter den mit hm $\ldots$ beginnenden Wörtern ${ }^{154}$ kommen danach nur die folgenden in Frage:

1. om „der Unwissende", Wb III, 280, 6-8

149 Ägyptisches Museum Berlin. Berlin 1967, S. 123, Nr. 1113.

150 für die Erlaubnis zur Auswertung des Textes in diesem Zusammenhang danke ich Herrn Dr. Karl-Th. Zauzich vom Ägyptischen Museum Berlin sehr herzlich.

151 zu ähnlichen fehlerhaften „Dual“-Schreibungen vgl. z.B. Erman, Adolf: Neuägyptische Grammatik. 2. Aufl. Leipzig 1933, § 156.

152 s. (Anm. 87), Band I, 487, 9-11.

153 s. oben S. 87, Nr. 11.

154 s. (Anm. 87), Band III, 277-285 
2. hmj.w „Feinde der Tempel“, Wb III,281, 6-9 und das weibliche Gegenstück hbmj.t, Wb III, 281, 10.

Das - im übrigen nur im Neuen Reich belegte - $\mathrm{bm}^{\mathrm{c}}$ „Art Steinarbeiter" (Wb III, 282, 8) kommt hier aus inhaltlichen Gründen sicher nicht in Betracht.

Die Entscheidung zwischen den „Unwissenden“ ( $\mathrm{hm}$ „Unwissender" ist häufig belegt im Gegensatz zum rb, dem „Wissenden, Gelehrten“) und den „Feinden der Tempel" muß offen bleiben, ist aber für das Verständnis der Passage im ganzen nicht von Belang, da sich die Bedeutungsrichtung nicht ändert.

Keinerlei Probleme bietet dagegen die zweite Zeile: b3 $w-R^{c} \quad m^{-}{ }^{c} n b n w$, die heiligen Schriften sind in den Händen von Kindern", sc. in die sie als "heilige Schriften" nie hätten gelangen dürfen!

Die Stelle P. Berlin 23040 b, col. 2, 19-20 ist demnach wie folgt zu lesen und zu übersetzen:

h.w.t $s 3$ w.tj sšw bd $m$ ḥr $n h m[w]$ (oder hbm[j.w])

b3 $w-R^{\circ} m_{-c}$ nbnw

„Das Haus des Hüters der Schriften ist (hell) erleuchtet in Gegenwart von [Unwissenden] (oder: [Tempelfeinden])"

"die heiligen Schriften befinden sich in den Händen von Kindern".

Es kann kein Zweifel bestehen: Hier liegt ein klarer und in seiner Art einzigartiger Beleg für die Zerstörung einer Bibliothek vor ( $\mathrm{da}$ es sich nicht um ein Archiv handelt, wie der - von uns heute so übersetzte - Titel „Archivar" bzw. die Bezeichnung „Haus des Hüters der Schriften" vermuten lassen könnte, zeigt das folgende $b_{3} w-R^{c}$, heilige Schriften " eindeutig)! Dieser Text, der etwa im 4. Jh. v.Chr. niedergeschrieben wurde (s. oben S.97), weist natürlich in eine diesem Termin vorausgehende Zeit zurück und fügt sich damit nahtlos in den durch die aramäische Notiz und die Papyrusfunde vorgegebenen Befund: In der ägyptischen Spätzeit, etwa im 9.-6. Jh. v.Chr., bestand auf Elephantine eine Bibliothek, die wohl im 5.-6. Jh. v.Chr., vielleicht 525 v.Chr. unter Kambyses, zerstört wurde.

Die Tempel von Elephantine wurden, wie oben erwähnt, später wieder aufgebaut und waren dann bis weit in die römische Zeit hinein in Betrieb. Auch aus diesen späteren Epochen stammt eine Reihe von Papyri, die vielleicht in Zusammenhang mit einem Tempelarchiv oder einer Bibliothek zu sehen sind: Neben Archivalien, die eindeutig im Kontext zu einem der Tempel stehen, sind offenbar auch Reste magischer und religiöser Texte erhalten. Dieses Material ist aber noch weitgehend unbearbeitet, eine Basis für gesicherte Folgerungen ist noch nicht gegeben. So sei hier lediglich vermerkt, daß möglicherweise auch aus dieser späten Epoche Belege für die Existenz einer Bibliothek vorliegen, die allerdings noch ihrer Auswertung harren.

Fazit

Die Existenz einer Bibliothek auf Elephantine zwischen dem 9. und 6. Jh. v.Chr. ist durch das Zusammenwirken von Indizien archäologischer und inschriftlicher Art gesichert. Die Bandbreite der erhaltenen Texte läßt eher auf ein „Lebenshaus“ schließen, doch ist gerade in diesem Fall besondere Vorsicht geboten: Neben dem allgemeinen, oben S. 92 formulierten Vorbehalt ist die singuläre Bezeichnung „Haus des Hüters der Schriften" des P. Berlin 23040 zu berücksich- tigen, die möglicherweise einer ganz anders gearteten Institution gilt. Weiterhin gibt es Anhaltspunkte dafür, daß auch in späterer Zeit eine Bibliothek auf Elephantine bestand, doch steht die Auswertung der diesbezüglichen Quellen noch aus.

\section{Heliopolis}

\section{Quellenlage}

1. Bei Ausgrabungen in Abydos wurde u.a. die Stele eines Königs Neferhotep aus der 13. Dynastie, also aus dem 17.-18. Jh. v.Chr. gefunden; die Stele wurde von Pieper publiziert ${ }^{155}$, die folgende Wiedergabe der in diesem Zusammenhang interessierenden Passagen stützt sich auf dessen Übersetzung:

Z. 2ff.: (Der König spricht) „Mein Herz hat verlangt, die uralten Bücher des (Gottes) Atum zu sehen. Breitet sie mir aus zu einer großen Revision ...". Z. 6ff.: (Antwort der Hofleute) „Da sagten diese Hofleute: 'Was du befohlen hast, geschieht, oh Herrscher und Herr. Deine Majestät gehe zu den Häusern der Schriften und sehe die Gottesworte.' Da ging Seine Majestät zum Bücherhaus. Seine Majestät breitete die Buchrollen aus, zusammen mit diesen Hofleuten. Da fand Seine Majestät die Bücher des Hauses des Osiris, des Ersten der Westlichen."

Das in dieser Inschrift erwähnte „Bücherhaus“ lokalisiert Pieper offenbar vor allem wegen der Erwähnung des in diesem Zusammenhang genannten, in Heliopolis beheimateten Gottes Atum in eben diese Stadt ${ }^{156}$.

2. In der Publikation eines heute im Museum von Brooklyn aufbewahrten magischen Papyrus berichtet Sauneron ${ }^{157}$ von einer Gruppe von Papyri, die meist noch unveröffentlicht sind und die aus einem Zeitraum von etwa 1080 bis um 400 v.Chr. stammen, wobei die Mehrzahl auf das 7.-8. Jh. v.Chr. zu datieren ist. Aufgrund verschiedener Indizien wie übereinstimmender orthographischer Besonderheiten, teilweiser Verwendung der gleichen, ansonsten bislang unbekannten Wörter oder teilweise identischer Handschrift schließt Sauneron zu Recht auf eine gemeinsame Herkunft. Die Tatsache, daß die Texte außerdem aus einer recht langen Epoche von immerhin mehr als 600 Jahren stammen, führt inn zu dem Schluß, daß dieser gemeinsame Herkunftsort nur eine Bibliothek gewesen sein kann. Dies werde auch durch die Bandbreite der Textgattungen nahegelegt: Neben einem starken Bestand an magischen Texten sind auch solche mythologischen, medizinischen, liturgischen, rituellen und literarischen Inhalts erhalten. Sauneron bemerkt hierzu: „On est ainsi amené à penser à la bibliothèque d'une centre religieux, moins peut-être d'un temple que d'une chapelle de guérisseurs, d'un 'sanatorium', comme on dit habituellement, ou d'une 'maison de vie'."

Die Lokalisierung dieser vermuteten Bibliothek bereitet Schwierigkeiten, da der Fundort der Papyri unbekannt ist. Ein direkter Hinweis findet sich nach Sauneron in

155 Pieper, Max: Die große Inschrift des Königs Neferhotep in Abydos. Leipzig 1929.

156 (Anm. 155), S. 9 und nochmals S. 14, wo er erneut betont, daß mit den Büchern des Osirishauses nicht ein lokaler Bezug zu Abydos hergestellt werden muß.

157 Sauneron, Serge:: Le papyrus magique illustrée de Brooklyn. New York 1970, S. VII-IX. 
keinem der Texte, doch hält er aufgrund verschiedener Indizien wie der Namen und Charakterisierung der in ihnen genannten Götter, bestimmter Ritualhandlungen und gewisser mythologischer Anspielungen den Standort der Bibliothek in Heliopolis für die wahrscheinlichste Lösung.

\section{Bemerkungen}

Trotz der wiederholt geäußerten Überzeugung Piepers, das in der Inschrift des Neferhotep genannte „Bücherhaus" könne nur in Heliopolis gesucht werden, kann die Stelle nicht als Indiz in diesem Sinne gewertet werden: So wie Atum nach Heliopolis weist, weist andererseits das „Haus des Osiris" nach Abydos, und dort wurde die Stele auch gefunden!

Solange dieser Beleg also für sich allein steht und durch kein weiteres Indiz gestützt wird, kann er lediglich als Beweis für die Existenz eines bestimmten, aber nicht eindeutig zu lokalisierenden „Bücherhauses“ im 17.-18. Jh. v.Chr. gewertet werden.

Anders ist der Sachverhalt beim zweitgenannten Beleg: Obwohl hier weder ein inschriftlicher Hinweis existiert, noch gar bauliche Reste bekannt sind, überzeugen die von Sauneron aufgeführten chronologischen und inhaltlichen Argumente so sehr, daß man davon ausgehen darf, daß die Bestände tatsächlich aus einer Bibliothek stammen.

Nicht in gleichem Maße eindeutig ist die Frage der Lokalisation dieser Bibliothek, doch ist es m.E. auch hier erlaubt, sich der Argumentation Saunerons anzuschließen: Die von ihm angeführten, aus den Texten selbst gewonnenen Indizien können zwar faktisch nicht abgesichert werden, dürfen aber doch zumindest einen recht hohen Wahrscheinlichkeitsgrad für sich in Anspruch nehmen.

Die Frage nach der chronologischen Einordnung dieser Bibliothek ist nur annähernd und innerhalb recht weiter Grenzen zu beantworten. Wenn die Texte aus der Zeit von etwa 1080-400 v.Chr. stammen, ist mit 1080 in etwa der terminus post quem gegeben, und das Jahr 400 markiert den Zeitpunkt, an dem die Bibliothek noch bestanden haben muß; ob und wie lange sie über diesen Zeitraum hinaus existierte, ist unbekannt.

\section{Fazit}

Heliopolis war eines der bedeutendsten theologischen Zentren Ägyptens ${ }^{158}$, die Annahme der Existenz einer Bibliothek an diesem Ort ist daher a priori zwingend. Dem entspricht aber nicht die Beweislage: Neben einem äußerst unsicheren, vorläufig zurückzustellenden Indiz aus dem 17.-18. Jh. v.Chr. ist bislang nur ein ebenfalls nicht völlig gesicherter, aber doch mit einem gewissen Wahrscheinlichkeitsgrad ausgestatteter Hinweis aus der Spätzeit Ägyptens zu verzeichnen, der auf vermutlichen Bestandsresten (eines ,Lebenshauses"?) basiert. Freilich darf diese Unsicherheit nicht verwundern: Von Heliopolis, im Gebiet des heutigen Kairo innerhalb des Fruchtlandes gelegen, sind fast keine inschriftlichen oder archäologischen Reste gröBeren Umfangs erhalten, Hinweise von dieser Seite können also kaum erwartet werden ${ }^{159}$.

\section{Hermopolis}

\section{Quellenlage}

In einer Weihinschrift des Pharao Merenptah (19. Dynastie, ca. 1224-1214 v.Chr.), die im Tempel von Hermopolis angebracht war ${ }^{160}$, lautet eine Passage: „,Deine (des Gottes Re) Reinigung ist vollzogen im Hause der Lebenden; siehe, das Lebenshaus [. . . ]"161.

\section{Bemerkungen}

Merenptah ließ diese Inschrift anläßlich der Einweihung eines neuerbauten Tempels in Hermopolis anbringen; das im Text beschriebene Zeremoniell ist eindeutig in diesem Tempel zu lokalisieren. Der Kontext, in dem die zitierte Passage mit der Erwähnung des Lebenshauses steht, handelt von der Schönheit und der reichen materiellen Ausstattung des neuen Tempels; in der zerstörten Stelle nach "Lebenshaus" war vermutlich dessen Ausschmückung erwähnt ${ }^{162}$

Obwohl dies das einzige Indiz ist, das auf die Existenz eines "Lebenshauses" und damit einer Bibliothek in Hermopolis - der Stadt des Gottes Thot, des Erfinders der Schrift und Gottes der Schreiber - hinweist, darf es als recht tragfähig gelten: Der beschriebene Textzusammenhang zeigt klar, daß von konkreten Einrichtungen in Verbindung mit dem neuen Tempel die Rede ist. Weitere, besonders archäologische, Hinweise fehlen, sie sind wohl auch nicht mehr zu erwarten: Das Gebiet des antiken Hermopolis ist heute nurmehr ein riesiger Schutthaufen, in dem kaum ein Stein mehr auf dem anderen steht.

\section{Fazit}

Aus Hermopolis existiert ein einziger, aber dennoch recht tragfähiger Hinweis auf die Existenz eines „Lebenshauses". In chronologischer Hinsicht muß dieser Beleg freilich punktuell bleiben, er ist beschränkt auf die Regierungszeit des Merenptah und evtl. seiner unmittelbaren Nachfolger, d.h. auf etwa den Beginn des 13. Jh. v.Chr. Weitere Anhaltspunkte aus anderen Epochen sind bislang nicht bekannt.

\section{Karnak}

\section{Quellenlage}

1. Paul Barguet berichtet in seiner ausführlichen Beschreibung des riesigen Tempelareals von Karnak ${ }^{163}$ u.a. von einem unter Thutmosis I. (1508-1493 v.Chr.) errichteten Gebäudekomplex, einem hypostylen Saal, der zwischen dem 4. und 5. Pylon, hinter der hyposty-

158 zur knappen aber umfassenden Orientierung über diesen Ort s. z.B. den Artikel von Bonnet (Anm. 122), S. 543-545 s.v. "On“.

159 s. im übrigen auch unter „snw.t-Heiligtum"; dieses Heiligtum, zu dem eine Bibliothek gehörte, wie inschriftlich nachgewiesen ist, wurde von Hermann Kees in Heliopolis vermutet; da jedoch sichere Hinweise fehlen, wurde es hier unter seiner ägyptischen Bezeichnung eingeordnet.

160 Roeder, Günter: Zwei hieroglyhpische Inschriften aus Hermopolis (Ober-Ägypten). In: Annales du Service des Antiquités de l'Egypte 52 (1952), $316 \mathrm{ff}$.

161 (Anm. 160), S. 331

162 so Roeder (Anm. 160), S. 332, Anm. e.

163 Le temple d'Amon-Rê à Karnak, essai d'exégèse. Le Caire 1962. 
Ien Halle Ramses'll. liegt ${ }^{164}$. In die Westwand dieses Saales sind rechts und links des Eingangs zwei Nischen eingelassen ${ }^{165}$. Barguet beschreibt diesen Gebäudeteil folgendermassen: „Près de l'angle SudOuest de la salle s'ouvre une chambre, dont le fond est creusé de deux niches, sortes d'armoires jadis fermées de vantaux de bois. A l'autre extrémité de la salle, dans l'angle Nord-Ouest, s'enforce aussi une petite chambre. Peut-être ces réduits correspondentils à la bibliothèque et à la sacristie du pronaos des temples ptolémaiques." 166

2. Im sog. "Annalensaal" in Karnak hat Thutmosis III. (1490-1440 v.Chr.) unter anderem Berichte seiner vor allem gegen Palästina und Syrien durchgeführten Feldzüge anbringen lassen. Dabei geht aus einer Stelle hervor, daß die „Kriegstagebücher“, die die Grundlage für den Text der Inschrift bildeten, ebenfalls in Karnak aufbewahrt wurden: „Sie wurden aufbewahrt auf einer Lederrolle im Tempel des Amun an diesem (heutigen) Tage." 167 Wessetzky schließt aus dieser Stelle, daß der Bericht, den er als „Dokument historischen Charakters" bezeichnet, ,als Lederrollbuch in die Bibliothek des Amuntempels " gelangt sei ${ }^{168}$.

3. Zwei Papyri, die heute in Berlin aufbewahrt werden ${ }^{169}$ und die in der 22. Dynastie (ca. 950-730 v.Chr.) niedergeschrieben wurden, enthalten die Texte des täglichen Kultbildrituals für den Gott Amun und die Göttin Mut. Sie stammen, auch wenn der genaue Fundort nicht bekannt ist, mit Sicherheit aus Karnak $^{170}$, wo die Haupttempel der Göttertrias Amun, Mut und Chons geweiht waren. Beide Texte erwecken deutlich den Eindruck von „Originalhandschriften“: sorgfältige Schrift, keine sinnentstellendden Fehler, sie sind also möglicherweise tatsächlich im Ritualdienst verwendet worden; wenn diese Vermutung zutrifft, kann die Schlußfolgerung nur die sein, daß wir mit innen die Reste der Bestände der Tempelbibliothek besitzen, und zwar aus inhaltlichen Gründen des „Bücherhauses".

4. Einen weiteren, aus Karnak stammenden, Ritualtext aus der frühen Ptolemäerzeit hat Barguet publiziert ${ }^{171}$. Er bemerkt dabei zu diesem und zu weiteren Texten ähnlichen Inhalts, die selbst zwar nur teilweise (aus anderen Orten und nicht im Zusammenhang mit Karnak) erhalten, deren Titel aber in Kolumne 5 und 6 des von ihm publizierten Ritualtextes überliefert sind: „Tous ces livres, sous forme de rouleaux de papyrus, devaient être conservés dans la ,bibliothèque“ du temple de Karnak, bibliothèque dont on ignore l'emplacement, mais qu'on peut supposer être l'une des deux

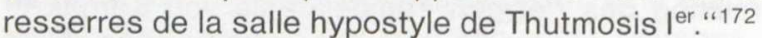

\section{Bemerkungen}

Die beiden ersten der oben aufgeführten Belege stammen aus der 18. Dynastie, liegen also zeitlich recht nahe beieinander: Die beiden Nischen im 4. Pylon, deren Anlage tatsächlich den Vergleich mit den beiden entsprechenden Gebäudeteilen im Tempel von Edfu aufdrängt, wurden zwischen 1508 und 1493 v.Chr errichtet, die inschriftliche Nachricht Thutmosis' III. stammt aus der Zeit nach 1490 und vor 1440 v.Chr. Neben der zeitlichen Nähe verbindet diese Belege leider aber auch ein weiterer Punkt: Beide sind nur sehr unsichere Indizien für die Existenz einer Bibliothek in Karnak. Für die beiden Nischen im 4. Pylon gilt diese Wertung, weil außer der architektonischen Ähn- lichkeit zur Anlage im Tempel von Edfu - wobei zu berücksichtigen ist, daß zwischen beiden Bauten ein zeitlicher Unterschied von rund 1200 Jahren besteht! - kein weiteres Indiz zur Unterstützung herangezogen werden kann; weder hat sich eine entsprechende Inschrift erhalten ${ }^{173}$, noch wurden mögliche Bestandsreste aus dieser Zeit gefunden.

Ähnlich ist der Sachverhalt bei der Inschrift Thutmosis' III.: Gerade weil es sich, wie Wessetzky richtig definiert hat, um ein ,Dokument historischen Charakters" handelt, muß gefragt werden, ob als Aufbewahrungsort eine Bibliothek oder ein Archiv bestimmt war. Durch die Ausgrabungen in Amarna (s. dort), d.h. von einer Zeit, die nur etwa 130 Jahre nach dem hier in Frage kommenden Zeitpunkt liegt, ist bekannt, daß diese beiden Einrichtungen räumlich voneinander getrennt und somit jeweils selbständig bestehen konnten. Natürlich ist es möglich und wohl sogar wahrscheinlich, daß in Karnak (dem alten Theben), der Hauptstadt des Reiches vor Amarna, ebenfalls beide Institutionen, vielleicht auch wie in Amarna getrennt nebeneinander, existierten, doch ist dies eben nur eine Vermutung; als konkreter Beleg für die Existenz einer Bibliothek kann die zitierte Stelle jedenfalls nicht gelten.

Entsprechend unsicher ist die Situation im Falle der beiden anderen oben genannten Belege: Sowohl bei den zwei Berliner Papyri aus der Wende vom 11. zum 10. Jh. v.Chr., wie auch beim P. Louvre N. 3176 (S) aus der Wende vom 4. zum 3. Jh. v.Chr. spricht eben nur die Tatsache, daß sie Ritualbücher des Tempelkults von Karnak sind, für eine Zugehörigkeit zur Tempelbibliothek - wohl dem „Bücherhaus“ -; dieses Indiz ist ganz sicher von einigem Gewicht, kann aber ohne zusätzliche Unterstützung nicht näher konkretisiert werden.

\section{Fazit}

Die Tempel von Karnak waren im Neuen Reich und auch später noch bis in die Ptolemäerzeit, also für eine sehr lange Epoche der ägyptischen Geschichte, das politische und besonders religiöse Zentrum Ägyptens; wenn überhaupt, dann muß man natürlich dort die Existenz einer Bibliothek voraussetzen. Doch entsprechen, wie dargelegt, leider die Realitäten nicht diesem Postulat: Nur wenige recht schwache Indizien, die zudem über einen langen Zeitraum, vom Ende des 15. bis zum Ende des 3. Jh.v.Chr., verteilt sind, verweisen auf die Existenz einer Bibliothek - meist (abgesehen

164 zur Lage s. Porter, Bertha, Moss, Rosalind: Topographical bibliography of ancient Egyptian hieroglyphic texts, reliefs, and paintings, II. Theban temples. 2. ed. Oxford 1972, Plan X.

165 s. auch oben S. $91 \mathrm{f}$

166 Barguet (Anm. 163), S. 97, n. 1; vgl. auch die unten in Quelle Nr. 4 zitierte Bemerkung Barguęts.

167 Urkunden des ägyptischen Altertums, Abt. IV: Urkunden der 18 Dynastie, bearb. von Kurt Sethe (Forts.: Wolfgang Helck), Leipzig 1905 ff. S. 662, 5-6.

168 Wessetzky (Anm. 139), S. 54-55.

169 P. Berlin 3014/3053 und 3055, vgl. Hieratische Papyrus aus den königlichen Museen zu Berlin, hrsg. von der Generalverwaltung, 1. Band: Rituale für den Kultus des Amon und für den Kultus der Mut. Leipzig 1901

170 neben der eindeutigen Zuweisung aus inhaltlichen Gründen wird das auch dadurch bekräftigt, daß die Papyri 1845 dort durch R. Lepsius von einem Antikenhändler gekauft wurden.

171 Barguet, Paul: Le papyrus N. 3176 (S) du Musée du Louvre. Le Caire 1962

172 Barguet (Anm. 171), S. 50.

173 s. auch oben S. 91. 
von der Inschrift Thutmosis'lll.) eines „Bücherhauses“ - in Karnak.

Freilich besteht durchaus die Hoffnung, daß diese unbefriedigende Beleglage Verbesserungen erfährt: Seit einer Reihe von Jahren finden im Tempelbezirk französisch-ägyptische Grabungen statt, die sich in besonderem $\mathrm{Maße}$ den bisher vernachlässigten $\mathrm{Re}-$ sten der den Tempeln angegliederten Lehmziegelgebäude widmen. Die dabei unter anderem zutage gekommenen Priesterhäuser wurden teilweise inzwischen veröffentlicht ${ }^{174}$; dabei wird auch von weiteren recht großen Lehmziegelkomplexen - vermutlich Resten von Verwaltungsgebäuden - berichtet, die entweder noch nicht vollständig ausgegraben oder noch nicht veröffentlicht sind: Vielleicht finden sich hier auch die Reste eines „Lebenshauses", für das bisher zwar jeder Beleg fehlt, dessen Existenz in einem Tempelareal dieser Größenordnung und Bedeutung aber wohl vorausgesetzt werden muß.

\section{Krokodilopolis}

\section{Quellenlage}

Im Besitz der Österreichischen Nationalbibliothek befindet sich eine größere Anzahl demotischer Papyri, die aus der Zeit zwischen dem letzten Jh. v.Chr. bis zum 4. Jh. n.Chr. stammen. Mit dieser Handschriftengruppe und ihrer Herkunft hat sich Reymond innerhalb der Publikation eines zu dieser Gruppe gehörenden medizinischen Papyrus ausführlich befaßt ${ }^{175}$.

Danach läßt sich die Mehrzahl dieser Texte inhaltlich wie folgt gliedern: historische Romane, Prophezeiungen, ethische Literatur, Weisheitstexte, naturwissenschaftliche Texte, astrologische Texte, Tiergeschichten, mythologische Erzählungen, Tempelrituale. Mit diesen Texten in Verbindung stehen Teile der Archive von Priestern des (Krokodil-)Gottes Suchos, der besonders im Faijum verehrt wurde.

Die Papyri lassen sich weiterhin nach äußerlichen Merkmalen unterscheiden:

1. demotische Texte der genannten Kategorien auf der Rückseite griechisch beschrifteter Verwaltungsurkunden. Diese Texte dienten, wie Reymond anmerkt, zweifellos dem privaten Gebrauch vermutlich der Priester ${ }^{176}$,

2. demotische Texte, die ausschließlich auf Papyrus der besten Qualität und nur auf dessen Vorderseite stehen. Diese Texte sind nach Reymond mit hoher Wahrscheinlichkeit (,,with a reasonable degree of probability") als Teile einer bedeutenden Bibliothek, wie etwa einer Tempelbibliothek, anzusehen. Als zusätzliche Begründung für diese Vermutung verweist Reymond auf die aus dem gleichen Fundzusammenhang stammenden oben erwähnten Reste der Archive der Suchos-Priester, durch die eine eindeutige Verbindung zu einem Tempel erkennbar wird.

Für einen Teil der Texte läßt sich diese Verbindung zu einem Tempel belegen: Sie stammen vom Kom el Dime im Faijum, dem griechischen Soknopaiu Nesos aus der Umgebung des dortigen Sobektempels ${ }^{177}$.

Ursprünglich hatte man angenommen, daß die gesamte Gruppe dieser Wiener Papyri aus Soknopaiu Nesos stamme. Doch konnte Reymond diese Ansicht - die wie so häufig wegen der vor allem im letzten Jahrhun- dert oft nur ungenau geführten Zugangsbücher der Museen entstehen konnte - eindeutig widerlegen: Soknopaiu Nesos wurde vor dem 3. Jh. n.Chr. aufgegeben. Da eine Reihe von Papyri aber jüngeren Datums ist, bleibt nur der Schluß, daß sie von einem anderen, ebenfalls mit einem Suchos-Kult in Verbindung stehenden Ort stammen müssen. Aufgrund inhaltlicher Indizien, geographischer Bezeichnungen und doch noch aufgefundener spärlicher Hinweise auf den Herkunftsort kann Reymond belegen, daß dieser andere Ort das griechische Krokodilopolis in der Nähe des heutigen Medinet el Faijum sein muß.

\section{Bemerkungen}

Es kann kein Zweifel bestehen, daß die Schlußfolgerungen Reymonds überzeugend sind: In Krokodilopolis hat eine Bibliothek existiert, ein Teil ihrer Bestände ist erhalten geblieben und wird jetzt in der Österreichischen Nationalbibliothek aufbewahrt.

Ein Einwand könnte jedoch von anderer Seite erhoben werden: Die Papyri - und damit natürlich auch die Bibliothek, aus der sie stammen - sind in die griechisch-römische Zeit, teilweise bis hinab ins 4.Jh. n.Chr. zu datieren: Können sie überhaupt als repräsentativ für das pharaonische Ägypten angesehen werden?

Ein wichtiger Schlüssel zur positiven Beantwortung dieser Frage liegt in Elephantine: Von dort stammen Papyri der gleichen inhaltlichen Gattungen, sie kommen ebenfalls aus der Nachbarschaft eines Tempels (in Elephantine fanden sich Hymnen für Chnum, in Krokodilopolis für Suchos) und sie stammen zweifelsfrei aus pharaonischer Zeit. Die Bibliothek des Tempels in Krokodilopolis ist - ebenso wie übrigens die von Soknopaiu Nesos und von Tebtynis, die die gleichen zeitlichen und inhaltlichen Kriterien aufweisen, s. unten unter diesen beiden Orten - sicher nicht das Produkt griechischen Einflusses, sondern steht klar in der Tradition ägyptischer Institutionen.

Die Frage nach der Art der Bibliothek in Krokodilopolis muß wie in Elephantine letztlich offen bleiben: Die Bandbreite der erhaltenen Textgattungen spricht eher für die Institutionen des "Lebenshauses", doch ist letzte Sicherheit nicht zu gewinnen.

Fazit

Für die Bibliothek - des „Lebenshauses“? - im Tempelbezirk von Krokodilopolis existiert bisher zwar weder ein inschriftlicher Hinweis, noch ist ein baulicher Rest bekannt; ihre Existenz darf jedoch aufgrund der von Reymond anhand der Wiener Papyri erarbeiteten Indizien als sicher gelten, die genannten Papyri bilden den erhaltenen Rest ihrer Bestände. Entsprechend der Datierung der Papyri hat diese Bibliothek wohl etwa zwischen dem 1.Jh. v. Chr. und dem 4. Jh. n.Chr. bestanden, ohne daß sich dieser Zeitraum genauer fassen ließe.

174 Anus, Pierre, Saad, Ramadan: Habitations de prêtres dans le temple d'Amon de Karnak. In: Kêmi 21 (1971), S. $217 \mathrm{ff}$.

175 Reymond, E.A.E.: A medical book from Crocodilopolis, P. Vindob. D.6257. Wien 1976, S. 22.

176 vgl. dazu auch oben S. 92.

177 s. dazu unten bei "Soknopaiu Nesos"; Sobek ist die ägyptische Bezeichnung für (das im Griechischen verwendete) Suchos. 


\section{Die ,Bibliothek im Gedächtnistempel Pepi's II.“}

\section{Quellenlage}

Im Totentempel Pepi's II. (6. Dynastie, ca. 2251-2157 v.Chr.), der zu seiner Pyramidenanlage in Saqqara gehört ${ }^{178}$, existierte nach Ansicht Schotts auch eine Bibliothek, wie aus folgender Bemerkung hervorgeht: „Im Gedächtnistempel Pepi's II. sind an den Wänden der Bibliothek seines Sanktuars an der Spitze der Götterreihen zwei Kapellen mit je zwei solchen (= hockenden) Affen dargestellt." 179

\section{Bemerkungen}

Diese so selbstverständlich scheinende Bemerkung Schotts erweist sich bei näherer Überprüfung des Sachverhalts als in dieser Weise nicht haltbar. Die Beischrift zu der von ihm beschriebenen Darstellung lautet: „[Verweilen im] Gottesbücherhaus im snw.tHeiligtum". Dem snw.t-Heiligtum (s. unten unter diesem Namen), einer Art Reichsheiligtum, war, wie inschriftlich mehrmals belegt ist, tatsächlich eine Bibliothek angegliedert; nur ist dieses Heiligtum nicht mit dem Gedächtnistempel Pepi's II. identisch, sondern es ist dort dargestellt. Diese Darstellung sagt aber nichts über die Funktion des Raumes aus, in der sie angebracht ist, die oben zitierte Beischrift verweist im Gegenteil ausdrücklich auf eine andere Stätte, eben auf das snw.t-Heiligtum.

Es ist daher nicht gerechtfertigt, mit Schott den Vorraum zum Sanktuar dieses Gedächtnistempels ${ }^{180}$ als Bibliothek zu interpretieren, dazu gibt es keinerlei Beweis. Dort ist vielmehr das - in Wirklichkeit natürlich existierende, aber nicht genau zu lokalisierende snw.t-Heiligtum mit seiner Bibliothek dargestellt; dazu paßt im übrigen auch die Darstellung der beiden hockenden Affen, also einer der möglichen Personifikationen des Schreibergottes Thot.

\section{Fazit}

Eine „Bibliothek im Gedächttnistempel Pepi's II.“ ist nicht nachweisbar. Wohl aber findet sich in diesem Tempel ein eindeutiger Beleg dafür, daß zur Zeit Pepi's II. ein snw.t-Heiligtum mit dazugehörendem „Gottesbücherhaus" existierte. Nur so läßt sich die genannte Darstellung interpretieren; wir besitzen mit ihr einen eindeutigen Beleg für die Existenz einer Bibliothek in der 6. Dynastie, freilich ohne diese exakt lokalisieren zu können ${ }^{181}$

\section{Philae}

\section{Quellenlage}

Das „Bücherhaus" des Isistempels auf der Insel Philae ist längst bekannt und ähnlich wie in Edfu durch die an seinen Wänden angebrachten Inschriften eindeutig in seiner Funktion zu bestimmen. Es genügt daher, hier auf die Bemerkungen Milkaus ${ }^{182}$ und zu einer bei Milkau noch nicht vermerkten Inschrift auf meine Ausführungen oben S. 85 zu verweisen.

\section{Bemerkungen und Fazit}

Gegenüber der Darstellung Milkaus haben sich inzwischen keine entscheidenden neuen Gesichtspunkte ergeben, lediglich ein Detail bedarf der Korrektur: Das „Bücherhaus“ liegt nicht, wie Milkau vermerkt, an der architektonisch gleichen Stelle wie in Edfu, sondern im ersten Tempelhof. Ph. Derchain hat darauf aufmerksam gemacht, ebenso auf die Tatsache, daß in Philae im Gegensatz zu Edfu und Tôd eine Bücherliste fehlt ${ }^{183}$. Derchain hat a.a.O. im übrigen auch die Möglichkeit angedeutet, daß das „Bücherhaus" in Philae - u.a. wegen der genannten Abweichungen von Edfu (und Tôd) - vielleicht eine andere Zweckbestimmung besessen habe; eine Alternativlösung kann er freilich auch nicht vorschlagen. Doch hat diese Frage - falls sie überhaupt gestellt werden muß, m.E. reichen die von Derchain angeführten Punkte nicht aus, seine Vermutung überzeugend zu belegen - allenfalls sekundäre Bedeutung: Die Tatsache der gesichert belegten Existenz eines „Bücherhauses“ in Philae wird davon nicht berührt. Wie lange dieses „Bücherhaus“ bestand, ist nicht bekannt, die Grenzen liegen innerhalb der Erbauungszeit des betreffenden Tempelteils, also im 1. Jh. n.Chr. unter der Regierungszeit des Kaisers Tiberius $^{184}$, und der Schließung des Tempels im 6. Jh. n.Chr.

Die Frage nach der Existenz eines „Lebenshauses" in Philae muß dagegen offenbleiben. Bisher ist dafür kein Beleg irgendeiner Art bekannt ${ }^{185}$.

\section{Ramesseum}

\section{Quellenlage}

Die Bibliothek im Ramesseum, dem „Grabmal des Osymandyas", von der uns Diodor (I, 47-49) berichtet, stand wie keine andere ägyptische Bibliothek im Interesse der Forschung. Im folgenden Überblick sind nur die wichtigsten Darstellungen, angefangen mit der Milkaus, berücksichtigt; weitere Untersuchungen sind entweder in diese Darstellungen eingegangen oder durch sie überholt, in jedem Fall aber dort im einzelnen nachgewiesen.

1. Milkau ${ }^{186}$ kommt insgesamt zu dem Ergebnis, daß die Bibliothek innerhalb des Ramesseums nicht sicher zu lokalisieren ist. Das, was Diodor $\tau \eta v \operatorname{\imath \varepsilon \rho \alpha ेv~} \beta 1 \beta \lambda$ เo $\eta x \eta v$ nannte, ist seiner Ansicht nach wie in Edfu nur der Raum, wo die für den Tempeldienst notwendigen Bücher aufbewahrt wurden. Er schließt das aus der Verwendung des bestimmten Artikels $\tau \eta v$ : damit sei ein selbstverständlicher Teil der Anlage bezeichnet, eben der, der dem erhaltenen Raum in Edfu (in der Zweckbestimmung), nicht in architektonischer Hinsicht) entspreche.

178 veröffentlicht von Jequier, Gustave: Le monument funèraire de Pepi II, tome 2, le temple. Le Caire 1938.

179 Schott (Anm. 138), S. 21; zur Darstellung vgl. Jequier (Anm. 178) pl. 50 .

180 in diesem Raum befindet sich die genannte Darstellung, vgl. auch Schott (Anm. 69), S. 194-105.

181 s. im einzelnen unter „snw.t-Heiligtum".

182 (Anm. 2), S. 13.

183 Derchain (Anm. 100), S. 58-61

184 vgl. z.B. Milkau (Anm. 2), S. 13.

185 Es ist deshalb berechtigt, in Philae nach einem "Lebenshaus " zu suchen, weil in diesem Tempel die "heidnische" Kultur und Religion Ägyptens mit Abstand am längsten Bestand hatte: Der Tempel wurde erst von Justinian (527-565 n.Chr.), also im 6. Jh. n.Chr. geschlossen und die Priester eingekerkert; vgl. z.B. Bonnet (Anm. 122), S. 594 s.v. Philae.

186 (Anm. 2), S. 10-12. 
2. Helck ${ }^{187}$ versucht in einer ausführlichen Betrachtung den Weg zu rekonstruieren, den Diodor bei seiner Besichtigung des Ramesseums zurückgelegt hat; er legt dabei Diodors Beschreibung zugrunde und zieht für die Gebäudeteile, die heute nicht mehr erhalten sind, die entsprechenden Räume des architektonisch ähnlich konzipierten Tempels von Medinet Habu zu Rate. Diese Rekonstruktion führt inn zu „dem im Ramesseum südlich des Raumes mit der astronomischen Decke festgestellten zweisäuligen Raum: in diesem möchte ich die Bibliothek erkennen". ${ }^{188}$ Helck befaßt sich außerdem kurz mit

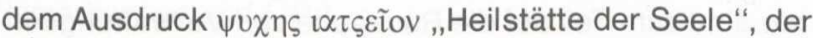
laut Diodor am Eingang zur Bibliothek gestanden habe, und hält es bei aller Zurückhaltung für die wahrscheinlichste Lösung, in diesem Ausdruck eine Übersetzung des ägyptischen $p r-^{c} n h$,Lebenshaus" zu sehen.

3. Wessetzky ${ }^{189}$ folgt Helck in der Lokalisierung der Bibliothek innerhalb des Hauptgebäudes, schlägt allerdings vor, sie nicht südlich, sondern nördlich des „astronomischen Saales" in einem oder zwei Räumen zu sehen, von denen die Grundmauern noch erhalten sind (s. den Plan, Abb. 3).

Von den Gründen, die Wessetzky für die von inm vorgeschlagene Lokalisierung anführt, ist vor allem die Plazierung zweier Reliefs beachtenswert:

a) eine Darstellung des Perseabaumes mit der Schreibergöttin Seschat ist im nördlichen Flügel des ,,astronomischen Saales " erhalten;

b) auf einer der nördlichen Säulen im hypostylen Saal befindet sich eine Darstellung von Thot und Seschat, wobei letztere den Titel „Herrin des Bücherhauses" trägt; diese Darstellung ist darüber hinaus auf der Seite der Säule angebracht, die nach dem von Wessetzky vermuteten Bibliotheksraum weist.

4. Einen gänzlich anderen Weg geht Derchain ${ }^{190}$, der in der Beschreibung Diodors eine Wende zwischen Kapitel 48 und 49 sieht: in letzterem sei im Gegensatz zu Kap. 48 nicht mehr von Räumen im Tempel, sondern von umliegenden Gebäuden die Rede. Die beschriebene Bibliothek sei folglich das "Lebenshaus", dessen Überreste er im Nordwesten der Magazingebäude des Ramesseums, genau in der Verlängerung der Tempelachse nach hinten, wiederzuerkennen glaubt. Die Details von Architekturteilen und Darstellungen, die Diodor aufzählt, entsprechen nach Meinung Derchains nicht den tatsächlichen Gegebenheiten, sondern sind Beschreibungen einer idealen Darstellung des "Lebenshauses", die er einem - nicht nachgewiesenen! - Buch etwa des Titels „,préceptes pour la décoration des parois de la maison de la vie" entnommen glaubt. $\mathrm{Zu}$ dieser Vermutung gelangte Derchain offenbar durch seine Bearbeitung des P. Salt 825 und die dort erhaltene ${ }^{191}$ Beschreibung eines (idealen?) ,Lebenshauses" in Abydos.

\section{Bemerkungen}

Es sind, wie sich gezeigt hat, zwei Wege, die auf der Suche nach dieser Bibliothek beschritten wurden; auf dem einen suchte man sie innerhalb des Hauptgebäudes, auf dem anderen in den umliegenden Bauten. Man kann diese beiden Möglichkeiten auch anders umschreiben: Im ersten Fall suchte man nach einem „Bücherhaus", im zweiten nach einem „Lebenshaus“, auch wenn dies teilweise nicht expressis verbis gesagt wurde. Da aber das „Lebenshaus" nicht innerhalb

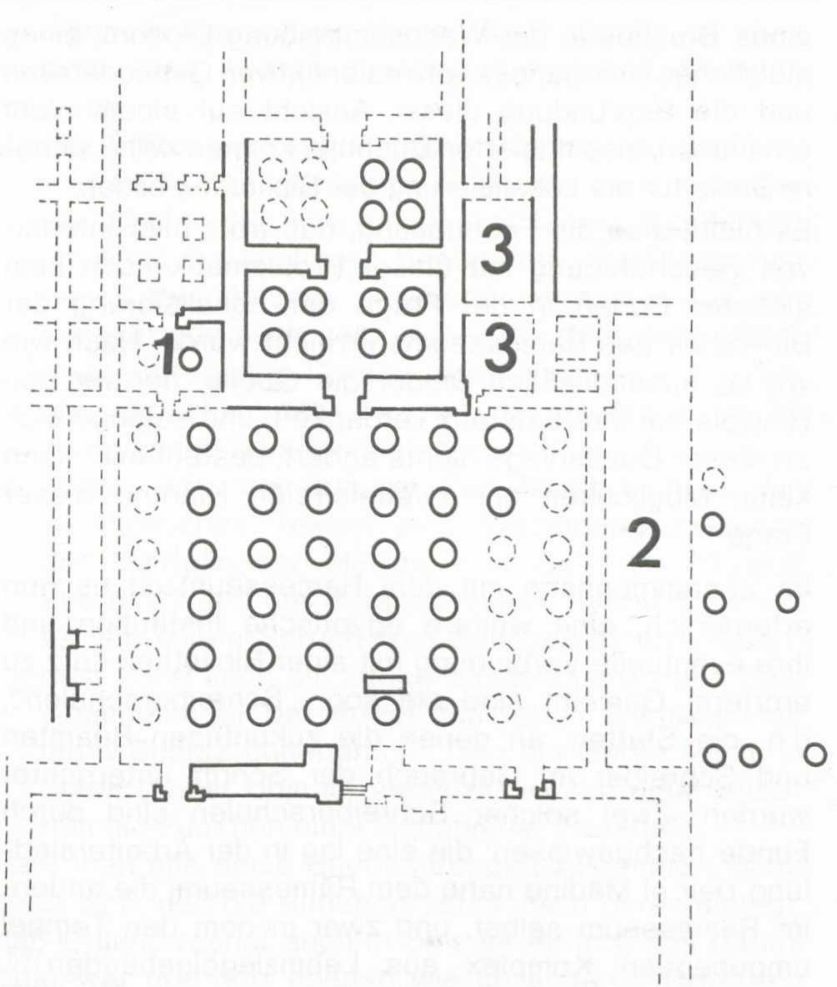

1. Die von Helck vermutete Bibliothek im Ramesseum.

2. Der Seiteneingang nördlich des Hypostyls.

3. Die vermuteten Bibliotheksräume.

Zeichnung von J. Hajnóczi

Abb. $3^{192}$

des Hauptgebäudes gelegen haben kann - dafür gibt es keinerlei Beleg -, ergibt sich diese Unterscheidung zwangsläufig.

Die erste Möglichkeit haben Helck und Wessetzky gewählt. Ihre Rekonstruktion des Weges, den Diodor zurücklegte, stimmt in weiten Teilen überein und divergiert nur im letzten, aber entscheidenden Punkt: der Frage der genauen Lage des Bibliotheksraumes. Ein Vergleich der beiden Argumentationen ergibt m.E. eine größere Plausibilität der Ansicht Wessetzky's, besonders aufgrund der oben genannten, aus den Darstellungen gewonnenen Indizien; aber, und das muß mit Nachdruck betont werden: Letzlich beweisen läßt sich keiner dieser Vorschläge, eine Entscheidung für eine der genannten Lösungen ist somit nicht möglich.

Die Rekonstruktion Derchains, so bestechend sie zunächst vielleicht erscheinen mag - vgl. auch den Vor-

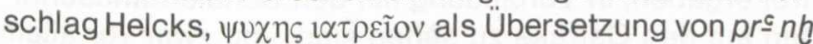
aufzufassen! -, weist dagegen zu viele Unbekannte auf, um beim derzeitigen Stand der Indizien ernsthaft in Erwägung gezogen werden zu können: Die Annahme

187 Helck, Wolfgang: Zum Grabmal des Osymandias, Diodor I, 47/9, in: Opus nobile, Festschrift zum 60. Geburtstag von Ulf Jantzen, hrsg. von Peter Zazoff. Wiesbaden 1969, S. 68ff.

188 (Anm. 187), S. 74; zu Helcks Lokalisierung s. den Plan in Abb. 3.

189 Wessetzky (Anm. 139), S. 54-59.

190 Derchain, Philippe: Le tombeau d'Osymandyas et la maison de la vie à Thèbes. In: Nachrichten der Akademie der Wissenschaften in Göttingen, I. Philologisch-historische Klasse 8 (1965), S. $165-171$.

191 s. oben S. 90

192 der Plan wurde der genannten Untersuchung Wessetzkyś (Anm. 139), S. 58 entnommen. 
eines Bruches in der Wegbeschreibung Diodors, eines plötzlichen Überganges von realenfiktiven Gebäudeteilen und die Begründung dieser Ansicht auf einem nicht erhaltenen, also fingierten Buchtitel können keine sichere Basis für die Lokalisierung der Bibliothek bilden.

Es bleibt also die Feststellung, daß trotz aller intensiven Beschäftigung mit dieser Problematik noch kein sicherer Boden in der Frage der Lokalisierung der Bibliothek des Ramesseums erreicht wurde. Nach wie vor ist ausschließlich Diodor die Quelle, der wir den Hinweis auf ihre Existenz verdanken, und solange sich an dieser Quellenlage nichts ändert, besteht m.E. auch keine Möglichkeit der zweifelsfreien Klärung dieser Frage.

Im Zusammenhang mit dem Ramesseum ist es nun erforderlich, eine weitere ägyptische Institution und ihre eventuelle Verbindung mit einer Bibliothek kurz zu erörtern: Gemeint sind die sog. „Schreiberschulen“, d.h. die Stätten, an denen die zukünftigen Beamten und Schreiber im Gebrauch der Schrift unterrichtet wurden. Zwei solcher Schreiberschulen sind durch Funde nachgewiesen: die eine lag in der Arbeitersiedlung Deir el Medine nahe dem Ramesseum, die andere im Ramesseum selbst, und zwar in dem den Tempel umgebenden Komplex aus Lehmziegelgebäuden ${ }^{193}$. Beide Schulen sind durch die dort in großer Zahl gefundenen Ostraka, die den Schülern als Beschreibstoff zu ihren Übungen dienten, sicher belegt. Die Ostraka erlauben darüber hinaus die Datierung dieser beiden Schulen in die 19.-21. Dynastie, also in das 13.-10. Jh. v. Chr. Die Texte, die diesen Schreibübungen als Vorlage dienten, sind vor allem literarischer und lehrhafter Natur und wurden großenteils schon im Mittleren Reich verfaßt, sind also etwa 500-700 Jahre älter.

Bei dieser Sachlage stellt sich die Frage, ob hier nicht ein Indiz für die Existenz von Bibliotheken vorliegt, denn diese Vorlagen müssen natürlich über den genannten Zeitraum hinweg aufbewahrt bzw. immer wieder neu kopiert worden sein. Hatten also diese Schreiberschulen eine eigene Bibliothek oder waren sie vielleicht dem "Lebenshaus" zugeordnet, das ja über eine eigene Bibliothek verfügte? Die letztere Möglichkeit, daß die Schreiber im "Lebenshaus" ausgebildet wurden, wird z.B. von Brunner ${ }^{194}$ erwogen, von anderen, z.B. von van de Walle ${ }^{195}$, verworfen.

Nun ist bereits im letzten Jahrhundert eine Reihe größerer Papyrushandschriften ${ }^{196}$ in europäische $\mathrm{Mu}$ seen gelangt, die, wie textkritische Indizien einwandfrei ergaben, in Verbindung mit den Schülerhandschriften auf den Ostraka zu sehen sind, und zwar vor allem denen des Ramesseums: Sie dienten als Schreibvorlagen für eine Reihe dieser Ostraka. Sind diese Papyri also als Teil der Bestände der Bibliothek dieser Schreiberschule oder gar der eines "Lebenshauses" anzusehen?

Doch so naheliegend der Gedanke auch sein mag, er muß verworfen werden: Diese Handschriften kennzeichnet ein gemeinsames Kriterium: Sie bieten zwar einen kompletten Text (abgesehen natürlich von im Laufe der Zeit entstandenen mechanischen Zerstörungen), sind aber über weite Passagen hin durch zahlreiche Entstellungen sinnlos und unverständlich. Sie können aus diesem Grunde nur dem Zweck gedient haben, als Vorlage für Schreibübungen verwendet zu werden. Dafür genügte ja, um es vereinfachend $\mathrm{zu}$ formulieren, ein fortlaufender Text mit jeweils sinnvollen Einzelwörtern, ohne Rücksicht auf einen ebenfalls sinnvollen Zusammenhang ${ }^{197}$.

Damit entfällt aber auch die Möglichkeit, in ihnen echte „Bibliothekshandschriften“ zu sehen, die womöglich sogar in einer so bedeutenden Institution, wie sie das „Lebenshaus" war, aufbewahrt wurden. Auch die Annahme der Existenz einer eigenen Bibliothek in den Schreiberschulen ist ohne zusätzliche Kriterien - und solche sind nicht bekannt - nicht zu rechtfertigen. Ein weiteres Indiz kommt hinzu: Diese großen Handschriften sind zum Teil auf die Rückseite von Verwaltungsurkunden o.ä. geschrrieben ${ }^{198}$. So ist wohl die plausibelste Erklärung, daß sie Privatkopien - von Schreiblehrern? - waren, nicht aber Bibliotheksexemplare ${ }^{199}$.

Es ist somit festzuhalten: Eine Verbindung zwischen der Schreiberschule und dem „Lebenshaus" und dessen Bibliothek ist ebenso wenig greifbar wie Indizien für eine eigene Bibliothek in der Schreiberschule, oder mit anderen Worten: Die nachgewiesene Existenz einer Schreiberschule kann kein Indiz für die Existenz einer Bibliothek sein. Auch von dieser Seite her gibt es also keine Möglichkeit, einer Bibliothek im Ramesseum auf die Spur zu kommen.

\section{Fazit}

Der sichere Nachweis der von Diodor erwähnten Bibliothek im Ramesseum ist nach wie vor nicht möglich. Von allen versuchten Lokalisierungen besitzt wohl der Vorschlag Wessetzky's die größte Wahrscheinlichkeit, besonders wegen der beiden genannten Darstellungen in unmittelbarer Nähe des von ihm vermuteten Bibliotheksraumes (der dann als „Bücherhaus “ zu definieren wäre); doch fehlt die letzte Sicherheit.

Keine gesicherte Basis hat auch Derchains Vorschlag, die Bibliothek in ein "Lebenshaus" zu verlegen und dieses hinter dem Tempelhauptgebäude zu suchen: Für ein "Lebenshaus" finden sich im Ramesseum keine Indizien, auch die sicher belegte Existenz einer Schreiberschule hilft in dieser Frage nicht weiter.

\section{Die ,Bibliothek des Königs Schepseskaf in Giza“}

\section{Quellenlage}

Im Grab eines Mannes namens Schepseskaf-anch in Giza $^{200}$ finden sich u.a. die folgenden Titel des Grabherrn: „Hausvorsteher des Großen Hauses und des

193 vgl. besonders van de Walle, Baudouin: La transmission des textes litteraires égyptiennes. Bruxelles 1948, S. 16 mit Anm. 15 ,

194 Brunner, Hellmut: Altägyptische Erziehung. Wiesbaden 1957, S. 28.

195 (Anm. 193), S. 13.

196 z.B. der schon erwähnte P. Anastasi I, P. Anastasi VII oder die beiden großen Papyri Sallier I und II, auf denen einige der bekanntesten Weisheitslehren erhalten sind. Faksimilia dieser Texte sind publiziert in: Select papyri in the hieratic character from the collections of the British Museum, with prefatory remarks by Samuel Birch. London 1841-1860 (P. Anastasi I und VII, P. Sallier II) und Budge, E.A.E. Wallis: Facsimiles of Egyptian hieratic papyri in the British Museum, 2nd series. London 1923 (P. Sallier I).

197 s. zu dieser Frage zuletzt Burkard (Anm. 148), bes. S. 318-322.

198 s. van de Walle (Anm. 193), S. 14.

199 vgl. auch oben S. 92

200 Grab Giza Nr. 16; zur Darstellung der zitierten Stelle s. Lepsius, Richard: Denkmäler aus Ägypten und Äthiopien II, Taf. 50 b. 
Hauses der Schriften“. Der Träger dieser Titel lebte, wie sein Name schon sagt, unter König Schepseskaf in der 4. Dynastie (um 2457-2450 v.Chr.), und seine Titulatur war schon früh Anlaß, diesem König eine Bibliothek zuzuschreiben, deren Bestände man sogar zu rekonstruieren versuchte. Doch hat schon Milkau festgestellt, daß die Stelle zwar als Indiz für die Existenz einer Bibliothek gelten kann, daß über deren Lokalisation und Bestände aber keine Angaben möglich $\operatorname{sind}^{201}$.

\section{Bemerkungen und Fazit}

Zusätzliche Indizien für die Lokalisierung dieser Bibliothek sind seither nicht bekanntgeworden, es bleibt also bei Milkaus Feststellung, daß wir mit dieser Quelle einen eindeutigen schriftlichen Beleg für die Existenz einer Bibliothek zumindest in der Zeit zwischen 2457 und 2450 v.Chr., also zu einem sehr frühen Zeitpunkt der ägyptischen Geschichte, besitzen, daß diese Bibliothek aber nicht zu lokalisieren ist.

Die Verwendung des Wortes „Haus der Schriften“ (ägyptisch pr ss') statt „Bücherhaus" ist kein entscheidendes Argument gegen die Annahme, daß wir es tatsächlich mit einer Bibliothek und nicht mit einem reinen Archiv zu tun haben. Das ergibt sich aus der Verwendung der beiden Begriffe nebeneinander für ein und dieselbe Institution auf der Stele des Neferhotep (s. oben S. 98 unter „Heliopolis“): Dort ist gesagt, daß im „Haus der Schriften" „Gottesworte“, also religiöse Schriften, aufbewahrt wurden, und das zeigt eindeutig, daß eine Bibliothek gemeint ist.

\section{Sais}

\section{Quellenlage}

Auf einer aus Sais stammenden Statue, die heute im Vatikan aufbewahrt wird ${ }^{202}$, berichtet der Eigentümer, der u.a. den Titel „Großer der Ärzte“" trägt, daß er von Darius (also während der ersten persischen Herrschaft in Ägypten im 5. Jh. v. Chr.) beauftragt worden sei, die zerstörten „Lebenshäuser" zu restaurieren. Leider sind keine einzelnen Orte genannt, in denen diese Arbeiten durchgeführt wurden. Man hatte ursprünglich eine zerstörte Stelle zu "Sais" ergänzt ${ }^{203}$, so daß der Schluß erlaubt schien, daß damit ein eindeutiger Beleg für die Existenz eines ,Lebenshauses" in Sais vorlag.

Doch hat Gardiner gezeigt ${ }^{204}$, daß diese Ergänzung aufgrund der erhaltenen Zeichenreste nicht möglich ist; er hat vielmehr klargestellt, daß, wie oben schon vermerkt, von "Lebenshäusern" in der Mehrzahl die Rede ist: Das bedeutet also, wenn man vom Wortlaut des Textes ausgeht, daß hier zwar kein direkter Beleg für ein bestimmtes „Lebenshaus“" vorliegt, daß aber in der Perserzeit eine in ihrer genauen Höhe unbekannte Anzahl dieser Institutionen in Ägypten existierte.

\section{Bemerkungen}

Die Möglichkeit eines direkten Beleges ist zwar durch Gardiners Untersuchung entfallen ${ }^{205}$, dennoch lassen sich einige Argumente aufzählen, durch die immerhin die Wahrscheinlichkeit aufgezeigt werden kann, daß in Sais ein ,Lebenshaus" bestand:

1. Es ist in Rechnung zu stellen, daß die Statue selbst aus Sais stammt; es wäre doch sehr überraschend, wenn ausgerechnet diese Stadt nicht von dem genannten Auftrag des Darius betroffen gewesen wäre.

2. Der Stifter der Statue, Udjahorresnet, war als Priester im Tempel der Göttin Neith von Sais und eben als "Großer der Ärzte" in Sais ansässig; die Medizin ist aber ein wichtiger Bestandteil der Disziplinen des ,Lebenshauses" - Udjahorresnet war aus diesem Grunde auch ganz sicher der geeignete Mann, den Auftrag des Darius auszuführen -: auch dies spricht dafür, daß wir mit der Existenz dieser Institution in Sais rechnen dürfen.

3. Schon aus viel früherer Zeit findet sich in den medizinischen Texten eine Verbindung zwischen der Disziplin der Medizin und Sais: Im Papyrus Ebers 1,2 und der Parallelstelle P. Hearst 6,6 heißt es von einem Spruch zum Auflegen eines Verbandes: „Und auch bin ich herausgekommen aus Sais zusammen mit der Mutter der Götter. Sie haben mir ihren Schutz gegeben."206 Und die Göttin Neith, in deren Dienst Udjahorresnet stand, hat unter anderem die Funktion einer Helferin der Frauen ${ }^{207}$.

Faßt man alle diese Beobachtungen zusammen, dann zeigt sich, daß die Annahme tatsächlich berechtigt ist, daß Udjahorresnet auch in Sais im Auftrag des Darius tätig war und dort ebenso wie an anderen Orten ein „Lebenshaus" restaurierte.

Eine Unterstützung dieser Vermutung von archäologischer Seite ist freilich vorläufig nicht möglich: Sais liegt im Ostdelta, also mitten im Fruchtland, so daß an baulichen Resten wenig erhalten und dieses Wenige auch noch teilweise unerforscht ist.

\section{Fazit}

Auch wenn nach Gardiners Untersuchungen ein direkter inschriftlicher Beleg für die Existenz eines „Lebenshauses" in Sais nicht mehr vorhanden ist, kann doch mit einiger Wahrscheinlichkeit angenommen werden, daß in der Zeit um die erste Perserherrschaft in Ägypten, also im 6. und 5. Jh. v.Chr., eine solche Institution an diesem Ort bestand. Wie lange dieses „Lebenshaus" allerdings vor seiner Zerstörung und nach seiner Restaurierung in Funktion war, ist nicht mehr festzustellen; doch scheint eine der dort gepflegten Disziplinen, die Medizin, nach Ausweis der medizinischen Papyri ${ }^{208}$ eine lange Tradition in Sais besessen zu haben.

\section{snw.t-Heiligtum}

Das sog. snw.t-Heiligtum war ein vermutlich sehr altes ägyptisches Reichsheiligtum, das im Alten und viel-

201 s. Milkau (Anm. 2), S. 8.

202 ausführlich publiziert von Posener, Georges: La première domination Perse en Egypte. Le Caire 1936, S. 1-26.

203 so z.B. Posener (Anm. 202), S. 23, Anm. g.

204 (Anm. 16), S. 158-159.

205 Siegfried Schott spricht (Anm. 138), S. 21 zwar nochmals davon, er hat aber offenbar Gardiners Darlegung, obwohl er sie a.a.O. zitiert, nicht berücksichtigt.

206 vgl. von Deines, Hildegard; Grapow, Hermann; Westendorf, Wolfhart: Übersetzung der medizinischen Texte. Berlin 1958, S. 308.

207 vgl. Kees, Hermann: Ägypten. München 1933, S. 307.

208 der Papyrus Ebers wie der Papyrus Hearst stammen aus dem Anfang der 18. Dynastie (vgl. Möller, Georg: Hieratische Paläographie, erster Band. Leipzig 1909, S. 29), also aus dem 16. Jh. v.Chr. 
leicht im Mittleren Reich wohl noch konkret existierte, später aber nur noch im zeremoniellen Gebrauch als Name fortlebte 209 . In einer Untersuchung zu einem Teilaspekt dieses und anderer Reichsheiligtümer geht Kees auch der Frage nach, wo das snw.t-Heiligtum zu lokalisieren sei - archäologische Spuren sind nicht gefunden worden - und vermutet aufgrund einiger Indizien, daß Heliopolis der gesuchte Ort sei ${ }^{210}$. Da sich diese Vermutung nicht eindeutig belegen läßt, wurde dieses Heiligtum hier unter seinem ägyptischen Namen und unter Verzicht auf eine Lokalisierung aufgenommen.

\section{Quellenlage}

Von den recht zahlreichen Belegen für das snw.tHeiligtum sind die folgenden für die hier interessierende Fragestellung von Bedeutung:

1. Urk. I,245,6: Auf dem sog. „Palermostein“, auf dem in der 5. Dynastie die Jahresannalen seit der 1. Dynastie zusammengestellt wurden, ist im 1. Regierungsjahr des Sahure (5. Dynastie, um 2442 v.Chr.) ein "Gottesbücherhaus des snw.t-Heiligtums" erwähnt.

2. Urk. I,246,10ff.: In einer Inschrift aus dem 1. Regierungsjahr des Neferirkare (5. Dynastie, um 2430 v.Chr.) wird ebenfalls das "Gottesbücherhaus des snw.t-Heiligtums" genannt, dessen Götter mit Ländereien beschenkt werden.

3. Von einem Beamten, der unter Teti und Pepil. diente (6. Dynastie, zwischen ca. 2290 und 2228 v.Chr.), ist in seinem Grab u.a. der Titel „Vorsteher der Geheimnisse des Gottesbücherhauses des snw.t-Heiligtums" erhalten ${ }^{211}$.

4. Helck hat darauf hingewiesen, daß im Alten Reich eine enge Verbindung zwischen dem Titel eines "Vorstehers des snw.t-Heiligtums" und dem eines "Schreibers des Gottesbuches" bestand, d.h. daß beide Titel oft von der gleichen Person geführt wurden. Er erklärt diese enge Verbindung durch die Existenz einer Bibliothek in diesem Heiligtum ${ }^{212}$.

\section{Bemerkungen}

Die aufgeführten Belege sind eindeutig: Dem snw.tHeiligtum war eine Bibliothek zugeordnet, zumindest in der 5. und 6. Dynastie, dem Zeitraum, aus dem die oben genannten Belege stammen. Sicher wird diese Bibliothek solange bestanden haben, wie das Heiligtum selbst existierte, doch sind aus früherer und späterer Zeit bisher keine Belege bekannt, die diese Vermutung bestätigen.

Von besonderem Interesse ist zweifellos Quelle Nr. 2 mit der Nachricht, daß die Bibliothek speziell - d.h. nicht nur im Rahmen allgemeiner Stiftungen für den Tempel als Ganzes - mit Ländereien beschenkt wurde, die natürlich, wie üblich, für die Versorgung des Personals, d.h. unter anderem wohl auch der in Quelle Nr. 4 genannten „Schreiber des Gottesbuches“, gedacht waren.

\section{Fazit}

Die Existenz einer Bibliothek im - nicht sicher zu lokalisierenden - snw.t-Heiligtum ist für die 5. und 6. Dynastie durch inschriftliche Belege gesichert. Für die Zeit vor und nach dieser Epoche sind bisher keine entsprechenden Quellen bekannt, doch ist die Vermu- tung zulässig, zumindest für die unmittelbar vorausgehende und folgende Zeit den gleichen Sachverhalt vorauszusetzen.

\section{Soknopaiu Nesos}

\section{Quellenlage}

Aus Soknopaiu Nesos, dem heutigen Dime, stammt eine Gruppe demotischer Papyri verschiedenartigen Inhalts; diese Papyri bilden zusammen mit einer Handschriftengruppe aus Krokodilopolis einen Bestandteil der Sammlung der Österreichischen Nationalbibliothek. Ihr Inhalt, ihre Herkunft und die von Reymond erarbeiteten Indizien, die sie als Reste von Bibliotheksbeständen ausweisen, wurden bereits oben S. 101 unter „Krokodilopolis" erörtert, hier genügt daher der Hinweis auf diese Stelle.

\section{Bemerkungen}

Für die Existenz einer Bibliothek in Soknopaiu Nesos sprechen die bereits oben für die Bibliothek in Krokodilopolis erörterten überzeugenden Indizien. Auch wenn im stark zerstörten Areal des örtlichen Tempels keine sicher identifizierbaren baulichen oder inschriftlichen Reste gefunden wurden, führt das Spektrum der erhaltenen Textgattungen $\mathrm{zu}$ dem eindeutigen Schluß, daß die von dort stammenden Wiener Papyri die Reste der Bestände der Bibliothek (des „Lebenshauses"?) des dortigen Tempels sind.

Ebenso wie in Krokodilopolis wurden im übrigen auch in Soknopaiu Nesos zusammen mit den genannten literarischen, religiösen und naturwissenschaftlichen Papyri auch Reste der Archive des Tempels gefunden, vgl. hierzu zuletzt Edda Bresciani, l'archivio demotico del tempio di Soknopaiu Nesos nel Griffith Institute di Oxford, vol. I, Milano 1975: Die Verbindung der Bibliothek mit dem Tempel wird somit auch an diesem Ort deutlich.

\section{Fazit}

Am Ende der griechischen und in der römischen Zeit Ägyptens, also zwischen dem 1.Jh. v. Chr. und dem Ende des 2. Jh. n. Chr. ${ }^{213}$ hat im Tempelareal von Soknopaiu Nesos eine Bibliothek existiert, möglicherweise als Bestandteil eines „Lebenshauses"214. Diese Feststellung gründet sich auf der Auffindung von Papyri in diesem Gebiet, die anhand verschiedener Kriterien eindeutig als Reste von Beständen einer Bibliothek bestimmt werden konnten.

209 s. Bonnet (Anm. 122), S. 631, s.v. Reichsheiligtum.

210 s. Kees, Hermann: Die Schlangensteine und ihre Beziehungen zu den Reichsheiligtümern. In: Zeitschrift für ägyptische Sprache und Altertumskunde 57 (1922), S. $120 \mathrm{ff}$.

211 s. James, T.H.G.: The mastaba of Khentika called Ikheki. London 1953, pl. V.

212 Helck, Wolfgang: Untersuchungen zu den Beamtentiteln des ägyptischen Alten Reiches, Glückstadt 1954, S. 38.

213 vgl. oben S. 101: Soknopaiu Nesos wurde vor dem 3. Jh. n. Chr. aufgegeben.

214 für diese Vermutungen gelten die gleichen Einschränkungen wie oben S. 101 für Krokodilopolis. 


\section{Tebtynis}

\section{Quellenlage}

1. Aksel Volten hat über die Papyrussammlung des ägyptologischen Instituts der Universität Kopenhagen berichtet, die aus einem Fund, und zwar aus Tebtynis im Faijum stammt ${ }^{215}$. Die Fragmente sind nach Volten meist in das 1. Jh. n. Chr. zu datieren, die Schrift ist hieratisch und demotisch, teilweise sind griechisch geschriebene Glossen erhalten. Der Kopenhagener Bestand ist auf wenigstens 200 literarische und wissenschaftliche Texte zu schätzen, im einzelnen enthält er folgende Textgattungen: Hieratisch bzw. hieroglyphisch geschrieben sind ein astronomischer Text (mit demotischem Kommentar), Onomastica ${ }^{216}$, Rituale für den Krokodilgott Suchos und weitere, noch nicht identifizierte Texte; demotisch geschrieben sind Orakelfragen, Listen, Verträge Privatbriefe, Weisheitslehren, literarische Texte (darunter so berühmte wie der „Setne-Roman“ und Erzählungen aus dem „Sagenkreis des Königs Petubastis"), hermetische Texte, Traumdeutungen, medizinische Texte u.a.m. Von besonderer Bedeutung für die hier zugrundeliegende Fragestellung ist, daß Volten ausdrücklich erwähnt, daß sich unter den Fragmenten literarischer und naturwissenschaftlicher demotischer Texte auch Duplikate befinden. Für Volten besteht kein Zweifel, daß diese Fragmente ursprünglich zu einer Tempelbibliothek gehört haben müssen.

2. Eine weitere Gruppe von Texten in hieratischer, demotischer und teilweise auch griechischer Schrift hat W.J. Tait veröffentlicht ${ }^{217}$. Sie stammen seinen Angaben zufolge in überwiegender Mehrzahl aus dem 2. Jh. n. Chr. Ihre inhaltliche Bandbreite entspricht der der Kopenhagener Sammlung, s. oben. Für Tait gibt es keinen Zweifel, daß diese Fragmente aus dem Tempelareal von Tebtynis stammen. Besonders ein hieratisch geschriebenes Fragment, das offenbar das Bruchstück eines Tempeltagebuches ist ( $P$. Tait 32, Tait a. a. O. S. 88 und pl. 7), spricht denn auch sehr deutlich für diese Annahme.

\section{Bemerkungen}

Wie in Krokodilopolis und in Soknopaiu Nesos sind auch in Tebtynis keine architektonischen oder inschriftlichen Indizien für die Existenz einer Bibliothek erhalten, dennoch ist auch hier der Befund eindeutig: Die Bandbreite der Texte, die Fundzusammenhänge (Archivalien und Texte der aufgezählten Gattungen), die durch Einzelindizien zu belegende Verbindung mit dem örtlichen Tempel sind klare Belege für eine Bibliothek. Großes Gewicht ist außerdem der Beobachtung zuzumessen, daß in Tebtynis Duplikate von Texten (,Mehrfachexemplare“!) gefunden wurden. Es sei hier noch ausdrücklich angemerkt, daß die große Anzahl griechischer Tebtynis-Papyri, die Grenfell, Hunt und andere in vier Bänden veröffentlicht haben ${ }^{218}$, nicht im Zusammenhang mit den oben besprochenen Papyrusfunden und damit auch nicht mit der Tempelbibliothek stehen: Nach den Angaben der Editoren ${ }^{219}$ stammen die von innen publizierten Papyri aus wiedergewonnener Mumienkartonage und aus Privathäusern der Siedlung von Tebtynis.

\section{Fazit}

Im ersten und zweiten Jahrhundert n. Chr. existierte im Tempelbezirk des Suchos-Tempels von Tebtynis eine Bibliothek. Diese ist sowohl in ihrer chronologischen Einordnung wie auch in der Art ihrer Bestände mit den Bibliotheken von Krokodilopolis und Soknopaiu Nesos zu vergleichen, d.h. vermutlich einem "Lebenshaus" zuzurechnen; diese drei genannten Bibliotheken, die im übrigen jeweils Heiligtümern des Gottes Suchos zugeordnet waren, bilden gleichzeitig die jüngsten Zeugnisse, die wir über altägyptische Bibliotheken besitzen. Gleich spät zu datieren ist nur noch das „Bücherhaus" auf Philae, das aber wohl einen anderen Bibliothekstyp, eben das „Bücherhaus", repräsentiert. Ob und wie lange die Bibliothek in Tebtynis vor dem 1. Jh. n. Chr. und nach dem 2. Jh. n. Chr. bestand, ist derzeit nicht zu ermitteln ${ }^{220}$

\section{Tôd}

\section{Quellenlage}

Im Verlaufe französischer Grabungen in Tôd in den Jahren 1934-1936 wurden in den Trümmern des dortigen Tempels auch einige aus ptolemäischer Zeit stammende Blöcke gefunden, die die Reste einer Bücherliste enthalten. Sie befanden sich nicht mehr an ihrem primären Standort, sondern waren in koptischer Zeit für einen Kirchenbau wiederverwendet worden. Sie gehörten ursprünglich, wie Bisson de la Roque in der Publikation der Grabungsergebnisse berichtet $^{221}$, zu einem in ptolemäischer Zeit dort errichteten Tempelbau, vermutlich zu einer der Räumlichkeiten der Vorhalle. Ihre genaue Lokalisation ist nicht mehr möglich, da die Zerstörungen so stark sind, daß der Grundriss des Tempels nicht mehr vollständig rekonstruierbar ist. Bisson kündigt die Publikation der Bücherliste in einem eigenen Band „inscriptions" an ${ }^{222}$, der aber bisher nicht erschienen ist.

Doch hat Sauneron einige Buchtitel wenigstens in französischer Übersetzung bekannt gemacht; er nennt die folgenden: „L'entrée du dieu Montou à Thèbes; rituel de compléter l'oeil d'Horus; livre des (offrandes) sur l'autel; (livre) du temple d'Amon; livre de fête de Thot, (livre) du temple de Khonsou; ritùel de la fête de la victoire; rituel pour la naissance du dieu." 223

\section{Bemerkungen}

Der Befund zeigt eindeutig, daß hier eine Parallele zum „Bücherhaus“ in Edfu vorliegt: Die Blöcke stammen aus ptolemäischer Zeit, die bisher bekannten Titel entsprechen denen der Gruppen 1 und 2 der

215 the papyrus-collection of the egyptological institute of Copenhagen. In: Archiv Orientalni 19 (1951), S. 70-74.

216 inzwischen publiziert von Iversen, Erik: Papyrus Carlsberg Nr. VII, fragments of a hieroglyphic dictionary. Kobnhavn 1958.

217 papyri from Tebtunis in Egyptian and in Greek (P. Tebt. Tait). London 1977.

218 the Tebtunis papyri, ed. by Bernard B. Grenfell, Arthur S. Hunt u.a. London $1902 \mathrm{ff}$.

219 (Anm. 218), Band I und II, S. V; Band IV, S. 1

220 zur genuin ägyptischen Tradition, in der diese Bibliotheken standen - trotz ihrer späten Datierung - vgl. oben S. 101 zu Krokodilopolis".

221 Tôd (1934 à 1936). Le Caire 1937, bes. S. 5, 12-13.

222 (Anm. 221), S. 156.

223 Sauneron, Serge: Les prêtres de l'ancienne Egypte. Paris 1962 S. $136-137$ 
Edfu-Listen (s. dazu oben S. 85): In Tôd existierte in ptolemäischer Zeit ein „Bücherhaus“, dessen Bestandsliste in seine Wände eingraviert war, und das, wie die Art der Titel zeigt, die gleiche Funktion besessen haben muß wie das "Bücherhaus" in Edfu. In Tôd liegt somit, wenn auch in etwas eingeschränkter Form, der oben S. 91 skizzierte Idealfall des Nachweises einer Bibliothek vor: Die Einschränkung betrifft dabei die Tatsache, daß die Zerstörungen eine exakte Lokalisation des Raumes innerhalb des Tempels nicht mehr ermöglichen. Doch ist aufgrund der Parallelen zu Edfu mit Bisson anzunehmen, daß dieses „Bücherhaus" sich etwa an entsprechender Stelle, d. h. in einer der Vorhallen des Tempels, befand.

\section{Fazit}

Im Tempel von Tôd existierte in ptolemäischer Zeit ein „Bücherhaus", wie durch einige - leider nicht mehr in situ aufgefundene - Blöcke dieses Gebäudeteils, die Reste einer Bücherliste enthalten, zweifelsfrei festgestellt werden konnte. Wie die bisher bekannten Titel dieser Bücherliste zeigen, entsprach dieses „Bücherhaus" in der Funktion - und somit wohl auch zumindest annähernd in der Lokalisation - dem aus der gleichen Epoche stammenden „Bücherhaus“ von Edfu.

\section{Ergebnisse und Perspektiven}

Die im dritten Kapitel durchgeführte praktische Anwendung der im zweiten Kapitel erarbeiteten Methodik führte zu einem Ergebnis, das die Situation der Bibliotheksforschung in Ägypten in einem doch um einiges positiveren Licht erscheinen läßt, als dies zu der Zeit der Fall war, da Milkau sich mit dieser Problematik befaßte. Obwohl in diesem Rahmen, wie schon mehrmals gesagt wurde ${ }^{224}$, nicht die Absicht (und auch nicht die Möglichkeit) bestand, Vollständigkeit anzustreben, sondern vor allem die Gangbarkeit des vorgeschlagenen Weges gezeigt werden sollte, ist das Resultat schon von den Zahlen her durchaus erfreulich: Hatte Milkau nur fünf Orte bzw. Namen nennen und dabei nur in zwei Fällen (Edfu und Philae) auf einigermaßen eindeutige Fakten verweisen können, hat sich die Zahl jetzt auf zwanzig erhöht. In 15 dieser Fälle war die Existenz von Bibliotheken mit Sicherheit oder zumindest mit sehr hoher Wahrscheinlichkeit zu belegen, wobei in zwei Fällen (Abydos und Edfu) sogar der Nachweis von je zwei Bibliotheken, eines „Lebenshauses" und eines „Bücherhauses" am gleichen Ort möglich war. Von den fünf verbliebenen Fällen betreffen drei Orte, für die Indizien zwar vorhanden sind, letzte Sicherheit aber nicht gewonnen werden konnte: Dendera, Karnak und das Ramesseum; nur in zwei Fällen, in denen Andere die Existenz von Bibliotheken vermutet hatten (die „Bibliothek Amenophis' III.“ und die „Bibliothek im Gedächtnistempel Pepi's II."), blieb das Resultat negativ.

Die Tendenz ist somit eindeutig: Die Ergebnisse, die Milkau erarbeitet und die er selbst „eine ziemliche Enttäuschung "genannt hatte 225 , sind durch die Forschung überholt, es ist heute möglich, erheblich mehr Bibliotheken nachzuweisen als dies vor vier Jahrzehnten der Fall war, und die sorgfältige Suche nach weiteren Belegen und Indizien wird ihre Zahl ganz sicher noch vergrößern.

Trotz der Vorläufigkeit der oben genannten Zahlen ist es von Interesse, nun noch kurz die geographische und chronologische Verteilung der Bibliotheken zu betrachten. Die geographische Verteilung wird aus den beiden Karten im Anhang ersichtlich, die oben im 3. Kapitel besprochenen Orte sind durch doppelte Unterstreichung gekennzeichnet.

Die chronologische Verteilung wird aus der Tabelle in Abb. 4 auf S. 109 ersichtlich. In diesem Schema sind nur die 15 Orte bzw. Namen zugrundegelegt, bei denen sichere und fast sichere Belege für die Existenz von Bibliotheken vorhanden sind. Die zeitliche Gliederung ist dabei nur grob nach den größeren Epochen vorgenommen; eine feinere Unterscheidung ist für diesen Überblick nicht erforderlich und in den meisten Fällen, wie sich gezeigt hat, auch gar nicht oder nur sehr schwer möglich.

Zunächst zur geographischen Übersicht: Hier zeigt sich eine recht gleichmäßige Verteilung Bibliotheken über das ganze Land, entsprechend der Verteilung der religiösen Einrichtungen, mit denen sie in der Regel in Verbindung standen. Eine Konzentration z. B. auf politische Zentren, wie sie an sich ja auch denkbar wäre, ist nicht zu beobachten; für die beiden Hauptstädte Memphis (Altes und Mittleres Reich) und Theben (bes. Neues Reich) ist im übrigen noch gar kein sicherer Beleg bekannt, obwohl man natürlich davon ausgehen muß, daß gerade dort Bibliotheken existiert haben.

Das scheinbare Fehlen von Bibliotheken im Nildelta hat rein "mechanische" Gründe: Die Deltastädte sind heute meist im Fruchtland, d. h. im Grundwasser versunken, die archäologischen Überreste sind daher in der Regel sehr spärlich und ein Nachweis von Bibliotheken somit nur ausnahmsweise möglich.

Das chronologische Schema muß zunächst ebenfalls „,bereinigt" werden: Es war von vornherein zu erwarten, daß die Mehrzahl der Belege aus der jüngsten Epoche der ägyptischen Geschichte stammt, da aus dieser Zeit auch die meisten archäologischen und inschriftlichen Überreste erhalten sind. Dementsprechend hat das Abnehmen der Zahl der Belege nach rückwärts rein äußerliche Gründe: Es kann kein Indiz für die Existenz von weniger Bibliotheken, sondern nur für die sich verschlechternde Nachweismöglichkeit sein. Besonders deutlich zeigt sich das für das Mittlere Reich, aus dem insgesamt - im Vergleich zu den übrigen Epochen - nur wenige archäologische Überreste erhalten sind; entsprechend negativ ist der Befund für die Suche nach Bibliotheken. Auch daß vor dem Neuen Reich kein "Lebenshaus" bekannt ist, muß als Zufall der Überlieferung gelten, das Wort $\mathrm{pr}^{\mathrm{c}}{ }^{\mathrm{C}} \mathrm{nh}$ ist zumindest seit dem Mittleren Reich geläufig, vgl. die Belege Gardiners in: JEA 24, 1938.

Insgesamt läßt sich also feststellen, daß selbst in einem ersten vorläufigen Überblick Bibliotheken zu allen Zeiten und über das ganze Land verteilt nachgewiesen werden können, wobei in den der Spätzeit vorausgehenden Abschnitten wegen der ungünstigeren Beleglage die Lücken größer sind. Über diese grundsätzliche Feststellung hinausgehende Einzelan-

224 s. oben S. 80 und 92

225 (Anm. 2), S. 16. 


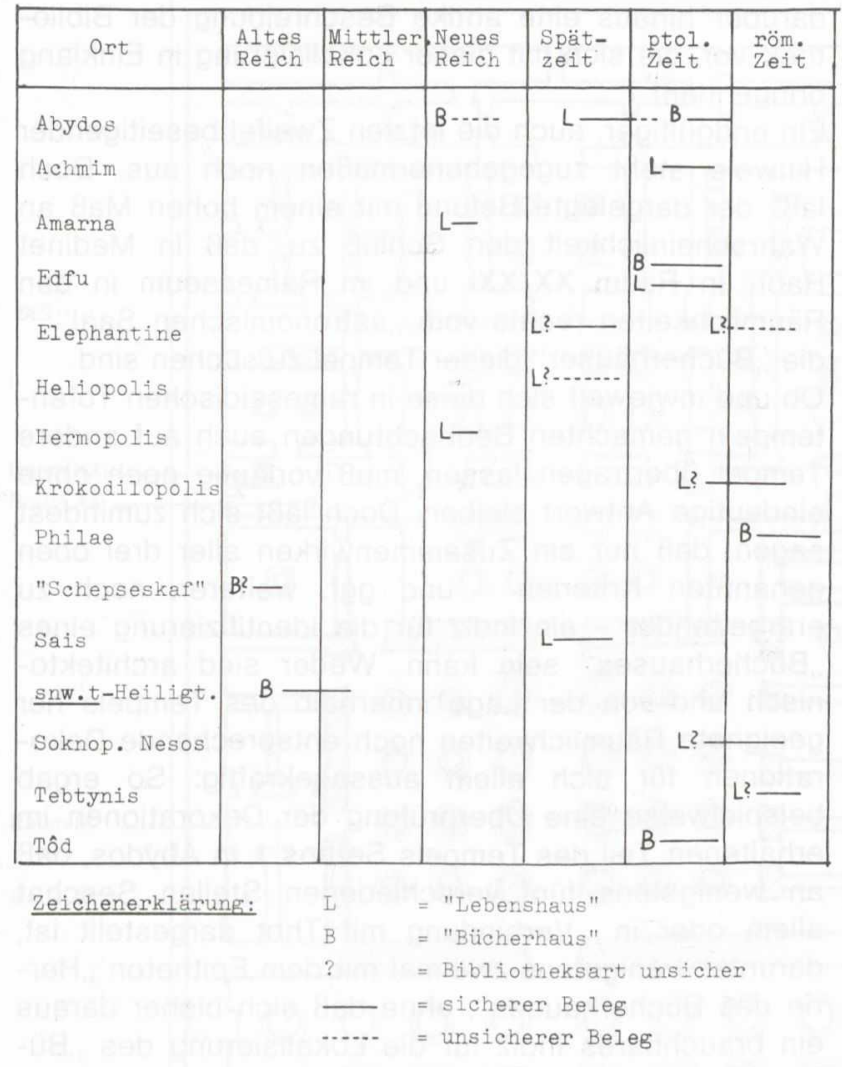

Abb. 4: Chronologische Übersicht

gaben bezüglich Zahl und Verteilung der Bibliotheken in den verschiedenen Epochen sind allerdings zumindest derzeit noch nicht möglich.

Um aber in dieser und in anderen Detailfragen Fortschritte zu erzielen, ist es zunächst erforderlich, nach weiteren Belegen für Bibliotheken zu suchen; eine Auswertung aller verfügbaren Quellen wird, das ist sicherlich keine gewagte Prognose, die Zahl der bekannten Bibliotheken noch erhöhen. Erst wenn dann eine möglichst breite Basis erarbeitet ist, können die übrigen Fragen in Angriff genommen werden. Diese müssen z. B. der möglichst genauen Differenzierung der einzelnen Bibliothekstypen gelten, ihrer Organisation, ihren Beständen, der Art der Aufbewahrung der Papyrusrollen, den Titelverzeichnissen ${ }^{226}$, dem Personal der Bibliotheken usw. All diese genannten Aufgaben sind im Laufe der Zeit sicherlich lösbar und die Ergebnisse können uns dann ein erheblich klareres Bild vom ägyptischen Bibliothekswesen vermitteln, als wir es derzeit besitzen.

\section{Nachtrag}

Während zweier Aufenthalte in Ägypten im Oktober 1979 und Anfang Januar 1980 war es mir möglich, die Problematik der Lokalisierung insbesondere der „Bücherhäuser" in einigen Tempeln des Neuen Reiches an Ort und Stelle zu studieren. Die dabei gewonnenen Beobachtungen sind im folgenden zusammengefaßt.

Ausgangspunkt der Untersuchungen waren einmal das oben S. $102 \mathrm{ff}$. bereits ausführlich besprochene Ramesseum, der Totentempel Ramses' ll., da von inm bei Diodor ein eindeutiger antiker Hinweis auf die Existenz einer Bibliothek erhalten ist. Zum anderen wurde der erheblich besser erhaltene Totentempel des unmittelbaren Nachfolgers, Ramses'lll., in Medinet Habu in die Untersuchung einbezogen, da diese Tempelanlage eine weitgehende bauliche Übereinstimmung mit dem Ramesseum aufweist ${ }^{227}$; denn gerade die entscheidenden Räumlichkeiten des Ramesseums, die Räume rechts und links vom ,astronomischen Saal", in denen Helck und Wessetzky das „Bücherhaus" lokalisieren möchten, sind leider bis auf die Grundmauern zerstört, so daß archäologische Indizien von dort mit Sicherheit nicht mehr zu erwarten sind.

Bereits Helck hat die vergleichbaren Räumlichkeiten in Medinet Habu herangezogen ${ }^{228}$ und sah, analog zu seiner Lokalisierung des „Bücherhauses“ im Ramesseum im zweisäuligen Raum südlich des ,,astronomischen Saales", die Räume Nr. IX/XI (s. Abb. 5) als möglichen Standort der Bibliothek an. Er legte sich dabei freilich mit der Formulierung: ,es wird sich um die Kammern handeln, die ... die Nummern IX/XI tragen", nicht eindeutig fest.

Ohne nun meinerseits eine definitive Antwort geben zu können, möchte ich einen anderen Vorschlag zur Diskussion stellen, der meines Erachtens durch das Zusammenwirken der folgenden Beobachtungen einen höheren Grad an Plausibilität beanspruchen darf:

1. Wie die erhaltenen „Bücherhäuser" der griechischrömischen Zeit zeigen, sollten dort offensichtlich nur die für die Durchführung der Kulthandlungen erforderlichen Buchrollen aufbewahrt werden. Dazu genügte ein kleiner Raum, und tatsächlich sind die Räume in Edfu und Philae auch sehr klein. Die Räume nun, in denen Helck in Medinet Habu und besonders im Ramesseum die Bibliothek sehen möchte, erscheinen demgegenüber unnötig groß; hier mag Helcks Vermutung, es habe sich jeweils um das "Lebenshaus" gehandelt ${ }^{229}$, - das natürlich ganz anders dimensioniert sein müßte - eine Rolle gespielt haben. Doch kommt, wie oben ausgeführt ${ }^{230}$, eine Lokalisierung des „Lebenshauses“" innerhalb des eigentlichen Tempelgebäudes sicher nicht in Betracht.

Aus dieser Sicht gewinnt somit Wessetzky's Vorschlag ${ }^{231}$, die Bibliothek im Ramesseum in kleineren Räumen rechts des ,astronomischen Saales" zu suchen, an Wahrscheinlichkeit.

2. Die ägyptischen Tempel waren prinzipiell in allen Räumen, also auch in den Nebenkammern und Magazinen, mit Darstellungen und Inschriften versehen. Sehr häufig - wenn auch nicht immer und nicht als Bedingung - ist nun ein Bezug zwischen der Zweckbestimmung der jeweiligen Räume und den Darstellungen erkennbar, vgl. Arnold, Dieter: Wandrelief und Raumfunktion in ägyptischen Tempeln des Neuen Reiches. Berlin 1962 (Münchner Ägyptologische Studien, 2). So waren z. B. in den Schatzkammern der

226 eine Zusammenstellung dieser Verzeichnisse, die, wie in Edfu und Tôd, teils auf den Wänden der „Bücherhäuser" erhalten sind, teils auf Papyri, hat Manfred Weber in: Beiträge zur Kenntnis des Schrift- und Buchwesens der alten Ägypter. Köln 1969, S. $127 \mathrm{ff}$ vorgenommen. Eine weitere Liste enthält der Weber noch nicht zugängliche unveröffentlichte Papyrus Berlin 15779 aus der 20.21. Dynastie, der damit mit Abstand des älteste Exemplar dieser Gattung bildet: die von Weber zusammengestellten Listen stammen alle aus der Spätzeit bzw. griechisch-römischen Zeit.

227 vgl. Helck (Anm. 187), S. 73

228 a.a.O. S. 74.

229 s. oben S. 103

230 z.B. S. 103

231 s. oben S. 103 
Tempel die dort aufzubewahrenden Gegenstände häufig auch an den Wänden dargestellt.

Daraus ergibt sich, daß, wenn schon das „Bücherhaus" nicht direkt als solches gekennzeichnet ist, ggf. Darstellungen Hinweise auf seine Lokalisierung geben $\mathrm{können.} \mathrm{Besonders} \mathrm{wichtig} \mathrm{erscheint} \mathrm{in} \mathrm{diesem}$ Zusammenhang auch die Beobachtung Arnolds, daß manchmal die Darstellungen nicht auf den jeweiligen Raum selbst hinweisen, sondern schon auf die Funktion eines nahegelegenen Raumes; sie befinden sich dann gewöhnlich in der Umgebung der Türe, die in diesen Raum hinausführt ${ }^{232}$.

3. Man darf wohl a priori davon ausgehen, daß die Lage der Tempelbibliothek nicht willkürlich, sondern entsprechend den kultischen Erfordernissen gewählt wurde. Dies ist z. B. in Edfu der Fall, wo sich das „Bücherhaus" in der Nähe der Räumlichkeiten befindet, in denen der Kult vollzogen wurde, d. h. in der Nähe der hinteren Tempelhälfte.

Mit diesen drei Beobachtungen als Grundlage erbrachte die Untersuchung der Räumlichkeiten im Tempel von Medinet Habu folgendes Ergebnis:

Im 2. hypostylen Saal führt in den beiden Seitenwänden jeweils ein Durchgang zu einer Reihe kleinerer

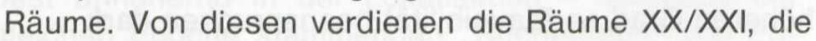
auf der linken Seite liegen, besonderes Interesse: Ursprünglich einem Raum wurde sekundär, aber noch zu Lebzeiten Ramses'lll., durch Einziehung einer Zwischenmauer ein zweiter, kleinerer Raum abgeteilt (s. den Plan). Dort nun, bei $a$, findet sich die Darstellung Ramses'lll., der vor einem Persea-Baum zwischen den Göttern Amun und Thot kniet; beide Götter schreiben den Namen des Königs auf Blätter dieses Baumes. Ebenfalls in Raum XX, bei $b$, ist der König mit der Göttin Seschat dargestellt. Sowohl Thot wie auch Seschat stehen in enger Verbindung mit dem Schreibwesen, Thot ist u. a. "Herr der Bücher", Seschat u. a. „Herrin des Bücherhauses".

Damit ergibt sich für Raum $\mathrm{XX} / \mathrm{XXI}$ der folgende Befund:

Es handelt sich um eine kleine Räumlichkeit, die in der Nähe der hinteren Räume des Tempels liegt und deren Dekoration einen deutlichen Bezug zum Schriftund Buchwesen erkennen läßt. Es spricht somit einiges für die Möglichkeit, daß das „Bücherhaus“ dieses Tempels hier zu suchen ist.

Leider sind die Darstellungen des Thot und insbesondere der Seschat so stark zerstört, daß sich kein zusätzlicher Hinweis durch ein Epitheton, etwa "Seschat, Herrin des Bücherhauses" erhalten hat. Doch kann hier ein Vergleich mit entsprechenden Räumlichkeiten des Ramesseums weiterhelfen, wo zwar nicht die Räumlichkeiten selbst, dafür aber die Darstellungen von Thot und Seschat - letztere mit dem Epitheton "Herrin des Bücherhauses" - erhalten sind, s. dazu oben S. 103.

Zusammenfassend läßt sich also sagen: In beiden Tempeln finden sich Räumlichkeiten, die von ihrer Größe und ihrer Lage innerhalb der Anlage her geeignet sind, das „Bücherhaus" aufzunehmen. In beiden Tempeln finden sich zudem entweder in diesen Räumlichkeiten (Medinet Habu) oder an ihrem Eingang (Ramesseum, vgl. die oben erwähnte Beobachtung Arnolds) Darstellungen, die einen deutlichen Bezug zu ihrer vermuteten Verwendung als „Bücherhäuser" aufweisen. Im Falle des Ramesseums liegt darüber hinaus eine antike Beschreibung der Bibliothek vor, die sich mit dieser Lokalisierung in Einklang bringen läßt

Ein endgültiger, auch die letzten Zweifel beseitigender Hinweis steht zugegebenermaßen noch aus. Doch läßt der dargelegte Befund mit einem hohen $\mathrm{Maß}$ an Wahrscheinlichkeit den Schluß zu, daß in Medinet Habu in Raum $X X / X X I$ und im Ramesseum in den Räumlichkeiten rechts vom ,,astronomischen Saal"233 die „Bücherhäuser" dieser Tempel zu suchen sind.

$\mathrm{Ob}$ und inwieweit sich diese in ramessidischen Totentempeln gemachten Beobachtungen auch auf andere Tempel übertragen lassen, muß vorläufig noch ohne eindeutige Antwort bleiben. Doch läßt sich zumindest sagen, daß nur ein Zusammenwirken aller drei oben genannten Kriterien - und ggf. weiterer, noch zu erarbeitender - ein Indiz für die Identifizierung eines "Bücherhauses" sein kann. Weder sind architektonisch und von der Lage innerhalb des Tempels her geeignete Räumlichkeiten noch entsprechende Dekorationen für sich allein aussagekräftig: So ergab beispielweise eine Überprüfung der Dekorationen im erhaltenen Teil des Tempels Sethos'I. in Abydos, daß an wenigstens fünf verschiedenen Stellen Seschat allein oder in Verbindung mit Thot dargestellt ist, darunter wenigstens zweimal mit dem Epitheton „Herrin des Bücherhauses", ohne daß sich bisher daraus ein brauchbares Indiz für die Lokalisierung des „Bücherhauses" in diesem Tempel gewinnen ließ.

Erfolgversprechender verlief andererseits die Suche im Tempel von Luxor. Dort befinden sich bei a an der Südwand von Raum XIII (s. Abb. 6), neben der Tür zu Raum XIV, Darstellungen von Thot und Seschat, letztere ist dort als "Erste des Bücherhauses" bezeichnet: Eine der Nischen an der Ostwand im Raum XIII oder XIV könnte das „Bücherhaus" enthalten haben, die drei genannten Bedingungen sind dort erfüllt.

Insgesamt gesehen liegt also hier vielleicht der Anfang eines Weges, der ein wenig weiter in Richtung auf die Lösung des Problems führen könnte, ägyptische Tempelbibliotheken zu identifizieren. 


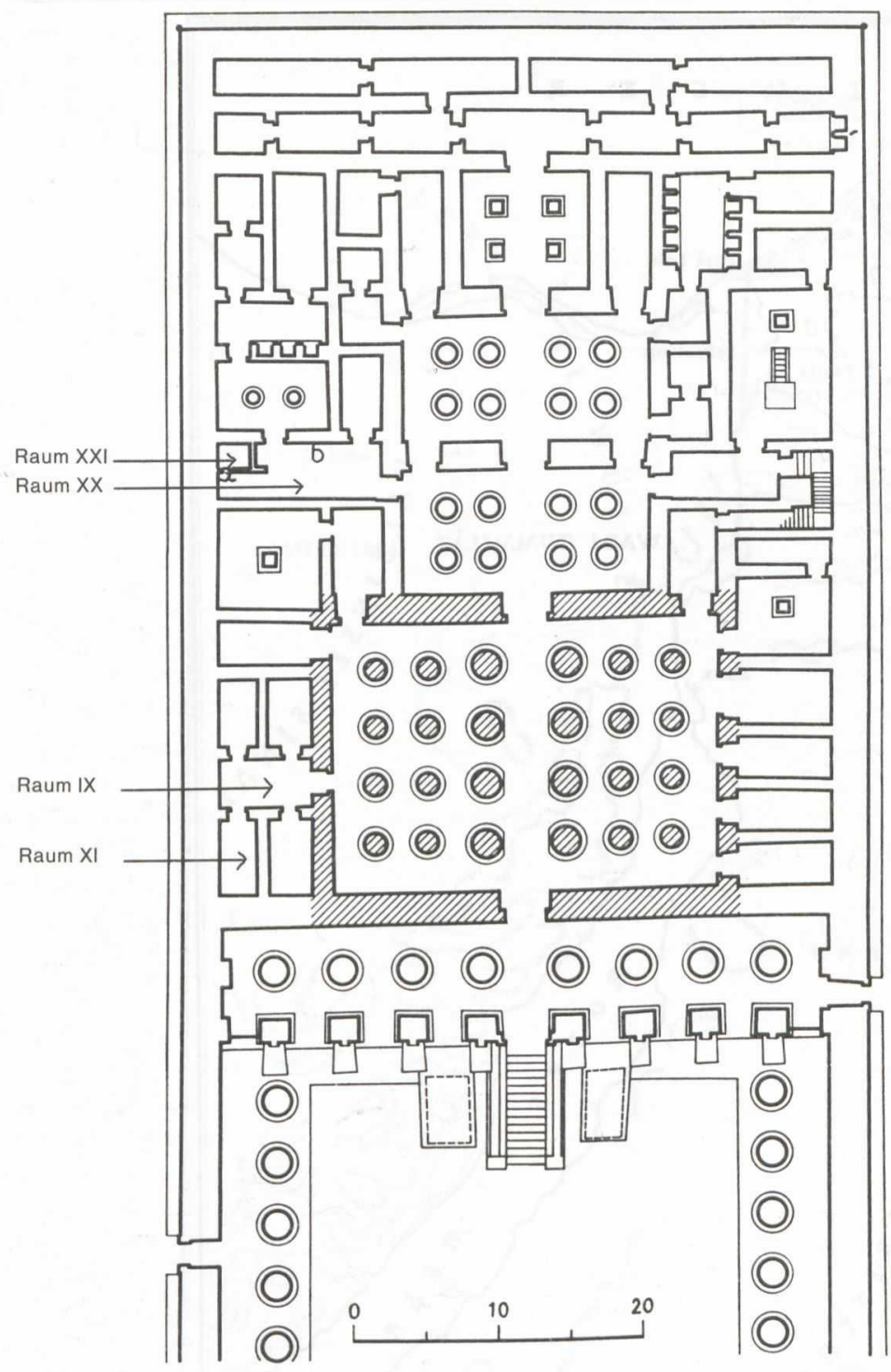

Abb. $5^{234}$

234 Plan der hinteren Räume des Tempels von Medinet Habu. Aus: Haeny, Gerhard: Basilikale Anlagen in der ägyptischen Baukunst des Neuen Reiches. Wiesbaden 1977, S. 63, Abb. 24 (Beiträge zur ägyptischen Bauforschung und Altertumskunde, Heft 9).

35 Plan des Tempels von Luxor. Aus: Schwaller de Lubicz, R.A.: Le temple de l'homme. Apet du sud a Louqsor. Paris 1977, tome II,

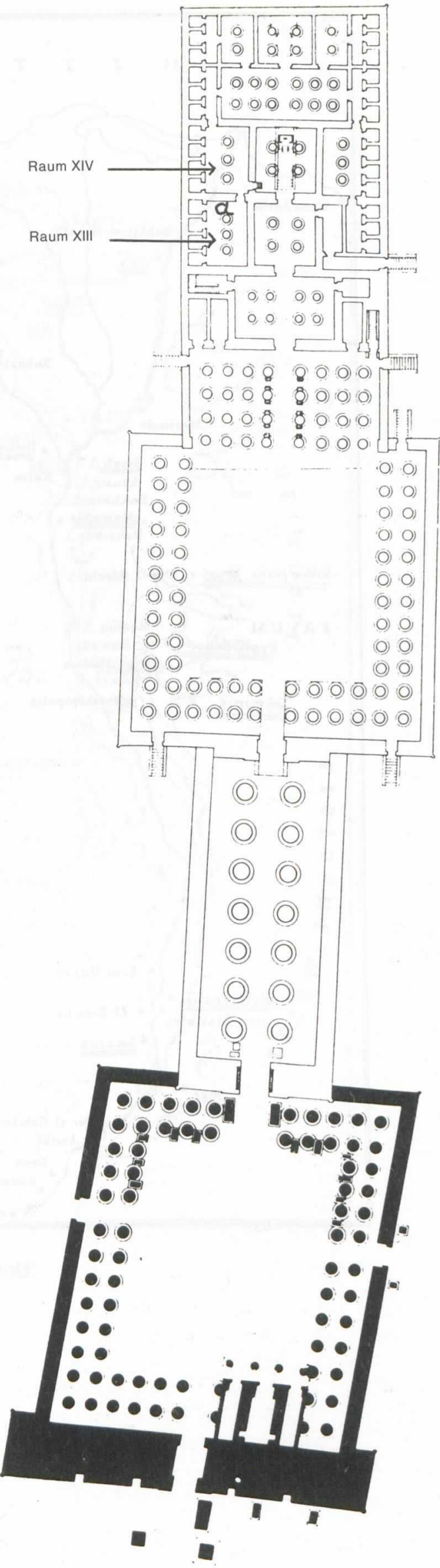

Taf. 14. 


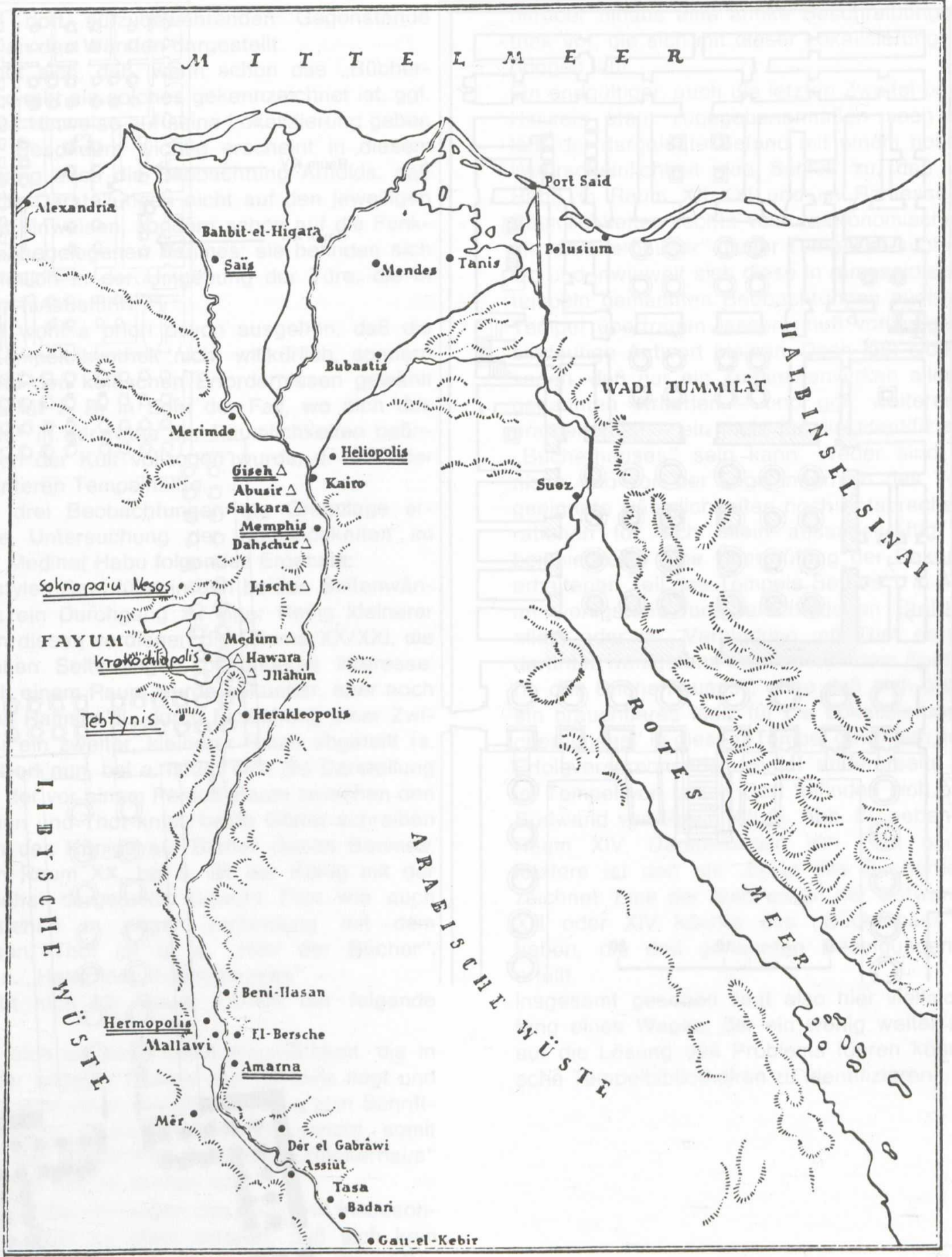

Unter- und Mittelägypten

Karte $\mathbf{I}^{236}$ 


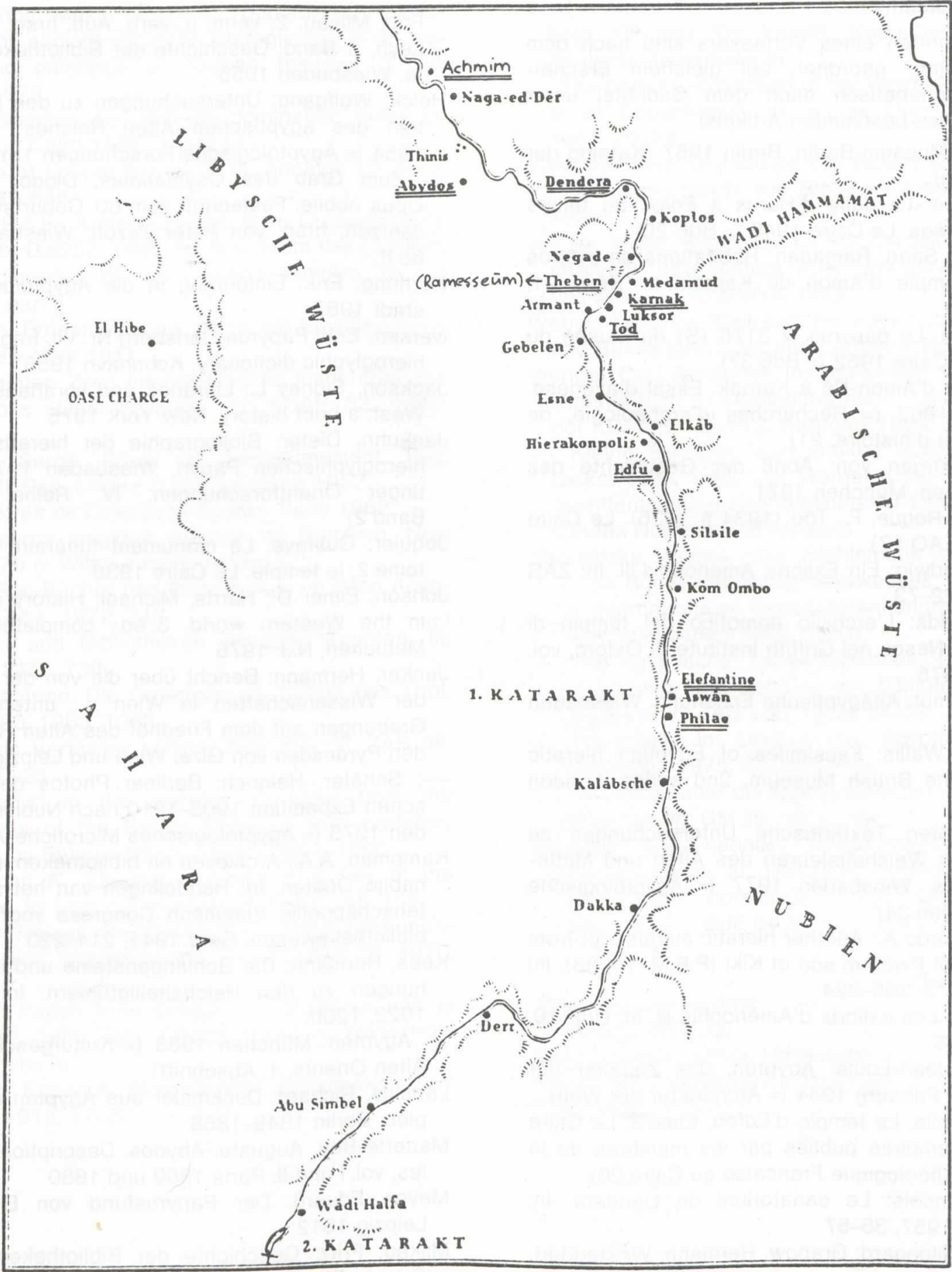

Oberägypten und Nubien

Karte II 


\section{Literaturverzeichnis}

(Mehrere Schriften eines Verfassers sind nach dem Erscheinungsjahr geordnet, bei gleichem Erscheinungsjahr alphabetisch nach dem Sachtitel unter Übergehung des bestimmten Artikels)

Ägyptisches Museum Berlin. Berlin 1967 (Katalog der Ausstellung)

Alliot, Maurice: Le culte d'Horus à Edfou au temps des Ptolémées. Le Caire 1949 (= BdE 20)

Anus, Pierre; Saad, Ramadan: Habitations de prêtres dans le temple d'Amon de Karnak. In: Kêmi 21, 1971, $217 \mathrm{ff}$.

Barguet, Paul: Le papyrus N. 3176 (S) du Musée du Louvre. Le Caire 1962 (= BdE 37)

- - Le temple d'Amon-Rê à Karnak. Essai d'exégèse. Le Caire 1962 (= Recherches d'archéologie, de philologie et d'histoire, 21)

Beckerath, Jürgen von: Abriß der Geschichte des alten Ägypten. München 1971

Bisson de la Roque, F.: Tôd (1934 à 1936). Le Caire 1937 (= FIFAO 17)

Borchardt, Ludwig: Ein Exlibris Amenophis'llI. In: ZÄS 33, 1895, 72-73

Bresciani, Edda: L'archivio demotico del tempio di Soknopaiu Nesos nel Griffith Institute di Oxford, vol. I. Milano 1975

Brunner, Hellmut: Altägyptische Erziehung. Wiesbaden 1957

Budge, E.A. Wallis: Facsimiles of Egyptian hieratic papyri in the British Museum, 2nd series. London 1923

Burkard, Günter: Textkritische Untersuchungen zu ägyptischen Weisheitslehren des Alten und Mittleren Reiches. Wiesbaden 1977 (= Ägyptologische Abhandlungen 34)

Caminos, Ricardo A.: Another hieratic manuscript from the library of Pwerem son of Kiki (P.B.M. 10288). In: JEA 58, 1972, 205-224

Capart, Jean: Les exlibris d'Aménophis III. In: CdE 10, $1935,23-25$

de Cenival, Jean-Louis: Ägypten, das Zeitalter der Pharaonen. Fribourg 1964 (= Architektur der Welt)

Chassinat, Emile: Le temple d'Edfou, tome 3. Le Caire 1928 (= Memoires publiés par les membres de la Mission Archéologique Francaise au Caire 20)

Daumas, Francois: Le sanatorium de Dendara. In: BIFAO 56, 1957, 35-57

von Deines, Hildegard; Grapow, Hermann; Westendorf, Wolfhart: Übersetzung der medizinischen Texte. Berlin 1958 (= Grundriß der Medizin der alten Ägypter IV,1)

Derchain, Philippe: Le papyrus Salt 825 (B.M. 10051), rituel pour la conservation de la vie en Egypte. Bruxelles 1965

- Le tombeau d'Osymandyas et la maison de la vie à Thèbes. In: NAWG 8, 1965, 165-171

Dunlop, Leslie W.: Readings in library history. New York and London 1972

Erman, Adolf: Neuägyptische Grammatik. 2. Auflage. Leipzig 1933

Gardiner, Alan H.: Egyptian hieratic texts, series I: literary texts of the new kingdom, part I. Leipzig 1911

-- The house of life. In: JEA 24, 1938, 157-179

- - The Ramesseum papyri, plates. Oxford 1955

Handbuch der Bibliothekswissenschaft, begründet von
Fritz Milkau. 2. verm. u. verb. Aufl. hrsg. von Georg Leyh, 3. Band: Geschichte der Bibliotheken, 1. Hälfte. Wiesbaden 1955

Helck, Wolfgang: Untersuchungen zu den Beamtentiteln des ägyptischen Alten Reiches. Glückstadt 1954 (= Ägyptologische Forschungen 18)

-- Zum Grab des Osymandias, Diodor I,47/9. In: Opus nobile. Festschrift zum 60. Geburtstag von Ulf Jantzen, hrsg. von Peter Zazoff. Wiesbaden 1969, $68 \mathrm{ff}$.

Hornung, Erik: Einführung in die Ägyptologie. Darmstadt 1967

Iversen, Erik: Papyrus Carlsberg Nr. VII, fragments of a hieroglyphic dictionary. Købnhavn 1958

Jackson, Sidney L.: Libraries and librarianship in the West: a brief history. New York 1975

Jankuhn, Dieter: Bibliographie der hieratischen und hieroglyphischen Papyri. Wiesbaden 1974 (= Göttinger Orientforschungen, IV. Reihe: Ägypten, Band 2)

Jequier, Gustave: Le monument funéraire de Pepi II, tome 2, le temple. Le Caire 1938

Johson, Elmer D.; Harris, Michael: History of libraries in the Western world. 3. ed., completely revised. Metuchen, N.J. 1976

Junker, Hermann: Bericht über die von der Akademie der Wissenschaften in Wien ... unternommenen Grabungen auf dem Friedhof des Alten Reiches bei den Pyramiden von Gîza, Wien und Leipzig $1929 \mathrm{ff}$.

- -; Schäfer, Heinrich: Berliner Photos der Preussischen Expedition 1908-1910 nach Nubien. Wiesbaden 1975 (= Ägyptologisches Microfiche-Archiv 3)

Kampman, A.A.: Archieven en bibliotheken in het oude nabije Oosten. In: Handelingen van het zesde wetenschappelijk Vlaamsch Congress voor boek- en bibliothekswesen. Gent 1941, 214-220

Kees, Hermann: Die Schlangensteine und ihre Beziehungen zu den Reichsheiligtümern. In: ZÄS 57, 1922, $120 f f$.

-- Ägypten. München 1933 (= Kulturgeschichte des Alten Orients, 1. Abschnitt)

Lepsius, Richard: Denkmäler aus Ägypten und Äthiopien. Berlin 1849-1858

Mariette-Bey, Auguste: Abydos. Description des fouilles, vol. I und II. Paris 1869 und 1880

Meyer, Eduard: Der Papyrusfund von Elephantine. Leipzig 1912

Milkau, Fritz: Geschichte der Bibliotheken im alten Orient. Aus dem Nachlass hrsg. von Bruno Meissner. Leipzig 1935

Möller, Georg: Über die in einem späthieratischen Papyrus des Berliner Museums erhaltenen Pyramidentexte. Berlin 1900

-- Hieratische Paläographie. 3 Bände Leipzig 19091912

Otto, Eberhard: Ägyptisches Buch- und Bibliothekswesen. In: Handbuch der Orientalistik, hrsg. von Bertold Spuler, 1. Band: Ägyptologie, 2. Abschnitt: Literatur. 2. Auflage. Leiden 1970, $251 \mathrm{ff}$.

Pendlebury, J.D.S.: The city of Akhenaten, part III. London 1951

Pieper, Max: Die große Inschrift des Königs Neferhotep in Abydos. Ein Beitrag zur ägyptischen Religions- und Literaturgeschichte. In: Mitteilungen der Vorderasiatisch-ägyptischen Gesellschaft, 32. Band, 2. Heft. Leipzig 1929 
Porter, Bertha; Moss, Rosalind: Topographical bibliography of ancient Egyptian hieroglyphic texts, reliefs, and paintings, II. Theban temples. 2. ed. Oxford 1972

Posener, Georges: La premiere domination Perse en Egypte. Le Caire 1936 (= BdE 11)

-- Histoire et Egypte ancienne. In: Annales 17, Paris 1962, 631-646

Reymond, E.A.E.: A medical book from Crocodilopolis, P. Vindob. D.6257. Wien 1976 (= From the contents of the libraries of the Suchos temples in the Fayyum, part I)

Richardson, Ernest Cushing: Some old Egyptian librarians. New York 1911

Roeder, Günter: Zwei hieroglyphische Inschriften aus Hermopolis (Ober-Ägypten). In: ASAE 52, 1952, $316 \mathrm{ff}$.

Sauneron, Serge: Rituel de l'embaumement, Pap. Boulaq III, Pap. Louvre 5.185. Le Caire 1952

- - Les prêtres de l'ancienne Egypte. Paris 1962

- - Le papyrus magique illustrée de Brooklyn. New York 1970 (= Wilbour monographs 3)

Schott, Erika: Bücher und Bibliotheken im alten Ägypten. In: GM 1, 1972, $24 \mathrm{ff}$.

- - Bücher und Bibliotheken im alten Ägypten. In: GM 25, 1977, 73ff.

Schott, Siegfried: Die Opferliste als Schrift des Thot. In: ZÄS 90, 1963, 103ff.

- - Thot als Verfasser heiliger Schriften. In: ZÄS 99, 1972, 20-25

Select papyri in the hieratic character from the collections of the British Museum, with prefatory remarks by Samuel Birch. London 1841-1860

Sperry, John A.: Egyptian libraries: a survey of the evidence. In: Libri 7, Copenhagen 1957, 145-155

Stadt und Tempel von Elephantine, erster Grabungsbericht. Von Werner Kaiser u.a. In: MDIK 26, 1970, $87 \mathrm{ff}$.

Tait, W.J.: Papyri from Tebtunis in Egyptian and in Greek (P. Tebt. Tait). London 1977 (= Texts from excavations 3)

Vogelsang, Friedrich: Altägyptische Bibliothekare? in: ZfB 30, 1913, 17-22
Volten, Aksel: Demotische Traumdeutung (Pap. Carlsberg XIII und XIV Verso). Kopenhagen 1942 (= Analecta Aegyptiaca 3)

- - The papyrus-collection of the egyptological institute of Copenhagen. In: Archiv Orientalni 19, Prag 1951, 70-74

Vorstius, Joris: Grundzüge der Bibliotheksgeschichte. 6. Aufl., neu bearb. von Siegfried Joost. Wiesbaden 1969

van de Walle, Baudouin: La transmission des textes littéraires égyptiennes. Avec une annexe de Georges Posener. Bruxelles 1948

Weber, Manfred: Beiträge zur Kenntnis des Schriftund Buchwesens der alten Ägypter. Köln 1969

Wendel, Carl: Bibliothek. In: Reallexikon für Antike und Christentum, in Verbindung mit ... hrsg. von Theodor Klausner, Band 2. Stuttgart 1954, Sp. 231-274

-- Kleine Schriften zum antiken Buch- und Bibliothekswesen, hrsg. von Werner Krieg. Köln 1974 (= Veröffentlichung des Bibliothekar-Lehrinstituts des Landes Nordrhein-Westfalen)

Wessetzky, Vilmos: Zur Problematik des altägyptischen Buch- und Bibliothekswesens. In: Akten des 24. internationalen Orientalistenkongresses in München. Wiesbaden 1959, 89-91

-- Die ägyptische Tempelbibliothek. Der Schlüssel zur Lösung liegt doch in der Bibliothek des Osymandyas? in: ZÄS 100, 1973, 54-59

-- Bibliothek, In: Lexikon der Ägyptologie, Band I, Wiesbaden 1975, Sp. 783-785

-- Gedanken über die Bearbeitung der altägyptischen Bibliothek. In: GM 25, 1977, 89ff.

Zauzich, Karl-Theodor: Textveröffentlichungen der Museen: Berlin. In: Textes et langages de l'Egypte pharaonique (hommage à J.-F. Champollion). Le Caire 1974 (= BdE 64,3), 131-139

\section{Anschrift des Autors:}

Dr. Günter Burkard

Universitätsbibliothek Heidelberg

Plöck 107-109, Postfach 105749

D-6900 Heidelberg 1 